University of Tennessee Health Science Center UTHSC Digital Commons

\title{
Military Sexual Trauma Exposure and Heart Rate Variability Outcomes in Female Veterans
}

\author{
Elizabeth Ann Davis Lee \\ University of Tennessee Health Science Center
}

Follow this and additional works at: https://dc.uthsc.edu/dissertations

Part of the Nursing Commons

\section{Recommended Citation}

Lee, Elizabeth Ann Davis, "Military Sexual Trauma Exposure and Heart Rate Variability Outcomes in Female Veterans" (2011). Theses and Dissertations (ETD). Paper 148. http://dx.doi.org/10.21007/ etd.cghs.2011.0174.

This Dissertation is brought to you for free and open access by the College of Graduate Health Sciences at UTHSC Digital Commons. It has been accepted for inclusion in Theses and Dissertations (ETD) by an authorized administrator of UTHSC Digital Commons. For more information, please contact jwelch30@uthsc.edu. 


\title{
Military Sexual Trauma Exposure and Heart Rate Variability Outcomes in Female Veterans
}

\begin{abstract}
Area of Investigation and Hypothesis: Decreased heart rate variability (HRV) has been used as a predictor of cardiac and all-cause mortality. Studies have documented decreased HRV in a variety of conditions, including posttraumatic stress disorder (PTSD), depression, age, coronary artery disease (CAD), diabetes mellitus (DM), and tobacco use but improvement with beta blocker (BB) treatment. No prior study evaluated the relationship between military sexual trauma (MST) exposure and HRV outcomes. The hypothesis of this study was that female veterans exposed to MST would have lower time domain HRV measures than a reference cohort reporting non-exposure. Methods and Procedures: Electronic medical records (EMR) containing Holter and electrocardiogram (ECG) tracings of female veterans 21 to 86 years of age examined from January 2007 through December 2010 at a Veterans Affairs (VA) Medical Center were used for this historical cohort study. The sample contained female veterans with MST exposure $(n=$ 27 ) and a reference group $(n=99)$ with no reported MST. Log transformed standard deviation of all normal to normal intervals (SDNN) and log transformed square root of the mean of the sum of the squares of differences between adjacent normal to normal intervals (RMSSD) were the primary comparison outcome measures and were derived from the mean of three 10-second ECG or Holter tracings for each subject. The MST universal screening tool, the PTSD ChecklistCivilian instrument, and the Patient Health Questionnaire-9 instrument for depression were used by the VA for diagnosis. History of MST, PTSD, depression, CAD, DM, tobacco use, and beta blocker treatment was obtained from the EMR. The expedited study was approved by the University of Tennessee Health Science Center and VA institutional review boards and the VA Research and Development Committee. Results: The mean (M) measures of log transformed SDNN and standard deviations (SD) differed significantly $(p=.0001)$ between subjects with MST exposure $(M=3.25, S D=0.11)$ and the reference cohort $(M=3.74, S D=$ 0.06). The mean measures of log transformed RMSSD and SD differed significantly $(p=.001)$ between female veterans with $M S T$ exposure $(M=3.43, S D=0.10)$ and the reference cohort $(M=3.81, S D=0.05)$. Eighty percent of female veterans with MST had PTSD. Female veterans with MST $(M=41, S D=11.67)$ were significantly $(p=.002)$ younger in years than those with no MST exposure $(M=51, S D=14.14)$. The projected SDNN of a 25 year old with MST exposure was comparable to that of a 69 year old without MST, while the RMSSD of a 25 year old with MST exposure was comparable to that of an 81 year old.

Conclusions: Female veterans with MST had significantly lower HRV at a younger age compared to a reference cohort that contained veterans with PTSD from other traumas, including combat-related PTSD. Early HRV decline in female veterans with MST may increase risk of premature death.
\end{abstract}

\section{Document Type \\ Dissertation}

\section{Degree Name}

Doctor of Philosophy (PhD)

\section{Program}

Nursing

\section{Research Advisor}

Michael A. Carter, DNSc

\section{Keywords}

Military sexual trauma, Heart rate variability, Posttraumatic stress disorder 


\section{Subject Categories}

Medicine and Health Sciences | Nursing 


\title{
MILITARY SEXUAL TRAUMA EXPOSURE AND HEART RATE VARIABILITY OUTCOMES IN FEMALE VETERANS
}

\author{
A Dissertation \\ Presented for \\ The Graduate Studies Council \\ The University of Tennessee \\ Health Science Center
}

\author{
In Partial Fulfillment \\ Of the Requirements for the Degree \\ Doctor of Philosophy \\ From The University of Tennessee
}

By

Elizabeth Ann Davis Lee

December 2011 
Copyright (C) 2011 by Elizabeth Ann Davis Lee.

All rights reserved. 


\section{DEDICATION}

This dissertation is dedicated to God, who opened my eyes, ears and heart to the abuse and suffering of women everywhere, including my Aunt Ethel who suffered at the hands of her husband when I was a child; my friend and former nursing student Micah, who died from her injuries; and all those abused that I cared for in numerous hospitals, clinics, and shelters through the years. I want to especially acknowledge the sacrifice made by the veterans who experienced military sexual trauma while serving our country. 


\section{ACKNOWLEDGEMENTS}

This material is the result of work supported with resources and the use of facilities at the Central Arkansas Veterans Healthcare System, Little Rock, Arkansas, during a WOC research assistantship for the primary investigator, Joe Bissett, MD. Contents reflect the view of the author and do not represent the views of the Department of Veterans Affairs or the United States Government. I appreciate their help.

I want to express gratitude to many friends who were instrumental in completing research deemed "impossible" by several nursing programs. I thank my dissertation chairman, Dr. Michael Carter, who always knew when to lift me up and when to push me forward. I appreciate the sage advice and guiding support from my committee members, Drs. Joe Bissett, Patricia Cowan, Patricia Speck, and Elizabeth Tolley. I am grateful to all those at the University of Tennessee Health Science Center and the Central Arkansas Veterans Healthcare System who provided the opportunity to conduct this research. My children, Candee, John, and Steve with their families, my parents, Ted and Bonnie Davis, and my sisters, Bonnie and Mary, have been a constant source of encouragement and strength. I am also grateful for my husband, Nick, who stayed by my side and grew with me throughout this journey of uncovering and sharing the story being told by the shattered hearts of women who experienced abuse. 


\begin{abstract}
Area of Investigation and Hypothesis: Decreased heart rate variability (HRV) has been used as a predictor of cardiac and all-cause mortality. Studies have documented decreased HRV in a variety of conditions, including posttraumatic stress disorder (PTSD), depression, age, coronary artery disease (CAD), diabetes mellitus (DM), and tobacco use but improvement with beta blocker (BB) treatment. No prior study evaluated the relationship between military sexual trauma (MST) exposure and HRV outcomes. The hypothesis of this study was that female veterans exposed to MST would have lower time domain HRV measures than a reference cohort reporting non-exposure.

Methods and Procedures: Electronic medical records (EMR) containing Holter and electrocardiogram (ECG) tracings of female veterans 21 to 86 years of age examined from January 2007 through December 2010 at a Veterans Affairs (VA) Medical Center were used for this historical cohort study. The sample contained female veterans with MST exposure $(n=27)$ and a reference group $(n=99)$ with no reported MST. Log transformed standard deviation of all normal to normal intervals (SDNN) and log transformed square root of the mean of the sum of the squares of differences between adjacent normal to normal intervals (RMSSD) were the primary comparison outcome measures and were derived from the mean of three 10-second ECG or Holter tracings for each subject. The MST universal screening tool, the PTSD Checklist-Civilian instrument, and the Patient Health Questionnaire-9 instrument for depression were used by the VA for diagnosis. History of MST, PTSD, depression, CAD, DM, tobacco use, and beta blocker treatment was obtained from the EMR. The expedited study was approved by the University of Tennessee Health Science Center and VA institutional review boards and the VA Research and Development Committee.
\end{abstract}

Results: The mean (M) measures of log transformed SDNN and standard deviations (SD) differed significantly $(\mathrm{p}=.0001)$ between subjects with MST exposure $(\mathrm{M}=3.25, \mathrm{SD}=0.11)$ and the reference cohort $(\mathrm{M}=3.74, \mathrm{SD}=0.06)$. The mean measures of log transformed RMSSD and SD differed significantly $(\mathrm{p}=.001)$ between female veterans with MST exposure $(\mathrm{M}=3.43, \mathrm{SD}=0.10)$ and the reference cohort $(\mathrm{M}=3.81, \mathrm{SD}=0.05)$. Eighty percent of female veterans with MST had PTSD. Female veterans with $\mathrm{MST}(\mathrm{M}=41, \mathrm{SD}=11.67)$ were significantly $(\mathrm{p}=.002)$ younger in years than those with no MST exposure $(\mathrm{M}=51, \mathrm{SD}=14.14)$. The projected SDNN of a 25 year old with MST exposure was comparable to that of a 69 year old without MST, while the RMSSD of a 25 year old with MST exposure was comparable to that of an 81 year old.

Conclusions: Female veterans with MST had significantly lower HRV at a younger age compared to a reference cohort that contained veterans with PTSD from other traumas, including combat-related PTSD. Early HRV decline in female veterans with MST may increase risk of premature death. 


\section{TABLE OF CONTENTS}

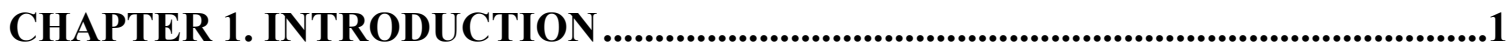

Response of Women's Hearts to Stress ...................................................................

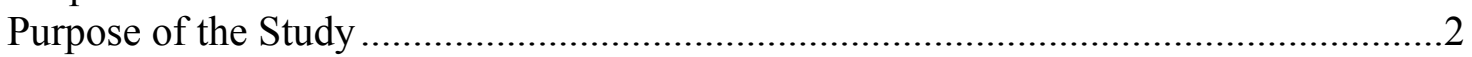

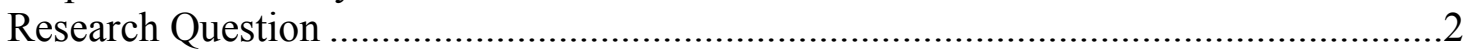

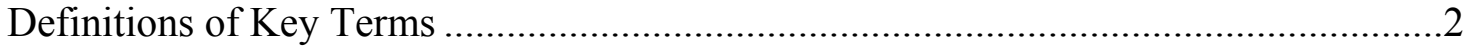

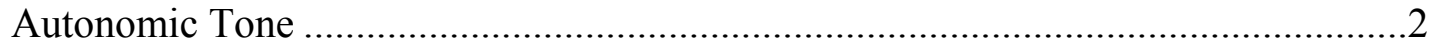

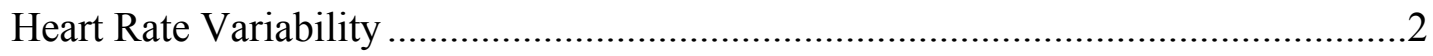

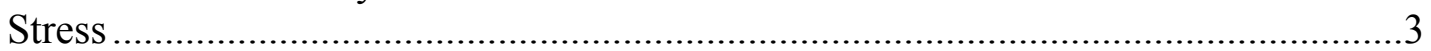

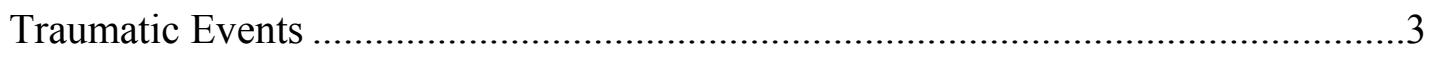

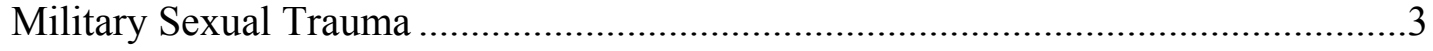

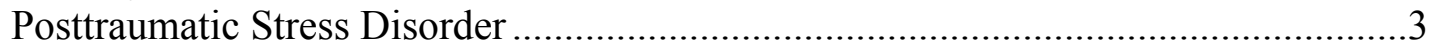

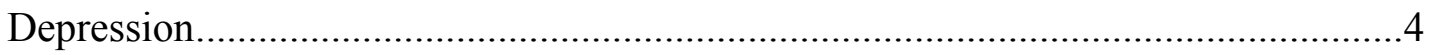

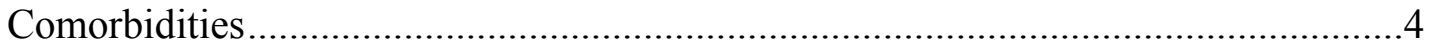

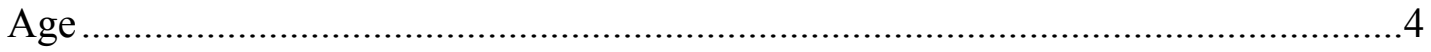

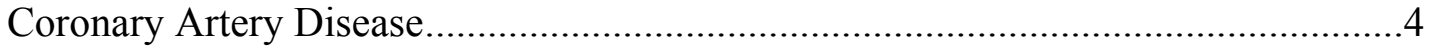

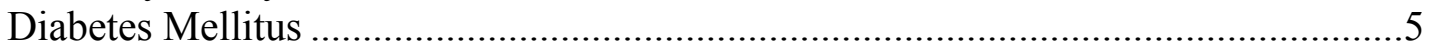

Cigarette Smoking ...........................................................................................

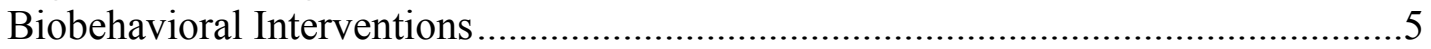

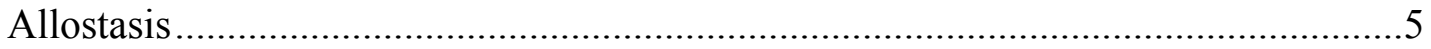

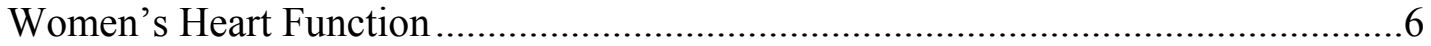

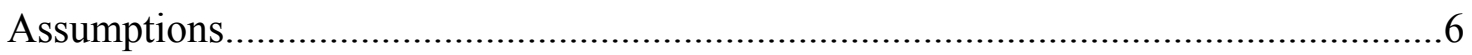

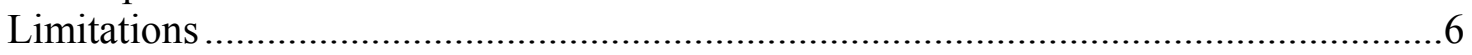

CHAPTER 2. LITERATURE REVIEW ...............................................................8

Significance of Decreased Heart Rate Variability .............................................

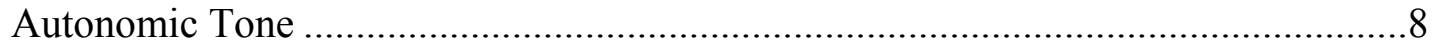

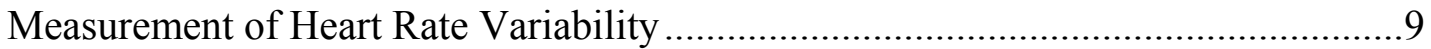

Heart Rate Variability and Physical Factors............................................................. 12

Heart Rate Variability and Psychosocial Factors ..................................................... 14

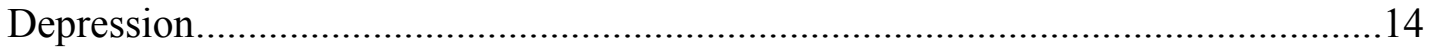

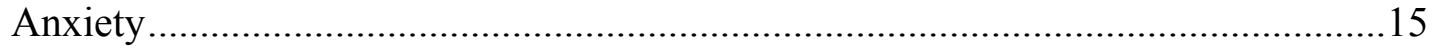

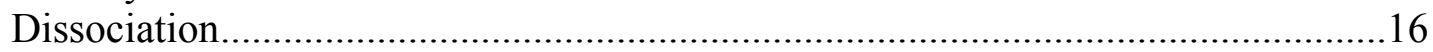

Catecholamine Influence with Mental Health Disorders .........................................16

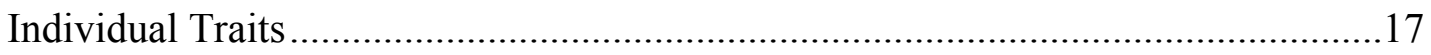

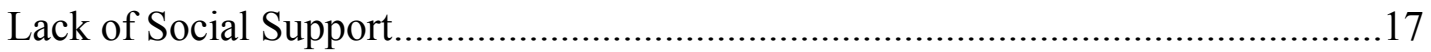

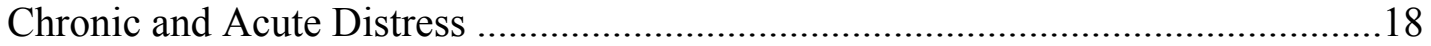

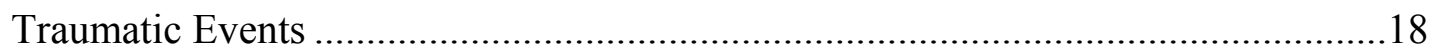

Military Sexual Trauma .......................................................................................... 19

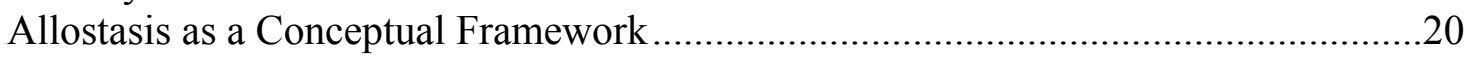

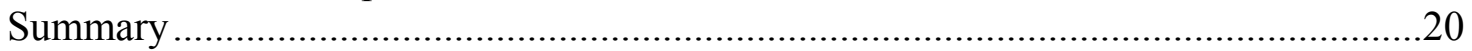

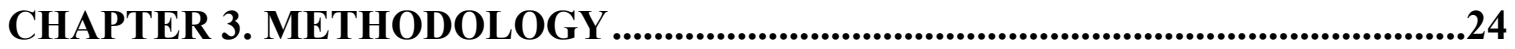

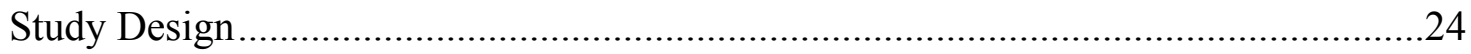




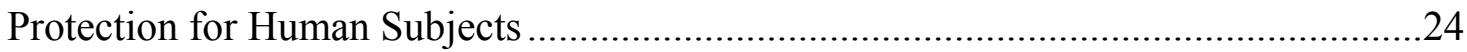

Setting and Sample

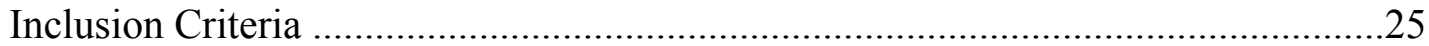

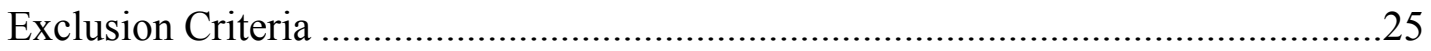

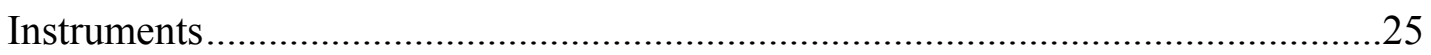

Universal Screening of Veterans for Military Sexual Trauma …………………......26

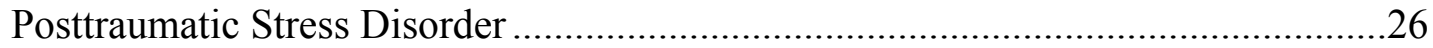

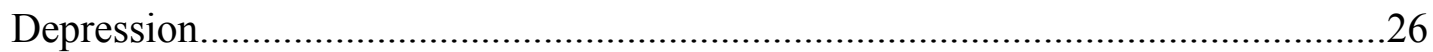

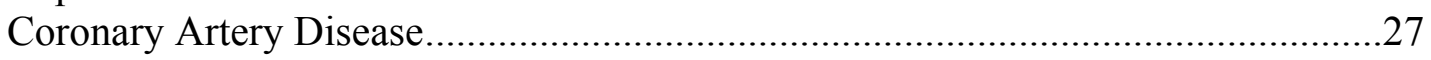

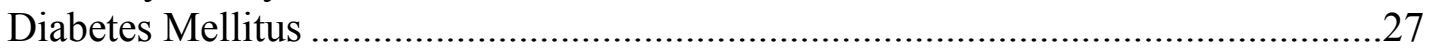

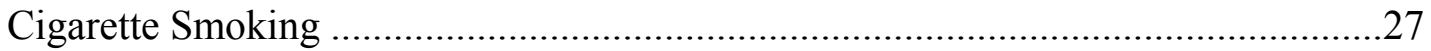

Beta Blocker Treatment ………………..........................................................2

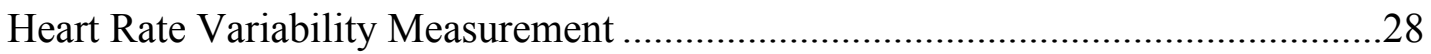

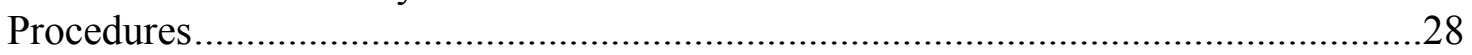

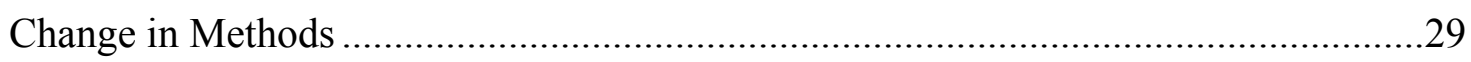

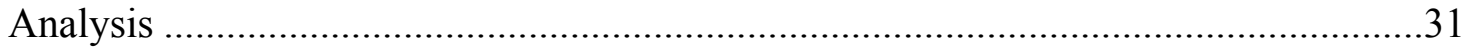

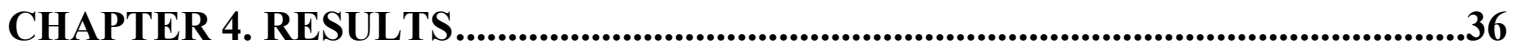

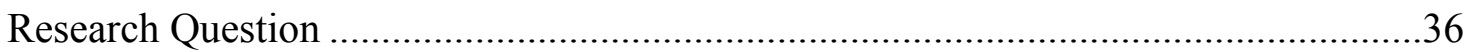

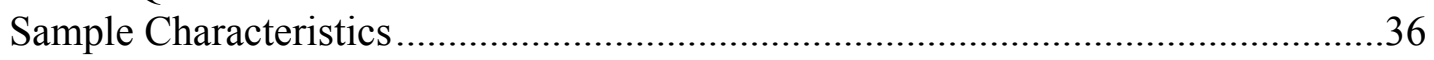

Association of Military Sexual Trauma with Other Study Variables ..........................38

Research Question Regarding the Effects of Military Sexual Trauma and Other

Characteristics of Female Veterans on Their Heart Rate Variability …………….........38

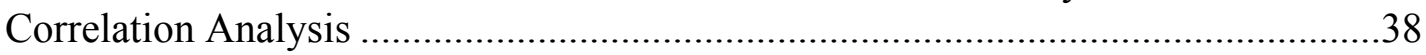

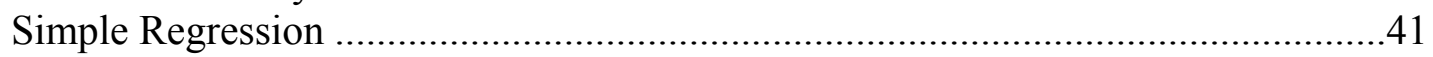

Independent Samples t Tests............................................................................4

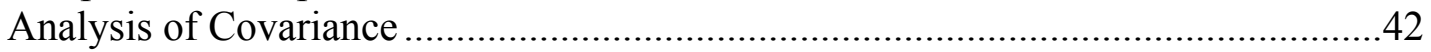

Partial Pearson Product Moment Correlation Coefficients........................................55

Research Question Regarding Estimation of Odds of Having Lower Quartile Heart

Rate Variability in Female Veterans with and without Military Sexual Trauma ..........55

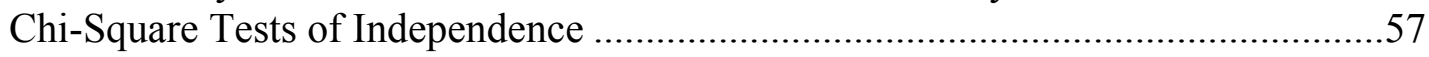

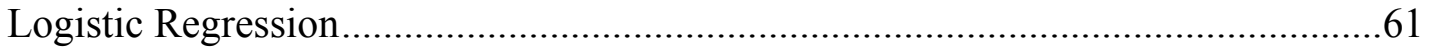

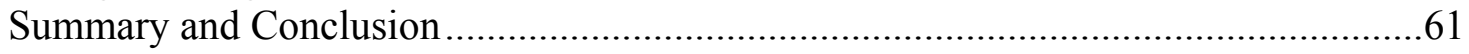

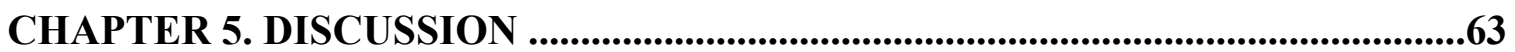

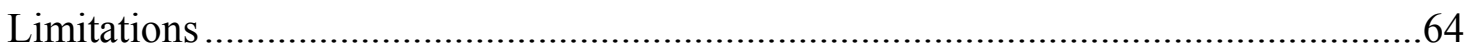

Implications for Theory Development....................................................................65

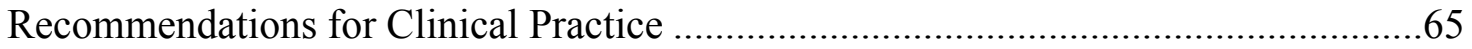

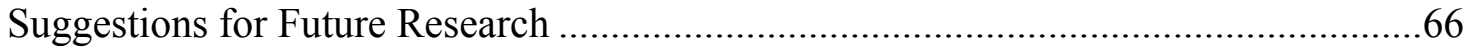

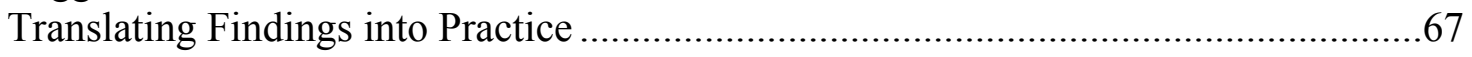

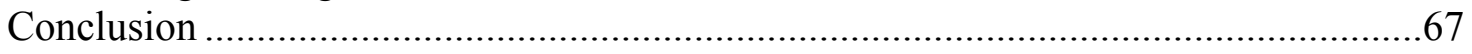

LIST OF REFERENCES.....................................................................................................68

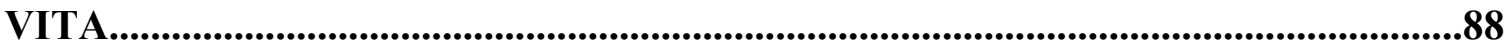




\section{LIST OF TABLES}

Table 2-1. Measurement of heart rate variability.

Table 3-1. A-priori sample size calculation for multiple regression for seven predictor variables.

Table 4-1. Sample characteristics of female veterans $(n=126)$ examined by electrocardiogram and Holter following cardiology consult 2007-2010 at a Veteran Affairs Medical Center.

Table 4-2. Frequencies of covariates of female veterans $(n=126)$ examined by electrocardiogram and Holter following cardiology consult 2007-2010 at a Veteran Affairs Medical Center.

Table 4-3. The association of military sexual trauma with heart rate variability outcomes and with confounders in female veterans $(\mathrm{n}=126)$ examined by electrocardiogram and Holter following cardiology consult 20072010 at a Veteran Affairs Medical Center.

Table 4-4. Estimated Pearson product moment correlation coefficients among study variables $(\mathrm{df}=124)$ in female veterans $(\mathrm{n}=126)$ examined by electrocardiogram and Holter following cardiology consult 2007-2010 at a Veteran Affairs Medical Center.

Table 4-5. Simple regression of heart rate variability on age in female veterans $(n=$ 126) examined by electrocardiogram and Holter following cardiology consult 2007-2010 at a Veteran Affairs Medical Center.

Table 4-6. Independent $t$ tests of the effect of military sexual trauma on continuous variables $(\mathrm{df}=124)$ in female veterans $(\mathrm{n}=126)$ examined by electrocardiogram and Holter following cardiology consult 2007-2010 at a Veteran Affairs Medical Center.

Table 4-7. Independent t tests of the effect of posttraumatic stress disorder on continuous variables $(\mathrm{df}=124)$ in female veterans $(\mathrm{n}=126)$ examined by electrocardiogram and Holter following cardiology consult 20072010 at a Veteran Affairs Medical Center.

Table 4-8. Independent $t$ tests of the effect of depression on continuous variables $(\mathrm{df}=124)$ in female veterans $(\mathrm{n}=126)$ examined by electrocardiogram and Holter following cardiology consult 2007-2010 at a Veteran Affairs Medical Center. 
Table 4-9. Independent t tests of the effect of coronary artery disease on continuous variables $(\mathrm{df}=124)$ in female veterans $(\mathrm{n}=126)$ examined by electrocardiogram and Holter following cardiology consult during 2007-2010 at a Veteran Affairs Medical Center.

Table 4-10. Independent $\mathrm{t}$ tests of diabetes mellitus on continuous variables $(\mathrm{df}=$ $124)$ in female veterans $(n=126)$ examined by electrocardiogram and Holter following cardiology consult during 2007-2010 at a Veteran Affairs Medical Center.

Table 4-11. Independent $\mathrm{t}$ tests of cigarette smoking on continuous variables $(\mathrm{df}=$ $124)$ in female veterans $(n=126)$ examined by electrocardiogram and Holter following cardiology consult during 2007-2010 at a Veteran Affairs Medical Center.

Table 4-12. Independent t tests of beta blocker treatment on continuous variables (df $=124)$ in female veterans $(\mathrm{n}=126)$ examined by electrocardiogram and Holter following cardiology consult during 2007-2010 at a Veteran Affairs Medical Center.

Table 4-13. Independent $t$ tests of effect of age category on heart rate variability ( $\mathrm{df}$ $=124)$ in female veterans $(n=126)$ examined by electrocardiogram and Holter following cardiology consult during 2007-2010 at a Veteran Affairs Medical Center.

Table 4-14. Test of homogeneity of slopes of change in heart rate variability for each unit of change in age $(\mathrm{df}=123)$ for female veterans $(\mathrm{n}=126)$ examined by electrocardiogram and Holter following cardiology consult during 2007-2010 at a Veteran Affairs Medical Center.

Table 4-15. Parameter estimates from analysis of covariance $(\mathrm{df}=123)$ based on a sample of female veterans $(n=126)$ examined by electrocardiogram and Holter following cardiology consult during 2007-2010 at a Veteran Affairs Medical Center.

Table 4-16. Independent $\mathrm{t}$-tests between least squares means $(\mathrm{df}=123)$ for presence or absence of military sexual trauma or posttraumatic stress disorder from analysis of covariance* of heart rate variability on age in female veterans $(n=126)$ examined by electrocardiogram and Holter following cardiology consult during 2007-2010 at a Veteran Affairs Medical Center.

Table 4-17. Parameter estimates of squared partial and total Pearson product moment correlation coefficients in female veterans $(n=126)$ examined by electrocardiogram and Holter following cardiology consult during 2007-2010 at a Veteran Affairs Medical Center. 
Table 4-18. Prevalence of eight independent variables by lower quartile of heart rate variability in female veterans.

Table 4-19. Unadjusted odds of having a heart rate variability in the lower quartile associated with military sexual trauma or posttraumatic stress disorder and being 65 years or older in female veterans $(n=126)$ examined by electrocardiogram and Holter following cardiology consult during 20072010 at a Veteran Affairs Medical Center.

Table 4-20. Adjusted odds of having a heart rate variability in the lower quartile associated with military sexual trauma or posttraumatic stress disorder and being 65 years or older in female veterans $(\mathrm{n}=126)$ examined by electrocardiogram and Holter following cardiology consult during 20072010 at a Veteran Affairs Medical Center. 


\section{LIST OF FIGURES}

Figure 2-1. Lee's model of the contribution of military sexual trauma to allostatic loading and its physical and psychological outcomes..............................21

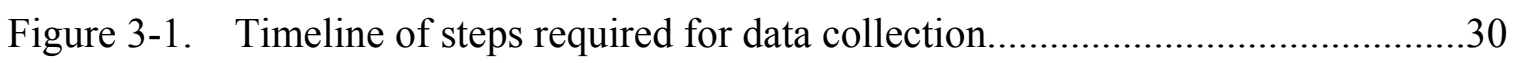

Figure 4-1. Log transformed standard deviation of all normal sinus rhythm R-R intervals on age by military sexual trauma group

Figure 4-2. Log transformed square root of the mean of the sum of the squares of differences between adjacent normal sinus rhythm R-R intervals on age

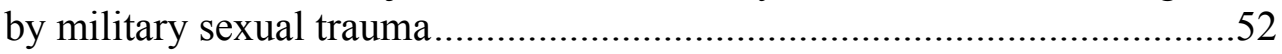

Figure 4-3. Log transformed standard deviation of all normal sinus rhythm R-R intervals on age by posttraumatic stress disorder.

Figure 4-4. Log transformed square root of the mean of the sum of the squares of differences between adjacent normal sinus rhythm R-R intervals on age by posttraumatic stress disorder diagnosis 


\section{LIST OF ABBREVIATIONS}

ACE

ADA

AHA

ANCOVA

ARIC

BMI

CAD

$\mathrm{CHF}$

DHHS

DM

DSM-IV

ECG

EMR

ESC

FFT

GAD

HDL

HF

HPA

HR

HRV

ICC

ICD

ICD-9

IRB

LDL

LF

$\mathrm{M}$

MI

MS

MST

$\mathrm{NIH}$

$\mathrm{NN}$

NN50

NASPE

OCD

OR

OSA

PCL-C

$\mathrm{PD}$

PHQ-2

PHQ-9
Angiotensin converting enzyme inhibitors

American Diabetic Association

American Heart Association

Analysis of covariance

Atherosclerosis Risk in Communities Study

Body mass index

Coronary artery disease

Congestive heart failure

Department of Health and Human Services

Diabetes mellitus

Diagnostic and Statistical Manual of Mental Disorders $4^{\text {th }}$ edition

Electrocardiogram

Electronic medical record

European Society of Cardiology

Fast Fourier transform

Generalized anxiety disorder

High density lipoprotein

High frequency

Hypothalamic pituitary axis

Hazard ratio

Heart rate variability

Intraclass correlation

Implantable cardioverter-defibrillator

International Statistical Classification of Diseases and Related Health

Problems

Institutional review board

Low density lipoprotein

Low frequency

Mean

Myocardial infarction

Milliseconds

Military sexual trauma

National Institutes of Health

Normal sinus rhythm R wave to R wave

Number of pairs of adjacent NN intervals differing by more than $50 \mathrm{~ms}$

North American Society of Pacing Electrophysiology

Obsessive compulsive disorder

Odds ratio

Obstructive sleep apnea

Posttraumatic stress disorder checklist-civilian

Panic disorder

Patient Health Questionnaire-2

Patient Health Questionnaire-9 
PNN50 NN 50 count divided by the total number of NN intervals in percent

PS Parasympathetic

PTSD Posttraumatic stress disorder

RMSSD Square root of the mean of the sum of the squares of differences between adjacent $\mathrm{NN}$ intervals

R-R Two consecutive $R$ waves

RR Relative risk

SAD Social anxiety disorder

SAS

Statistical Analysis Software

SD

Standard deviation

SDANN Standard deviation of averages of NN intervals

SDNN Standard deviation of all NN intervals

SDSD

Standard deviation of differences between adjacent NN intervals

SSRI

TP

Selective serotonin reuptake inhibitor

ULF

Total power

UTHSC

Ultra-low frequency

VA

University of Tennessee Health Science Center

Veterans Affairs

VAGFE

VLF

Veterans Affairs Government Furnished Equipment

Very low frequency

WOC

Without compensation 


\section{CHAPTER 1. INTRODUCTION}

\section{Response of Women's Hearts to Stress}

Stresses that women experience throughout their lives can adversely affect autonomic tone and heart function (Bonomi, Anderson, Rivara, \& Thompson, 2007; Campbell et al., 2002; Eby, 2004; Eby, Campbell, Sullivan, \& Davidson, 1995; Felitti et al., 1998; Goodwin \& Stein, 2004; Heim et al., 2000; Rainville, Bechara, Naqvi, \& Damasio, 2006; Schmaus, Laubmeier, Boquiren, Herzer, \& Zakowski, 2008; Stemmler, Aue, \& Wacker, 2007). Researchers postulate that stress may have a negative effect on the heart through autonomic stimulation (Cannon, 1939; Cohen \& Benjamin, 2006; McEwen, 2005; Sharkey et al., 2005; Wittstein et al., 2005). Additionally, women exposed to stress from traumatic events are 2.8 times more likely to develop posttraumatic stress disorder (PTSD) than men (Holbrook, Hoyt, Stein, \& Sieber, 2002). Women who develop PTSD often experienced numerous traumatic events in life (mean (Gill, Page, Sharps, \& Campbell, 2008; Holbrook et al., 2002) and are at risk of repeatedly re-experiencing traumatic events through flashbacks, intrusive thoughts, and dreams (Gill, Saligan, Henderson, \& Szanton, 2009; United States Department of Veterans Affairs [US Department of Veteran Affairs], 2010a) with potential for additional impact on autonomic tone (Cohen, Benjamin, et al., 2000). Stress had a greater effect on the sinus and atrioventricular nodes in women (Insulander \& Vallin, 2005), and women exhibited greater cardiac response with repeated stress than men (Schmaus et al., 2008).

Female veterans are especially prone to stress from traumatic events, with $92 \%$ reporting at least one episode and 43\% developing associated PTSD; threatened or perpetrated military sexual trauma (MST) can pose a more significant predictor of PTSD than other traumas combined (Yaeger, Himmelfarb, Cammack, \& Mintz, 2006). MST was cited by female veterans as the worst traumatization $(68.3 \%)$ over physical assault (15.8\%) and combat (5.6\%) (Schnurr, Friedman, \& Engel, 2007) and was found closely associated with increased victimization after discharge (Sadler, Booth, Mengeling, \& Doebbeling, 2004). Dose response to level of MST and its association with subsequent PTSD (Kang, Dalager, Mahan, \& Ishii, 2005) prompted mandated routine universal MST screening (Kimerling, Street, Gima, \& Smith, 2008) and provides impetus for exploration of association with autonomic tone.

Heart rate variability (HRV) is a noninvasive measure of association between autonomic function and cardiovascular status (Kapa \& Somers, 2008). Increasingly, HRV is used to measure the loss of autonomic response associated with stress and psychophysiologic response (Berntson \& Cacioppo, 2004). Additionally, HRV can improve with stress reducing exercise (Melanson, 2000; Rosenthal, Grosswald, Ross, \& Rosental, 2011), psychotherapy (Carney et al., 2000), or use of drugs, such as beta blockers that attenuate sympathetic overstimulation of the heart (Dantev, 2002; Guzzetti et al., 1988). Early identification of antecedents to decreased HRV may enhance 
opportunities for timely intervention and prevention of excess sympathetic stimulation of the heart.

Allostasis, the dynamic interplay of an organism's regulatory compensation to continual change is a theoretical framework (Groer \& Burns, 2009; McEwen, 2004; Sterling \& Eyer, 1988) for the contribution of stress to excessive sympathetic and decreased parasympathetic activity. Ongoing research supported by the National Institutes of Health (NIH) is presently exploring the cardiovascular impact of traumatic events (Rich-Edwards, 2008) and PTSD (Kibler, 2008) in civilian women. However, additional work exploring the relationship between exposure to MST in female veterans and decreased HRV is needed to add to the existing body of scientific knowledge.

\section{Purpose of the Study}

The purpose of this study was to evaluate the association between HRV and MST in female veterans who underwent electrocardiogram (ECG) and Holter monitoring in a Veterans Affairs (VA) Medical Center.

\section{Research Question}

The research question is: What is the relationship between MST and HRV in female veterans evaluated in a VA Medical Center by ECG and Holter monitoring from January 2007 through December 2010? PTSD, depression, age, coronary artery disease (CAD), diabetes mellitus (DM), cigarette smoking, and beta blockers were considered in analysis as covariates or confounding variables.

\section{Definitions of Key Terms}

\section{Autonomic Tone}

Autonomic tone is the effect of the autonomic nervous system on heart rate with both sympathetic and parasympathetic influence providing continual regulation (Woo, 2008). Altered balance between sympathetic and parasympathetic tone influences heart rate and HRV and can promote arrhythmogenesis.

\section{Heart Rate Variability}

HRV involves measurement of two consecutive $R$ waves (R-R) on an electrocardiogram (ECG) to detect variation in instantaneous heart rate on long-term (24 hour Holter) or short-term recordings (Task Force of the European Society of Cardiology and the North American Society of Pacing Electrophysiology [ESC \& NASPE], 1996). 
HRV occurs in a normal heart but is diminished in a damaged one. The two most common evaluations of HRV are by time and frequency. The standard deviation of normal sinus R-R intervals (SDNN) and the square root of the mean of the sums of squares of the differences of successive normal sinus R-R intervals (RMSSD) are often used for simple time measurement, while the frequency method commonly uses fast Fourier transformation to divide R-R intervals into four frequency bands (Kapa \& Somers, 2008). High frequency (HF) provides a measure of vagal control and is influenced by respirations; low frequency (LF) is derived from both vagal and sympathetic influence; very low frequency (VLF) is associated with physical fitness; and ultra-low frequency (ULF) reflects circadian fluctuation.

\section{Stress}

Stress is any threat that triggers adaptive response for survival, including secretion of catecholamines and increased heart and respiration rates, and blood pressure (Scanga, 2008). Heart rate variability is affected by acute stress, lasting less than one month, or longer chronic stress exposure (Schubert et al., 2009).

\section{Traumatic Events}

Traumatic events are life stressors that are often intense in magnitude, may be repeated over prolonged periods, and can trigger development of PTSD (Holbrook et al., 2002; Lang et al., 2008) thereby impacting health outcomes throughout life (Felitti et al., 1998). Traumatic events are described as stressful, threatening experiences that create a sense of horror or helplessness (United States Department of Health and Human Services, 2009), such as crime victimization experiences (Kubany et al., 2000). Early life physical, emotional, and sexual trauma can increase premature mortality by decades (Brown et al., 2009).

\section{Military Sexual Trauma}

MST is defined as sexual harassment or assault that occurs while a person is serving in the military (Department of Veteran Affairs, 2010c). Sexual harassment includes: "a put-down because of your gender, flirting when you've made clear it's not welcome, sexual comments or gestures about your body or lifestyle, or pressure for sexual favors," while sexual assault includes: "touching or grabbing, intercourse [rape], oral or anal sex, or penetration with an object" (ब 1) forced against one's will.

\section{Posttraumatic Stress Disorder}

PTSD is an anxiety disorder that may occur not only after personally surviving an event that threatened either injury or death (American Psychological Association, 2004), 
but also after witnessing one (Department of Veteran Affairs, 2010a). Intrusive recollection of the event, avoidance or numbing behaviors, a state of hyper-arousal, and impairment of lifestyle for longer than a month after the traumatic event are symptoms of PTSD.

\section{Depression}

Depression, defined for this study of veterans, is a depressive feeling that interferes with personal function and enjoyment in daily living (McIntyre et al., 1999). Feeling excessively tired and sluggish, hopeless, and restless, eating too much or too little, having insomnia or hypersomnia, and experiencing difficulty concentrating are characteristic of depression. More severe depression may include preoccupation with self-injury or death.

\section{Comorbidities}

Comorbidities are defined as medical conditions that exist in addition to the initial diagnosis ("Comorbidity," 2009). Pragmatic application of retrospective data collection will limit this study's definition to comorbidities documented in the subject's electronic medical record.

\section{Age}

Length of life or existence customarily measured in years is used to describe age ("Age," 2002). In this study age is limited to 18 years, the minimum adult military recruitment without parental consent, through the latter part of geriatric life.

\section{Coronary Artery Disease}

$\mathrm{CAD}$ is a narrowing of arterial lumen with artherosclerotic plaque cited as the most common cause of progressive restriction of blood flow (Morrow \& Gersh, 2008). Initial small lipid lesions appearing in infancy increase in size and location over the life span (Stary, 1990) and are exacerbated by numerous risk factors including hypertension, tobacco use, dyslipidemia, diabetes mellitus, sedentary lifestyle, and endothelial inflammation and dysfunction of vessel lining (Morrow \& Gersh, 2008). Half of those diagnosed with CAD in the United States experience subsequent myocardial infarction from vessel occlusion (American Heart Association [AHA], 2010). CAD syndromes occur less frequently with vessel spasm or with the diminished blood flow accompanying congestive heart failure (CHF), cardiac arrhythmias, defective heart valves, or cardiomyopathies, such as Takotsubo. 


\title{
Diabetes Mellitus
}

$\mathrm{DM}$ is a group of metabolic disorders characterized by hyperglycemia from diminished insulin secretion, decreased tissue uptake and response to insulin, or both (American Diabetes Association [ADA], 2004). DM includes Type-1 (total destruction of pancreatic beta cells), Type-2 (varying degrees of insulin deficiency and resistance), and gestational diabetes (insulin deficiency or resistance occurring during pregnancy). An intermediate group with impaired glucose tolerance and impaired fasting glucose that precedes development of DM is also recognized by the American Diabetes Association (ADA). Diabetes is the most common disease contributing to secondary autonomic failure (Kapa \& Somers, 2008) reflected by a decrease in HRV (Burger, Charlamb, Winerauch, \& D'Lia, 1997; Ewing, Martin, Young, \& Clarke, 1985; Malpas \& Maling, 1990). For purposes related to this research, only diagnosed DM documented in the medical record will be included.

\section{Cigarette Smoking}

Cigarette smoking is defined as the inhalation of nicotine and carcinogenic gases generated by slow burning tobacco ("Smoking," 2009). Heavy smoking is defined as 20 or more cigarettes, two packs or more, per day (Cagirci et al., 2009). Smoking tobacco can alter HRV even without CAD (Sajadieh et al., 2004).

\section{Biobehavioral Interventions}

Biological, psychosocial, or behavioral interventions may either treat disease or delay its progression ("Biobehavioral," 2007; Hamberger, Ambuel, Marbella, \& Donze, 1998; Kubzansky, Park, Peterson, Vokonas, \& Sparrow, 2011; Linden, Stossel, \& Maurice, 1996; Linden, Phillips, \& Leclerc, 2007). An example of a biological intervention includes treatment with beta blockers, a class of drugs that reduce stress on the heart by blocking sympathetic stimulation thereby decreasing heart rate and contractility ("Beta blocker," 2011) and increasing HRV (Guzzetti et al., 1988).

\begin{abstract}
Allostasis
Allostasis describes extensive and diverse biobehavioral adaptive regulation in response to changing events and involves interplay between the autonomic nervous system and the hypothalamic-pituitary-adrenal (HPA) axis which regulate catecholamines and other hormone mediators (McEwen \& Seeman, 1999; Sterling \& Eyer, 1988). Chronic stress can wear the body down through continual neuroendocrine bombardment and result in the depleted state of allostatic load.
\end{abstract}




\section{Women's Heart Function}

Heart function in women is not just the function of a mechanical pump carrying unoxygenated blood to the lungs and oxygen-saturated blood to the rest of the body (Tanser, 2006), but it is also a reflection of response to stress and allostatic loading (Groer \& Burns, 2009) with ECG changes occurring with extreme emotional stress even in the presence of normal coronary arteries (Akashi et al., 2003; Sharkey et al., 2005; Wittstein et al., 2005).

\section{Assumptions}

The primary assumption is that the presence of heightened stress on the heart through perception of traumatic events and reliving traumatic events through PTSD flashbacks and intrusive thoughts can contribute to repeated release of catecholamines, chronic autonomic stimulation, increased resting heart rate, and decline in HRV. The cascade of events stemming from trauma contributes to negative health outcomes (Street, Stafford, Mahan, \& Hendricks, 2008; Suris \& Lind, 2008), greater utilization of health services (Sadler et al., 2004; Suris, Lind, Kashner, Borman, \& Petty, 2004), more disability applications (Murdoch, Polusny, Hodges, \& Cowper, 2006), and increased homelessness of female veterans (Desai, Harpaz-Rotem, Najavitis, \& Rosenheck, 2008). Another assumption is that the accuracy of occurrence, severity, or frequency of selfreported MST. Finally, it is assumed that, because of extensive health screening at induction into the military, female veterans are free from decreased HRV prior to the occurrence of MST. However, it is doubtful that the assessment of consecutive R waves necessary to evaluate HRV was conducted during the military induction process. HRV is not abnormal in young adults. Generally, only those inductees with arrhythmias or other

clinical signs of cardiac abnormalities would have been identified and discharged during the early screening process.

\section{Limitations}

Several factors contribute to limitations of this historical cohort study of female veterans. Evaluation of R-R intervals, scrutiny for artifacts and erroneous beats, and interpretation requires skilled analysis (ESD \& NASPE, 1996). Compared to the available 10-minute ECGs, 24-hour Holter tracings provide more data for HRV calculation. Although gender, age, circadian rhythm, respiration and body position can influence $\mathrm{HRV}$, it is a noninvasive and highly reproducible measure of autonomic tone. Conditions that alter autonomic regulation, such as age, DM, CAD, depression or PTSD may be present in cohort subjects exposed or unexposed to MST. Medications, such asbeta blockers, may temper HRV decline. Individual differences in autonomic response to medications cannot be controlled (Berntson et al., 1994). Potential bias from suppression of recall of traumatic events through mental coping efforts, or withholding of information to protect sexual trauma perpetrators because of fear of retaliation, may hinder reporting of MST. Experiencing PTSD from other traumatic events, such as 
childhood abuse, car accidents, or combat exposure without MST, could influence HRV. Uniqueness and consistency of individual stress response across time may vary (Berntson \& Cacioppo, 2004). Psychosocial factors, emotions, level of social support, and types of life stress are not routinely recorded and are difficult to control with a retrospective design. Screening and diagnosis scores are not recorded on every veteran so PTSD and depression severity cannot be analyzed due to excessive numbers of missing values. Cohort studies do not establish causality, but can provide informative data. 


\section{CHAPTER 2. LITERATURE REVIEW}

This review of literature provides an overview of the evolving significance of heart rate variability (HRV) as a surrogate measure of autonomic function. HRV is defined and a synthesis of its measurement methods and parameters given. Research exploring cardiac and non-cardiac physical conditions, and psychosocial factors, including military sexual trauma (MST) exposure, associated with decreased HRV are described. Allostasis is presented as a dynamic conceptual framework for guiding research exploring the decline in HRV following autonomic stimulation with severe or repeated stress exposure.

\section{Significance of Decreased Heart Rate Variability}

Decreased HRV measured from 10-second ECG recordings was presented as a predictor of morbidity and mortality in the population based study of men born in 1913 (Tibblin, Eriksson, Bjuro, Georgescu, \& Svardsudd, 1975), but widespread acceptance of HRV usefulness came a decade later from 24 hour Holter readings of the Multicenter Post-Infarction Project revealing a 5.3 higher relative risk of death with low HRV after myocardial infarction (MI) (Kleiger, Miller, Bigger, \& Moss, 1987). More recently, decreased HRV was predictive of all-cause mortality $(\mathrm{p}<.0001)$ in the male population $(\mathrm{n}=6595)$ West of Scotland Study (Macfarlane \& Norrie, 2007), and documented risk of all cause death for both genders $(n=14,672)$ in the Atherosclerosis Risk in Communities (ARIC) Study by all HRV indices (Dekker et al., 2000).

By definition, HRV reflects each normal sinus $\mathrm{R}$ wave to $\mathrm{R}$ wave (R-R) interval variation of instantaneous heart rate oscillations on ECG readings (Kapa \& Somers, 2008; ESC \& NASPE, 1996). A normal heart will display normal sinus fluctuations, but variations decline with sympathovagal imbalance. Decreased HRV can occur from problems with transmission or reception of autonomic nervous system modulation, or from bombardment of the heart with sympathetic stimulation that increases autonomic tone (Stein \& Kleigher, 1999). At the sinoatrial level, HRV provides a noninvasive view of basic autonomic nervous system function (Acharya, Joseph, Kannathal, Lim, \& Suri, 2006) and general mortality risk.

\section{Autonomic Tone}

The autonomic nervous system modulates heart contraction frequency through the dynamic balance between the parasympathetic influence that reduces heart rate, via the vagal nerve, and sympathetic activity that increases it (Akselrod et al., 1985; Kapa \& Somers, 2008; Woo, 2008). At rest in a healthy individual, there is parasympathetic dominance with low sympathetic activity and catecholamine levels. Sympathetic activation, through physical or mental triggers, releases catecholamines that promote calcium influx into cells to enhance cardiac contractility (Anderson, 2007) allowing 
adaptive "fight or flight" (Cannon, 1939). However, excessive catecholamines and sympathetic activity can be toxic to myocytes (Mann, Kent, Parsons, \& Cooper, 1992), and arrhythmogenic in animals (Cerrone et al., 2007; Doppalapudi et al., 2008) and humans (Anderson, 2007) even in the presence of normal coronary arteries (Akashi et al., 2003; Wittstein et al., 2005).

Primary or secondary disorders that affect the autonomic system can also affect autonomic tone and alter HRV (Goldstein, Robertson, Esler, \& Straus, 2002; Kapa \& Somers, 2008; Woo, 2008). Testing indicators of autonomic function, HRV, heart rate recovery, baroreflexer and chemoreceptor activity, and catecholamine concentrations, aids in identification of individuals at higher risk of morbidity and mortality from a growing number of psychological and physical conditions (Stein \& Kleigher, 1999). HRV provides numeric measures of parasympathetic and sympathetic contributions to end organ damage.

\section{Measurement of Heart Rate Variability}

The most common approaches for evaluating HRV are time domain and frequency domain (ESC \& NASPE, 1996). Time domain procedures involve statistical analysis of normal sinus $\mathrm{R}$ wave to $\mathrm{R}$ wave $(\mathrm{NN})$ intervals, the difference of successive $\mathrm{NN}$ intervals, or conversion of $\mathrm{NN}$ intervals into a geometric pattern. The most commonly used estimates of HRV are the standard deviation of all NN intervals (SDNN) and the square root of the mean of the sum of the squares of differences between adjacent NN intervals (RMSSD) (Sztajzel, 2004). Geometric methods are less affected by artifact and ectopic beats, but require a 20 minute ECG recording for statistical analysis. Guidelines recommend using the SDNN, RMSSD, and the standard deviation of the averages of NN intervals (SDANN) from 24 hour Holter readings whenever accessible (ESC \& NASPE, 1996).

By the nonparametric fast Fourier transformation (FFT) or the complex parametric method, frequency domain methods split power (variance) and central frequency of R-R intervals of short-term or long-term ECG readings into separate spectral components: high frequency (HF), low frequency (LF), very low frequency (VLF), and ultra-low frequency (ULF) (ESC \& NASPE, 1996). Through seminal work using pharmacological blockade in anesthetized dogs $(n=7)$, the HF index was found to be under parasympathetic influence and LF was modulated by both parasympathetic and sympathetic components (Akselrod et al., 1985). Spectral analysis is less reliable with low power and high artifact data (Acharya et al., 2006). See Table 2-1 for comparison of time and frequency domain indices. Other less common methods of analysis include interval spectrum, spectrum of counts, "peak-valley" procedure, Fourier spectra, $\mathrm{H}$ scaling, and Coarse Grading Spectral Analysis (ESC \& NASPE, 1996). HRV is highly reproducible, but requires skilled analysis of normal sinus rhythm tracings (Acharya et al., 2006). 
Table 2-1. Measurement of heart rate variability.

\begin{tabular}{|c|c|c|c|c|c|c|c|}
\hline \multirow[b]{2}{*}{ Proposed origin } & \multicolumn{4}{|c|}{ Time } & \multicolumn{3}{|c|}{ Frequency } \\
\hline & Domain & $\begin{array}{l}\text { Cutpoint } \\
10 \mathrm{sec} \text { ECG }\end{array}$ & $\begin{array}{l}\text { Cutpoint } \\
2 \text { min ECG }\end{array}$ & $\begin{array}{l}\text { Cutpoint } \\
24 \text { hr Holter }\end{array}$ & Domain & $\begin{array}{l}\text { Range } \\
24 \mathrm{hr} \text { Holter }\end{array}$ & $\begin{array}{l}\text { Range } \\
5 \text { min ECG }\end{array}$ \\
\hline Autonomic tone & SDNN ms & $\begin{array}{l}20-40^{1} \\
9.6-25.9^{2} \\
8-44^{3}\end{array}$ & $23.9-35.4^{4}$ & $\begin{array}{l}<50 \text { very low } \\
<102 \text { low }^{5}\end{array}$ & TP & $\approx \leq 0.40 \mathrm{~Hz}^{5}$ & $\approx \leq .40 \mathrm{~Hz}^{5}$ \\
\hline Autonomic tone & $\begin{array}{l}\text { HRV } \\
\text { triangular } \\
\text { index }\end{array}$ & & & $\begin{array}{l}<15 \text { very low } \\
<22 \text { low }^{5}\end{array}$ & $\mathrm{TP}$ & & $\mathrm{N} / \mathrm{A}$ \\
\hline Autonomic tone & TINN & & & & $\mathrm{TP}$ & & $\mathrm{N} / \mathrm{A}$ \\
\hline Circadian rhythm & SDANN & & & & ULF & $\leq .003 \mathrm{~Hz}^{5}$ & $\mathrm{~N} / \mathrm{A}$ \\
\hline Autonomic tone & SDNN & & & & $\mathrm{TP}$ & & $\mathrm{N} / \mathrm{A}$ \\
\hline $\begin{array}{l}\text { Physical wellbeing; } \\
\text { sympathetic }\end{array}$ & & & & & VLF & $.003-.04 \mathrm{~Hz}^{5}$ & $\leq .04 \mathrm{~Hz}^{5}$ \\
\hline $\begin{array}{l}\text { Baroreceptor loop; } \\
\text { sympatho-vagal }\end{array}$ & & & & & LF & $.04-.15 \mathrm{~Hz}^{5}$ & $.04-.15 \mathrm{~Hz}^{5}$ \\
\hline PS/Respiration & RMSSD ms & $10-27^{3}$ & $14.7-22.3^{4}$ & $<15^{5}$ & $\mathrm{HF}$ & $.15-.40 \mathrm{~Hz}^{5}$ & $.15-.40 \mathrm{~Hz}^{5}$ \\
\hline PS/Respiration & SDSD & & $11.3-16.4^{4}$ & & $\mathrm{HF}$ & & \\
\hline PS/Respiration & NN50 & & & & $\mathrm{HF}$ & & \\
\hline PS/Respiration & pNN50 & & $0.8 \%-5.9 \%{ }^{4}$ & & $\mathrm{HF}$ & & \\
\hline PS/Respiration & $\begin{array}{l}\text { Differential } \\
\text { index }\end{array}$ & & & & $\mathrm{HF}$ & & $\mathrm{N} / \mathrm{A}$ \\
\hline PS/Respiration & $\begin{array}{l}\text { Logarithmic } \\
\text { index }\end{array}$ & & & & $\mathrm{HF}$ & & $\mathrm{N} / \mathrm{A}$ \\
\hline Autonomic balance & & & & & $\begin{array}{l}\mathrm{LF} / \mathrm{HF} \\
\text { ratio }\end{array}$ & $\begin{array}{l}\text { Risk } \\
<1.2 \text {-high }^{6} \\
>3.7 \text {-low }^{6}\end{array}$ & $1-2^{7}$ \\
\hline
\end{tabular}




\section{Table 2-1. (Continued).}

Note: $\mathrm{PS}=$ Parasympathetic. $\mathrm{ms}=$ milliseconds. $\mathrm{SDNN}=$ Standard deviation of all NN intervals. $\mathrm{SDANN}=\mathrm{Standard}$ deviation of the averages of NN intervals. RMSSD $=$ Square root of the mean of the sum of the squares of differences between adjacent NN intervals. SDSD $=$ Standard deviation of differences between adjacent NN intervals. NN50 = Number of pairs of adjacent NN intervals differing by more than $50 \mathrm{~ms}$. pNN50 count $=$ NN50 count divided by the total number of NN intervals in percent. HRV triangular index = Total number of all NN intervals divided by the height of the histogram of all NN intervals measured on 20 minute recording. $\mathrm{TP}=$ Total power. ULF $=$ Ultra low frequency. VLF $=$ Very low frequency. $\mathrm{LF}=\mathrm{Low}$ frequency. $\mathrm{HF}=$ High frequency.

Sources: ${ }^{1}$ Preset cutpoints from Dekker, J. M., Schouten, E. G., Klootwijk, P., Pool, J., Sweene, C. A., \& Kromhout, D. (1997). Heart rate variability from short electrocardiographic recordings predicts mortality from all causes in middle-aged and elderly men: The Zutphen study. American Journal of Epidemiology, 145, 899-908. ${ }^{2}$ Cutpoints derived from sample quartiles in de Bruyne, M. C., Kors, J. A., Hoes, A. W., Klootwijk, P., Dekker, J. M., Hofman, A., . . Grobbee, D. E. (1999). Both decreased and increase heart rate variability on the standard 10-second electrocardiogram predict cardiac mortality in th elderly: The Rotterdam Study. American Journal of Epidemiology, 150, 1282-1288. ${ }^{3}$ Cutpoints derived from sample quartiles in Rautaharju, P., Kooperberg, C., Larson, J. C., \& LaCroix, A. (2006). Electrocardiographic predictors of incident congestive heart failure and all-cause mortality in postmenopausal women the Women's Health Initiative. Circulation 113, 481-489. ${ }^{4}$ Two-minute recording cutpoints from Dekker, J. M., Crow, R. S., Folson, A. R., Hannan, P. J., Liao, D., Swenne, C. A., \& Schouten, E. G. (2000). Low heart rate variability in a 2-minute rhythm strip predicts risk of coronary heart disease and mortality form several causes: The ARIC study. Circulation, 102, 1239-1244. ${ }^{5}$ Frequency domain cutpoints from Task Force of the European Society of Cardiology and the North American Society of Pacing Electrophysiology. (1996). Heart rate variability: Standards of measurement, physiological interpretation, and clinical use. Circulation, 93, 1043-1065. ${ }^{6} \mathrm{LF} / \mathrm{HF}$ cutpoints for 24 hour Holter recordings from Syed, Z., Scirica, B. M., Morrow, D. A., Mohanavelu, S., Stultz, C. M., \& Guttag, J. V. (2008). ECG Markers to Predict Cardiovascular Death: Heart Rate Variability, Deceleration Capacity and Morphologic Variability in Non-STElevation ACS from the MERLIN-TIMI 36 Trial. Circulation, 118, S670. Abstract retrieved September 28, 2011 from http://circ.ahajournals.org/cgi/content/meeting_abstract/118/18_MeetingAbstracts/S_670-b. ${ }^{7}$ LF/HF cutpoints for 5-minute tracings from Sztajzel, J. (2004). Heart rate variability: A noninvasive electrocardiographic method to measure the autonomic nervous system. Swiss Medical Weekly, 134, 514-522. 
Numerous sources contributed to time domain and frequency domain analysis for Table 2-1 (Acharya et al., 2006; Acharya, Kannathal, Ong, Luk, \& Chua, 2004; de Bruyne et al., 1999; Dekker et al., 2000; Dekker et al., 1997; Rautaharju et al., 2006; Stein \& Kleigher, 1999; Syed et al., 2008; Sztajzel, 2004; ESC \& NASPE, 1996). Quantitative synthesis of short term time domain studies revealed SDNN (range $=32-93$ $\mathrm{ms}$ ) and RMSSD (range $=19-75 \mathrm{~ms}$ ) varied by disease (Nunan, Sandercock, \& Brodie, 2010), and HRV measures were higher in younger, well-trained healthy individuals (Melanson, 2000; Sandercock, Hardy-Shepherd, Nunan, \& Brodie, 2008). Five-minute or longer recordings may be processed by frequency domain methods such as FFT to obtain HF (a measure of parasympathetic activity) and LF (a measure of sympathetic activity, parasympathetic influence on vagal tone, and baroreceptor reflex loop delay); however, accuracy of VLF (a measure of general physical fitness) by short-term 5-minute recordings is considered questionable (ESC \& NASPE, 1996). Use of frequency domain values with short-term ECG recordings less than five minutes was challenged as unreliable (Dekker et al., 2000). Therefore, frequency domain cutpoints for 10-second ECG recordings are not listed in Table 2-1.

Often in the clinical setting, ECG recordings are limited to 10 -second tracings and several studies have used them successfully. In the West of Scotland Coronary Prevention study of 45-65 year old men $(n=6595)$, SDNN from a 10-second ECG recording was the sole HRV index predictive of all-cause mortality $(\mathrm{p}<.0001)$ (Macfarlane \& Norrie, 2007). Both low HRV (hazard ratio $=1.8,95 \% \mathrm{CI}=1.0-3.2$ ) and high HRV (hazard ratio $=2.3,95 \% \mathrm{CI}=1.3-4.0$ ) measures from 10 -second ECG recordings were strong predictors of cardiac mortality in elderly men $(n=2088)$ and women $(n=3184)$ (de Bruyne et al., 1999). In a study of combat veterans $(n=69)$, advancing age was predicted by HRV from 10 -second ECG tracings $(\mathrm{p}<.01)$ (Ginsberg, Ayers, Burriss, \& Powell, 2008). For several years, only the Rotterdam study reported prediction of mortality using 10-second ECGs (Hamilton, MacKechnie, \& Macfarlane, 2004). Cardiac vagal tone was accurately predicted from 10 -second ECG readings for RMSSD $\left(r^{2}=92.9 \%\right)$, and SDNN $\left(r^{2}=87.9 \%\right)$ in study subjects $(n=50)$ in 2004 (Hamilton et al., 2004). In more recent years, studies reported usefulness of 10-second HRV measures for predicting all-cause mortality (Macfarlane \& Norrie, 2007) and age (Ginsberg et al., 2008). Use of the average of three 10-second ECGs, each containing a minimum of five successive normal to normal beats, enhanced intraclass correlation coefficients (ICC) for SDNN (ICC = .65) and RMSSD (ICC = .74) (Schroeder et al., 2004). Computer analysis comparing 10-second ECGs to five minute recordings found consistency with RMSSD indices but not with SDNN (Hamilton et al., 2004; Nussinovitch et al., 2011; Thong, Li, McNames, Aboy, \& Goldstein, 2003). Use of the 10 -second ECGs allows easily accessible calculation of HRV in routine clinical practice, but more research is needed comparing accuracy between 10-second recordings and longer Holter tracings (ESC \& NASPE, 1996).

Established in guidelines over a decade ago, time and frequency HRV measures derived from 24 hour Holter readings are useful in predicting prognosis for a variety of conditions (ESC \& NASPE, 1996). HRV from Holter readings have been used for predicting development of ventricular arrhythmias and sudden cardiac death after MI 
(Algra, Tijssen, Roelandt, Pool, \& Lubsen, 1993) and the 50\% five year mortality rate after detection of diabetic autonomic neuropathy (ESC \& NASPE, 1996; Rothman \& Greenland, 1998). Predictive benefits of HRV indices are internationally accepted.

\section{Heart Rate Variability and Physical Factors}

In several landmark studies over the last three decades, decreased HVR was identified in patients with cardiac disease. Relative risk (RR) of cardiac (RR 3.9), arrhythmic (RR 3.7), and all-cause (RR 4.1) death increased four-fold for those $(n=275)$ with low total power HRV ( $p<.05$ all $)$ in patients $(n=715)$ tracked up to four years post MI (Bigger et al., 1992) which coincides with greater risk of sudden death (RR 4.1, 95\% $\mathrm{CI}=2.6-8.1)$ with SDNN less than $25 \mathrm{~ms}$ in a larger study of patients $(\mathrm{n}=6693)$ with damaged post MI hearts (Algra et al., 1993). Seminal work tracking norepinephrine uptake in patients $(\mathrm{n}=11)$ undergoing cardiac catheterization, revealed the heart had higher levels of norepinephrine than other organs $(\mathrm{p}<.05)$ and was highly dependent on uptake by neurons to reduce levels in the heart ( $\mathrm{p}<.05$ (Goldstein, Brush, Eisenhofer, Stull, \& Esler, 1988). Based on in vitro research, excess adrenergic stimulation at the cellular level was toxic to myocytes from cyclic adenosine monophosphate mediated calcium overload and lead to decreased function or death of cells (Mann et al., 1992). Alteration in autonomic balance is supported by the comparison of ventricular tachycardia (VT) episodes in CHF (congestive heart failure) patients $(n=63)$ with implantable cardioverter defibrillators (ICD) to controls; a significant increase in mean $\mathrm{NN}$ intervals preceded slow VT $(\mathrm{p}<.01)$ and a decrease in mean $\mathrm{NN}$ intervals preceded fast VT $(\mathrm{p}<.05)$ (Meyerfeldt et al., 2002). Fluctuations in autonomic tone have also been documented in patients $(\mathrm{n}=28)$ five minutes prior to onset of atrial fibrillation with episodes $(\mathrm{n}=18)$ of abrupt decrease in LF and increase in HF consistent with increased parasympathetic tone $(\mathrm{p}<.001)$ and episodes $(\mathrm{n}=18)$ of abrupt increase in LF and decrease in HF consistent with increased sympathetic dominance $(\mathrm{p}=.004)$ (Fioranelli et al., 1999), or similarly, a sudden drop in SDNN and increase in LF/HF ratio six minutes prior to onset of atrial flutter $(n=12)$ (Wen, Chen, Tai, Huang, \& Cheang, 1998). Decrease in HF following ablation and resumption of HF levels one to six months later suggests altered autonomic tone within cardiac nerve receptors (Kocovic, Harada, Shea, Soroff, \& Friedman, 1993). Expression of arrhythmia conduction may also depend on individual intrinsic conduction pathways (Bissett, de Soyza, Kane, \& Murphy, 1976).

In a gender stratified random sample $(n=2,252)$ in the ARIC studies, monitoring development of coronary artery disease (CAD) over time, those with the lowest HRV indices were at greatest risk of MI, coronary occlusion, or death from CAD and had higher adjusted relative risk for $\mathrm{HF}(\mathrm{RR} 1.72,95 \% \mathrm{CI}=1.17-2.51)$ measures but nonsignificant LF, RR interval, and HF/LF ratio (Liao et al., 1997). Three years later in a random sample $(n=900)$ of the same ARIC population $(n=14,672)$, even more HRV indices showed statistically significant increased risk for cardiovascular mortality including SDNN (RR 2.10, 95\% CI $=1.21-3.64)$ and RMSSD (RR 2.60, 95\% CI $=1.48$ 4.59) (Dekker et al., 2000). Conversely, only decreased LF index increased mortality risk (RR 3.6, 95\% CI $=1.3-10.5)$ for both genders $(\mathrm{n}=773)$ in the European Myocardial 
Infarction Amiodarone Trial (Wichterle et al., 2004). A recent case ( $\mathrm{n}=50,24$ women) control study $(\mathrm{n}=35,19$ women) of coronary artery ectasia reported significance for SDNN and SDANN $(\mathrm{p}<.001$ both) but not for RMSSD (Turker, Ozaydin, \& Yucel, 2010).

Improvement in HRV indices that were significantly decreased could reflect change in cardiac outcomes mediated by medications, such as beta blockers, that alter catecholamine influence. In a study of Italian patients with CHF, cases $(n=30)$ had significantly $(\mathrm{p}<.001$ both) lower SDANN and geometric HRV histogram values than controls $(n=30)$ (Casolo, Balli, Taddei, Amuhasi, \& Gori, 1989). However, increase in the HF index $(50 \%, \mathrm{p}=.03)$ was reported in patients $(\mathrm{n}=13)$ with congestive heart failure (CHF) who received angiotensin-converting enzyme (ACE) inhibitors (Binkley et al., 1993), and even greater increases in $\mathrm{HF}(144 \%, 95 \% \mathrm{CI}=42-320 \%)$ were found in CHF patients $(n=20)$ treated with beta blockers, with the greatest improvement among those with the lowest values $(r=0.78, p<.01)$ (Goldsmith et al., 1997). Despite improvement in CHD mortality and some HRV values with the use of beta blockers and antiarrhythmics, a low SDNN was still predictive of all-cause mortality (hazard ratio 1.9, $95 \% \mathrm{CI}=1.2-3.2)$ in Dutch men $(\mathrm{n}=885)$ and may be a better indicator of general ill health (Dekker et al., 1997).

HRV assessment is useful in patients who have common comorbidities that can affect cardiac function. In a subset of normotensive men and women $(n=7,099)$ in the ARIC study, low HRV was associated with developing hypertension (Schroeder et al., 2003). In preliminary work, decreased HRV was initially detected in $40 \%$ of patients $(n=$ 543 ) with varying degrees of diabetic autonomic neuropathy (Ewing et al., 1985).A case $(\mathrm{n}=25)$ control $(\mathrm{n}=11)$ study found significantly $(\mathrm{p}<.01)$ lower HRV in two diabetic groups compared to the non-diabetic controls (Malpas \& Maling, 1990). Geometric HRV triangular index and ULF measures in cases ( $\mathrm{n}=120,49 \%$ female, $36 \%$ diabetic) undergoing chronic hemodialysis were predictive of cardiac death (adjusted RR 3.28, $95 \% \mathrm{CI}=1.08-9.95$ and $1.92,95 \% \mathrm{CI}=1.01-3.67$ respectively), but not for all cause death when compared with 62 year old matched healthy controls (Fukuta et al., 2003). Adult cases with moderate to severe obstructive sleep apnea (OSA) $(\mathrm{n}=15)$ and mild OSA $(n=18)$ had lower HVR ( $p=.01$ and $p=.02$ respectively) compared to controls ( $n$ $=16$ ) (Narkiewicz et al., 1998). Exploring circadian rhythm influence, a loss of HRV occurred during REM sleep with post MI cases $(\mathrm{n}=8)$ compared to healthy controls $(\mathrm{n}=$ 8) (Vanoli et al., 1995). Cigarette smoking was associated with decreased HRV with significant HRV increases of $7.3 \pm 1.0$ beats $/ \mathrm{min}(\mathrm{p}<.0001)$ during a 24 hour cessation period in normotensive habitual smokers $(\mathrm{n}=39)$ (Minami, Ishimitsu, \& Matsuoka, 1999). Additionally, in a preliminary study of patients $(n=38)$ with severe mitral regurgitation, decreased HRV was significantly associated with subsequent need for surgery $(p<.001)$, early mortality $(p<.02)$, atrial fibrillation onset (RR 3.1; $p=0.03)$, and decreased ejection fraction $(\mathrm{r}=.49, \mathrm{p}=.002)$ (Stein et al., 1993). In heart transplant cases $(n=41)$ erratic HRV changes were tracked during exercise with an initial significant increase $(\mathrm{p}<.01)$ followed by significant decrease $(\mathrm{p}<.01)$ during recovery suggestive of possible re-innervation compared to consistent increase of HRV in controls $(n=6)$ (Radaelli et al., 1996). Finally, decreased HRV was a significant predictor of 
mortality in elderly in the Rotterdam $(\mathrm{n}=5,272$; hazard ratio $=1.8,95 \% \mathrm{CI}=1.0-3.2)$ (de Bruyne et al., 1999) and Zutphen $(\mathrm{n}=878, \mathrm{RR}=1.4,95 \% \mathrm{CI}=0.9-2.2)$ (Dekker et al., 1997) studies.

Transient decreases in HRV were seen in patients $(n=10)$ with Takotsubo cardiomyopathy characterized by normal coronary arteries with temporary but reversible ballooning of the apex of the left ventricle (Akashi, Barbaro, Sakurai, Nakazawa, \& Miyake, 2007) and significantly elevated catecholamine levels (Wittstein et al., 2005). In a three year Swiss population study only $0.3 \%(n=41)$ of patients receiving coronary agiography $(\mathrm{n}=13,715)$ had Takotsubo, a rare form of cardiomyopathy most often seen in postmenopausal women (Eshtehardi et al., 2009). Rapidly resolving myocardial stunning has been suggested as an underlying contributor to Takotsubo cardiomyopathy and temporary HRV decline (Akashi et al., 2007; Wittstein et al., 2005). Up to 61\% of patients report physical or psychological stress prior to onset (Eshtehardi et al., 2009).

\section{Heart Rate Variability and Psychosocial Factors}

In recent decades, interest in studying sympathetic overload, vagal withdrawal, and altered HRV in patients with psychological and social stress has accelerated. Impetus is provided by the association between psychosocial factors and CAD (Carney et al., 2001; Krittayaphong et al., 1997; Walters, Rait, Petersen, Williams, \& Nazareth, 2008). For ease of discussion, psychosocial contributors to negative cardiac outcomes can be organized into general domains: depression, anxiety, individual traits, social support, and chronic and acute stress (Rozanski, Blumenthal, \& Kaplan, 1999).

\section{Depression}

Decreases in SDNN values were inversely associated with severity of depression $(\mathrm{p}=.009)$ in a small early study of men $(\mathrm{n}=33)$ and women $(\mathrm{n}=9)$ with CAD (Krittayaphong et al., 1997). This finding is supported by subsequent larger research in the Enhancing Recovery in Coronary Heart Disease (ENRICHD) study $(n=804)$, as decreases in several HRV indices correlated inversely with severity of depression in patients $(\mathrm{n}=380)$ post MI (ULF, $\mathrm{r}=-0.12, \mathrm{p}<.003$; VLF, $\mathrm{r}=-0.16, \mathrm{p}<.0001 ; \mathrm{LF}, \mathrm{r}=$ $-0.13, \mathrm{p}<.0001$ respectively) (Carney et al., 2001). In melancholic major depression ( $\mathrm{n}=$ 16), HRV was lower $(\mathrm{p}<.025)$, LF was higher $(\mathrm{p}<.001)$ in a panic disorder group $(\mathrm{n}=$ 16), but there was no significance with suicidal patients $(n=16)$ (Rechlin, Weis, Spitzer, \& Kaschka, 1994). The combination of depression with DM was associate with greater relative risk of all-cause mortality $(\mathrm{RR}=3.1,95 \% \mathrm{CI}=2.70-3.58)$ than depression $(\mathrm{RR}=$ $1.76,95 \% \mathrm{CI}=1.64-1.89)$ or $\mathrm{DM}(\mathrm{RR}=1.71,95 \% \mathrm{CI}=1.54-1.89)$ alone (Pan et al., 2011). However, only LF/HF ratio was significantly $(\mathrm{p} \leq .05)$ associated with depression in a study of healthy Swedish women $(\mathrm{n}=300)$ (Horsten, Erigson, Perski, Wamala, \& Schenck-Gustafsson, 1999), and no association was found between lower HRV and depression in stable cardiac patients $(\mathrm{n}=873)$ in the Heart and Soul Study (Gehi, Mangano, Pipkin, Browner, \& Whooley, 2005). 
Treatment may alter depression's influence on HRV. In subjects evaluated post MI $(n=103)$, patients with depression who had not received a beta blocker $(n=32)$ had lower SDRR index $(\mathrm{p}=.016)$ prior to discharge compared to those already receiving beta blockers and those with anxiety; the level of depression was significantly correlated with SDRR changes $(r=-0.47)$ and baroreflex sensitivity $(r=-0.04)$ (Pitzalis et al., 2001). Additionally, treatment with selective serotonin reuptake inhibitors (SSRI) was credited with decreasing catecholamine secretion $(\mathrm{p}=.004)$ and spillover $(\mathrm{p}=.008)$ in patients $(n=39)$ with major depressive disorder compared to healthy $(n=76)$ controls (Barton et al., 2007). Conversely, in the larger $(n=2,059)$ Netherlands Study of Depression and Anxiety, significant decrease in HRV was associated with SSRI $(\mathrm{p}=.004)$, tricyclic, and other antidepressant use ( $\mathrm{p}<.001$ both) (Licht, De Geus, Van Dyck, \& Penninx, 2009). However, it is unclear whether the decrease in HRV was attributable to the underlying depression rather than medication. In a case $(n=30)$ control $(n=22)$ study, RMSSD improved $(\mathrm{p}=0.01)$ after cases received 16 sessions of cognitive behavior treatment for mild to severe depression (Carney et al., 2000). In summary, some biobehavioral interventions appear to moderate HRV response in depression, but more research is needed.

\section{Anxiety}

A cluster of five disorders compose anxiety: panic disorder (PD), generalized anxiety disorder (GAD), social anxiety disorder (SAD), obsessive compulsive disorder (OCD), and posttraumatic stress disorder (PTSD) (National Institute of Mental Health, 2010). In a prospective study of men $(n=33,999)$, PD increased the risk of sudden cardiac death (RR 6.08; 95\% CI 2.35-15.75) but not that of nonfatal MI (Kawachi et al., 1994). A British ( $n=57,615 ; 73 \%$ women) cohort study found an increased hazard ratio (HR) for CHD with PD compared to those without PD $(<50$ years, HR $1.44 ; 95 \% \mathrm{CI}=$ $1.25-1.65 ; \geq 50$ years, HR $1.11,95 \% \mathrm{CI}=1.03-1.20)$ but only those with PD who were less than 50 years old had an increased hazard for MI $(<50$ years, HR $1.38,95 \% \mathrm{CI}=$ 1.06-1.79) (Walters et al., 2008).

In two small studies, resting LF was not significantly associated $(\mathrm{p}>.05)$ with PD (Alvarenga, Richards, Lambert, \& Esler, 2006; Pitzalis et al., 2001), and there was no association between HRV values and PD in a larger $(\mathrm{n}=150)$ mixed gender study (Virtanen et al., 2003). In the Netherlands Study of Depression and Anxiety, decrease in HRV was not significantly associated with any tracked anxiety diagnosis $(n=2059)$, including GAD, SAD, or PD (Licht et al., 2009). These findings conflict with previous small studies. One before-after treatment in patients $(n=17)$ with PD using SSRIs was associated with increased LF/HF ratio $(\mathrm{p}<.05)$ that was not found in unmedicated controls $(\mathrm{n}=16)$ (Tucker et al., 1997). Also, another small study found a lower HF $(\mathrm{p}<$ $.05)$ in PD cases $(n=20)$, irrespective of SSRI use, compared to healthy controls $(n=20)$ (Alvarenga et al., 2006). 
In exploring the impact of remaining anxiety disorders, research on PTSD and OCD used small samples but raises important questions of association with HRV. The LF was higher and HF lower in untreated PTSD compared to both controls $(n=16)$ and those with PTSD who responded to treatment $(\mathrm{n}=16)$ with SSRIs $(\mathrm{p}<.001$ both $)$ (Cohen, Kotler, Matar, \& Kaplan, 2000). PTSD participants $(n=14)$ had significantly higher resting heart rate and lower HRV measures of LF, HF, and LF/HF ratio $(\mathrm{p}<.001$ all) than controls $(n=25)$ (Cohen, Benjamin, et al., 2000). Post-MI veterans with PTSD $(\mathrm{n}=34)$ had significant differences in HRV indices with decreased R-R intervals $(\mathrm{p}=$ $.02)$ and HF $(p=.03)$ and increased LF $(p=.01)$ and LF/HF ratio $(p=.02)$ compared to post-MI veterans without PTSD $(\mathrm{n}=34)$ (Lakusic et al., 2007). Mortality risk was increased threefold (hazard ratio 3.45; 95\% CI $=1.57-7.60 ; \mathrm{p}=.002$ ) in patients with an ICD who had PTSD $(n=38)$ over those with and ICD and no PTSD $(n=109)$ (Ladwig et al., 2008). In a small case-control study of women $(n=40)$, those with PTSD $(n=20)$ had increased LF values with laboratory induced stressors $(\mathrm{p}<.05)($ Keary, Hughes, \& Palmieri, 2009). HRV was not significantly decreased in a PD group $(\mathrm{n}=24)$, a control group $(\mathrm{n}=24)$, or those with OCD $(\mathrm{n}=26)$ (Slaap, Nielen, Boshuisen, van Roon, \& den Boer, 2004).

\section{Dissociation}

Dissociative disorder was significantly associated with PTSD in Vietnam combat veterans $(n=34)$ compared to those without PTSD $(p<.01)$ (Bremner \& Brett, 1997), and significant deficits in attention $(\mathrm{r}=-2.953, \mathrm{p}=.007)$ and word recall $(\mathrm{r}=-3.464$, $\mathrm{p}=0.002)$ were present in those with both dissociative disorder and PTSD $(n=10)$ compared to those with only PTSD $(n=17)$ (Roca, Hart, Kimbrell, \& Freeman, 2006). Female veterans with MST $(\mathrm{n}=29,418)$ developed dissociative disorder two times more $($ OR 7.47; CI 99\% = 5.29-10.54) and PTSD three times more (OR 11.82; CI 99\%= 11.18-12.50) than other psychiatric illnesses (Kimerling, Gima, Smith, Street, \& Frayne, 2007). Depersonalization disorder, dissociative amnesia, dissociative fugue, dissociative identity disorder, and non-specified dissociative disorder states provide the range of expression (APA, 2000), but traumatized individuals with PTSD $(n=55)$ were more likely to experience numbing in the presence of either hyperarousal or avoidance symptoms (OR 4.5) or both (OR 10.7) than those without PTSD (n=103) (Foa, Riggs, \& Gershuny, 1995). Significant decrease in HRV in patients with dissociative disorders was reported in two recent studies of small sample size $(n=40, p<.01 ; n=11, p=.002$, respectively) (Bob, Susta, Grequsova, \& Jasova, 2008; Reinders et al., 2006).

\section{Catecholamine Influence with Mental Health Disorders}

Increased epinephrine levels ( $\mathrm{p}<.01)$ (Wilkinson et al., 1998) and ECG changes indicative of MI despite normal coronary arteries (Mansour et al., 1998) have been documented in controlled laboratory settings during panic attacks. Delay in norepinephrine and epinephrine plasma clearance was significant $(\mathrm{p}<.01)$ in patients with PD $(n=19)$ compared to normal controls $(n=20)$, while HF was decreased and 
LF/HF ratio increased $(p<.05)$ despite SSRI treatment (Alvarenga et al., 2006). The norepinephrine spillover rate, time from release of norepinephrine by sympathetic nerves to uptake into circulating plasma, was delayed exclusively in five patients with depression in a controlled laboratory setting compared to six healthy controls (Esler et al., 1982). Following traumatic events, plasma levels of norepinephrine in patients with $\operatorname{PTSD}(\mathrm{n}=31)$ were lower at 10 days $(\mathrm{p}=.02)$, one month $(\mathrm{p}=.002)$, and five months $(\mathrm{p}=.02)$, than in those without PTSD $(\mathrm{n}=124)$ suggesting emotional distancing (Videlock et al., 2007). Sympathetic stimulation through catecholamine excess and delayed norepinephrine uptake may contribute to PD coronary spasm and acute MI changes in the ECG despite normal coronary arteries (Mansour et al., 1998). HRV values may vary by anxiety disorder and by individual response (Berntson \& Cacioppo, 2004).

\section{Individual Traits}

Personal emotions, attitudes, and lifestyle choices can impact the autonomic system and HRV. Hostility carried increased risk for all-cause mortality and cardiovascular mortality (relative hazard $2.30,95 \% \mathrm{CI}=1.47-3.59 ; 2.70,95 \% \mathrm{CI}=1.27$ 5.76) respectively in the prospective Kuopio Ischemic Heart Disease Risk Factor Study of men $(\mathrm{n}=2,125)$ (Everson et al., 1997). Correspondingly in a French mixed gender $(\mathrm{n}=14,445)$ prospective study, neurotic hostility was a predictor for death from all internal and external causes (Relative Index of Inequality $2.62,95 \% \mathrm{CI}=1.68-4.09$ and $3.24,95 \% \mathrm{CI}=1.03-10.18$ ) respectively (Nabi et al.). In the prospective Veterans Administration Normative Aging Study of male veterans $(\mathrm{n}=1305)$, anger increased relative risk of total CAD and coronary events $(3.15,95 \% \mathrm{CI}=0.94,10.5 ; 2.66,95 \%$ $\mathrm{CI}=1.26,5.61$, respectively) (Kawachi, Sparrow, Spiro, Vokonas, \& Weiss, 1996), and women $(\mathrm{n}=688)$ in the Women with Chest Pain Study with high anger-out scores had higher odds of having a cluster of cardiac risk factors, low levels of high density lipoprotein (HDL), high levels of low density lipoprotein (LDL), and a greater body mass index (BMI) (OR 4.0, 95\% CI = 1.4-11.1; OR 4.8, 95\% CI $=1.5-15.7$; OR 3.5, 95\% CI $=$ 1.1-10.8) respectively (Rutledge et al., 2001). Conversely, anger and hostility were not significantly associated $(\mathrm{p}>.05)$ with decreased $\mathrm{HRV}$ in a small study of men $(\mathrm{n}=71)$ and women $(\mathrm{n}=79)$ (Virtanen et al., 2003). In a study of healthy Swedish women ( $\mathrm{n}=$ 300 ), obesity, hypertension, smoking, and sedentary lifestyle were associated with lower SDNN and RMSSD, but failing to discuss anger was only significant with lower SDNN $(\mathrm{p} \leq .05$ all) (Horsten et al., 1999).

\section{Lack of Social Support}

Loneliness can contribute to cardiac risk of premature mortality (Lynch, 2000). Lack of supportive significant relationships was associated with increased development of CAD (RR 2.9, 95\% CI = 1.3-6.5) in the Stockholm Female Coronary Risk Study ( $\mathrm{n}=$ 187) (Orth-Gomer et al., 2000) and cardiovascular mortality $(\mathrm{p}<.0001)$ in a cardiovascular cohort study $(\mathrm{n}=1368)$ (Williams et al., 1992). Having an income at or below $\$ 10,000$ also increased hazard risk $(1.9,95 \% \mathrm{CI}=1.57-2.32, \mathrm{p}=.002)$. Living 
alone and low social support were associated with significantly lower SDNN in a study of healthy Swedish women $(\mathrm{n}=300),(\mathrm{p} \leq .05)$ (Horsten et al., 1999).

\section{Chronic and Acute Distress}

Research induced stress is limited because of ethical protection provided study participants (Briere, 1992), but increased cardiac response to cognitive task stressors was associated with subsequent cardiovascular risk $(\mathrm{r}=.094)$ in a meta-analysis of stress reactivity and post recovery studies $(n=36)$ (Chida \& Steptoe, 2010). Fear while viewing horror films lowered HRV in three separate studies; laboratory induced fear significantly reduced HRV $(\mathrm{p}<.05)$ in healthy participants $(\mathrm{n}=43)$ (Rainville et al., 2006), reduced $(\mathrm{r}=-.32, \mathrm{p}<.01)$ vagal tone HRV in healthy volunteers $(\mathrm{n}=149)$ (Stemmler et al., 2007), and reduced LF measures (effect size .93) in healthy volunteers ( $n=37)$ (Kreibig, Wilhelm, Roth, \& Gross, 2007). Of participants $(n=59)$ randomly assigned to laboratory stressors before bedtime, both genders experienced significantly $(\mathrm{p}<.05)$ lower HF during non-rapid eye movement (NREM) and REM sleep (Hall et al., 2004). However, women $(n=65)$ had significantly $(\mathrm{p}<.01)$ higher heart rate response with second exposure to laboratory stressors than men $(n=65)$ suggesting women may be more vulnerable to repeated stress exposure (Schmaus et al., 2008). In a study of 50 healthy men and women, short term acute laboratory stress from having to give a speech initially increased heart rate $(p<.001)$, LF $(p<.001)$, and HF $(p=.019)$ but geometric changes were more associated with chronic hassle stressors $(\mathrm{r}=-.35, \mathrm{p}=.019)$ (Schubert et al., 2009). While undergoing ECG and hemodynamic monitoring during separate testing from word-conflict exercises, atropine, and propranolol, women $(\mathrm{n}=12)$ displayed more effect on the sinus $(\mathrm{p}<.05)$ and AV $(\mathrm{p}<.01)$ nodes than men $(\mathrm{n}=11)$ with refractory and conduction time decreased during stress (Insulander \& Vallin, 2005). Overall, laboratory induced stress increased sympathetic and decreased parasympathetic activity on the heart when measured during pharmacologic blockade; however, there were notable differences in individual response $(n=10)$ (Berntson et al., 1994). Laboratory induced stress in a controlled setting may not reflect the intensity of stress response encountered in real life threatening situations.

\section{Traumatic Events}

Providing medical care to individuals following natural disasters, gives insight into actual life stress response. The year following the 9-11 terrorist attack, there were significantly more admissions $(\mathrm{p}=.008)$ with $\mathrm{MI}$ and tachyarrhythmias based on a retrospective review of charts $(\mathrm{n}=1,653)$ at a hospital within four miles of the disaster site (Feng, Leniham, Johnson, Karri, \& Redd, 2006). In a probability sample $(n=2,729$, $52.2 \%$ female) from the National Health Interview Survey, there was increased relative risk of heart problems nationally at one $(2.98,95 \% \mathrm{CI}=1.19-7.49, \mathrm{p}<.05)$, two $(3.12$, $95 \% \mathrm{CI}=1.37-7.12, \mathrm{p}<.01)$, and three $(1.38,95 \% \mathrm{CI}=0.55-3.41, \mathrm{p}<.001)$ years following the 9-11 terrorist attack (Holman et al., 2008). Compared to a sample of controls from the general Croatian population, arrhythmias were 2.5 times $(\mathrm{p}<.01)$ more 
common in Croatian prisoners of war $(\mathrm{n}=182$, mean age $35.8 \pm 11$ years $)$ examined within two weeks of release from imprisonment (164.5 \pm 87.1 days) and mistreatment in Serbian detention camps (Corovic, Durakovic, Zavallic, \& Zrinscak, 2000). True "fight or flight" responses can stress the heart, especially with repeated exposure.

\section{Military Sexual Trauma}

In evaluating the mandatory universal screening for MST program for 2005, positive history was reported in $19.5 \%$ of the women veterans $(n=33,259)$ and was significantly associated with more than twofold increase in post-screen mental health treatment ( $\mathrm{RR} 2.52,95 \% \mathrm{CI}=2.38-2.66$ ) over those with a negative history (Kimerling et al., 2008). Of 192 female veterans recruited to compare MST to other types of trauma, $60 \%$ of female veterans with MST had subsequent PTSD $(\mathrm{p}=.0001)$ contrasted with $43 \%$ with PTSD from other traumatic events $(\mathrm{p}=.02)$ (Yaeger et al., 2006). Although $92 \%$ reported at least one traumatic event, women $(n=284)$ rated sexual trauma as the worst type of trauma (68.3\%), followed by physical assault (15.8\%), and combat exposure $(5.6 \%)$, even though MST had occurred before $(\mathrm{M}=23$ years $)$ the study (Schnurr et al., 2007).

In a sample of female veterans ranging from the Vietnam War to $2004(\mathrm{n}=520)$, $41 \%$ reported rape and/or physical assault during active service even though half of these stated they joined the military to escape an abusive home life (Sadler et al., 2004). Of the $29 \%$ reporting military service rape trauma as the only type of trauma experience, over half reported repeated rape events. Childhood sexual abuse $(\mathrm{p}<.001)$, rape before and after military service $(\mathrm{p}<.001)$, and both chronic physical $(\mathrm{p}<.01)$ and psychological $(\mathrm{p}$ $<.001)$ illness occurred more in women who experienced multiple MST events.

Although reported MST decreased from $46 \%$ of female Vietnam War veterans in 1995 to $24 \%$ of Gulf War female veterans in 2002, those who experienced sexual harassment (AOR 2.52, 95\% CI $=1.91-3.33$ ) or assault (AOR 5.41, 95\% CI =3.19-9.17) were more likely to have PTSD from MST even after statistical adjustment for other trauma covariates, including combat exposure (Kang et al., 2005). Additionally, a significant dose response association between PTSD and level of trauma (none being lowest and sexual assault highest) was supported $(\mathrm{p}<.0001)$ (Kang et al., 2005). In a study of activated reserve troops $(\mathrm{n}=3,946)$, MST was associated with greater risk of depression (AOR 4.51, 95\% CI = 3.30-6.16) and lifetime PTSD (AOR 7.03, 95\% CI = 5.05-9.79) (Street et al., 2008).

According to the Women's Health Initiative, higher resting heart rate reflecting autonomic tone was independently associated with coronary events (Hsia et al., 2009). Autonomic dysregulation occurs with stress, mood, lifestyle, and many biophysical disorders (Grippo \& Johnson, 2009). Autonomic changes are associated with a plethora of increased acute and chronic cardiac risk factors including hypertension, elevated BMI, altered glucose metabolism, atherosclerosis, MI, CHF, and arrhythmias. Low HRV in depression is supported by several studies (Barton et al., 2007; Carney et al., 2000; 
Carney et al., 2001; Cohen, Marmar, Ren, Bertenthal, \& Seal, 2009; Krittayaphong et al., 1997) and accepted in medical textbooks (Berntson \& Cacioppo, 2004), but small study size and variation in individual response to anxiety and stress contribute to conflicting reports of their contribution to decreased HRV.

Female veterans are a group that experiences high levels of stress and traumatic events, with many developing PTSD after surviving MST. Additionally, the VA electronic database provides retrospective access to a larger sample size. No previous study described HRV in victims of MST, and accumulating evidence of association among HRV and physical and psychosocial factors warranted further research into the relationship between MST exposure and HRV outcomes in female veterans.

\section{Allostasis as a Conceptual Framework}

A generalized conceptual model depicts the biobehavioral response to MST exposure with hypothalamic pituitary (HPA) axis activation and release of the catecholamine epinephrine and norepinephrine mediators, as well as cortisol to enhance allostasis regulation (McEwen, 2004, 2005; McEwen \& Seeman, 1999). Transient decreases in HRV are seen with increased sympathetic activity that accompanies acute stress, and persistent decreased HRV is seen with the vagal withdrawal response that accompanies chronic stress (Dantev, 2002). With severe or repeated exposure to traumatic stress, allostasis gives way to a diminished capacity for compensation signified by increased allostatic load and altered heart, mental, endocrine, and immune function. An expected steady decline in HRV occurred with the stress of aging, before leveling around 75 years of age (Stein, Barzilay, Chaves, Domitrovch, \& Gottdiener, 2009). However, female veterans with a positive history of MST may have numerous episodes of autonomic stimulation, cardiocyte stimulation, electrical remodeling, and opportunity for developing decreased HRV prematurely. In meta-analysis of studies over five decades, clinical depression increased risk of developing CAD (RR 2.69, 95\% CI $=1.63$ $4.43, \mathrm{p}<.001)$ (Rugulies, 2002) and was included as a contributing variable to allostatic load in military women (Groer \& Burns, 2009). Continual suppression of insulin secretion during chronic stress may contribute to evolving DM (Sterling \& Eyer, 1988). Interrelationship of PTSD with autonomic stimulation may contribute to immunosuppression (Woods et al., 2005); however, immunosuppression is not explored in this retrospective research limited to existing records. Review of literature indicates treatment with beta blockers increased HRV, while age, CAD, DM, smoking and depression decreased it. The hypothesis of this study is that MST and subsequent PTSD may also decrease HRV. See Figure 2-1 for model.

\section{Summary}

Measuring HRV assesses parasympathetic and sympathetic contributions on end organ response and indicates an index of general health. Psychological treatment to prevent premature cardiac mortality may not be as beneficial in women, especially as 
Figure 2-1. Lee's model of the contribution of military sexual trauma to allostatic loading and its physical and psychological outcomes.

Note: Concepts were derived from literature review to construct the model.

Sources: Groer, M. W., \& Burns, C. (2009). Stress response in female veterans: An allostatic perspective. Rehabilitation Nursing, 34, 96-104. McEwen, B. (2004). Protective and damaging effects of the mediators of stress and adaptation: Allostasis and allostatic load. In J. Schulkin (Ed.), Allostasis, homeostasis, and the costs of physiological adaptation (pp. 65-98). New York: Cambridge University Press. McEwen, B. (2005). Stressed or stressed out: What is the difference? Journal of Psychiatry \& Neuroscience, 30, 315-318. Woods, S. J., Wineman, M., Page, G. G., Hall, R. J., Alexander, T. S., \& Campbell, J. C. (2005). Predicting immune status in women from PTSD and childhood and adult violence. Advances in Nursing Science, 28(4), 306-319. 


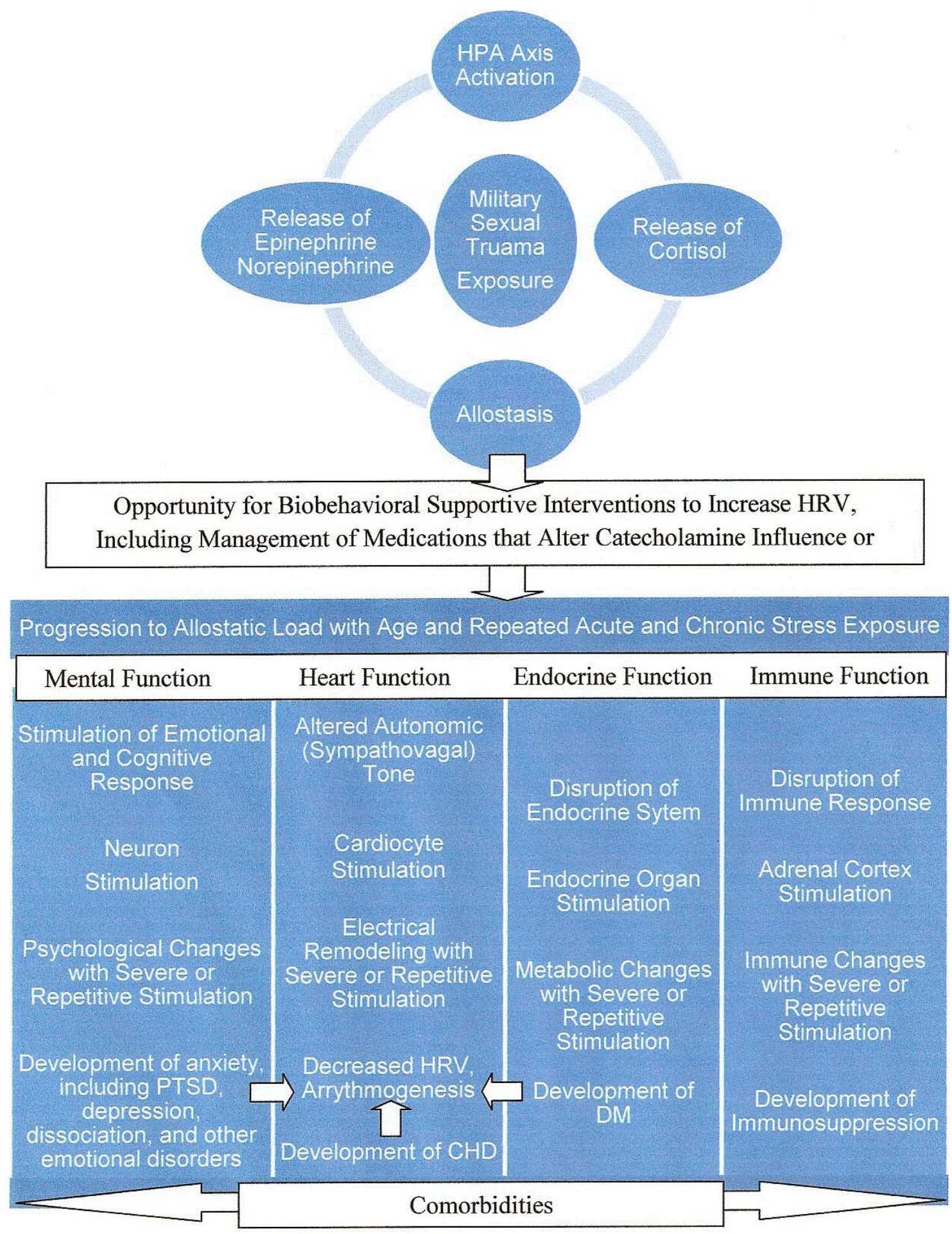


they age (Linden, Phillips, \& Leclerc, 2007). Biobehavioral intervention strategies focused on prevention and detection of psychosocial risk earlier in life are needed, rather than waiting to treat a damaged heart (European Society of Cardiology, 2007). An exploratory historical cohort study will benefit female veterans with MST by documenting risk of early decline in HRV and will provide support for future large scale prospective research of the relationship between MST and HRV. 


\section{CHAPTER 3. METHODOLOGY}

The purpose of the study was to explore the relationship between military sexual trauma (MST) and heart rate variability (HRV) controlling for posttraumatic stress disorder (PTSD), depression, age, coronary artery disease (CAD), diabetes mellitus (DM), cigarette smoking, and beta blockers and also to estimate association of having a decline in HRV with MST exposure. The underlying general hypothesis was that HRV was lower in female veterans with a history of MST exposure. This chapter provides a detailed description of the study design, sample, setting, and the instruments. Procedures for data collection and statistical analyses, as well as protection of human subjects, are discussed.

\section{Study Design}

A historical cohort design is appropriate when subjects are selected by exposure status and the follow up period documenting diminished health outcomes is based on existing records (Rothman, 1986; Rothman \& Greenland, 1998). Enough time must elapse from exposure to symptom manifestation for assumptions of induction and latency to be addressed (Rothman \& Greenland, 1998). Cutpoints for decreased HRV established in older patients with cardiac disease may not be appropriate for a sample of women with a mean age of less than 50 years and only a few cases of CAD. In this study, the incidence of reduced HRV could not be assessed and the emphasis is placed on the continuum of HRV values.

\section{Protection for Human Subjects}

An exempt study protocol was initially filed with the institutional review boards (IRB) at University of Tennessee Health Science Center (UTHSC) and Veterans Affairs (VA) and the VA Research and Development Committee, but the protocol was resubmitted and approved as expedited research. A Health Insurance Portability and Accountability Act waiver was granted by the VA as this retrospective chart review posed minimum risk to female veterans. A study modification amendment was approved by the VA and UTHSC IRB's for exploration of additional variables after dissertation and defense are completed. Identifier numbers instead of participant names were assigned to depersonalized data collected from EMRs and the VA data warehouse to minimize risk to confidentiality. Data were entered into the computer data management system using only code numbers with no association to identifiable protected patient information. Request to Transport/Use De-Identified Research Data was filed and approved. If any change in investigators occurred, access would have terminated immediately. If access was obtained by someone other than the primary investigator, the event would have been reported immediately to the Information Security Officer, Privacy Officer, and VA and UTHSC IRBs. Access to the electronic data folder and code notebook will be terminated by the IRB at the end of the study prior to July 17, 2012. 
This exploratory historical cohort study provided needed information for comparison of HRV between the two groups with and without MST exposure history to generate data and strategies for future traumatic stress research. Knowledge to be gained from this study outweighed potential risk to study participants.

\section{Setting and Sample}

The VA Medical Center used for this study conducted 24 hour Holter monitoring on 152 female veterans from January 2007 through December 2010. All subjects were referred for cardiology consult for cardiac symptoms, and four 10-second Holter strips and 10 -second ECG tracings were recorded in electronic medical records (EMRs). This was not a random sample but, rather, a subsample of female veterans with and without MST seen by VA cardiology for evaluation of cardiac symptoms. Of the 152 subjects, only 126 met inclusion criteria; 26 were excluded for insufficient Holter and ECG tracings.

\section{Inclusion Criteria}

Female veterans in normal sinus rhythm who had three 10-second ECG or Holter tracings from January 2007 through December 2010 were included for HRV analysis.

\section{Exclusion Criteria}

Subjects with less than four consecutive normal sinus rhythm R-R intervals on the 10-second ECG and Holter recording were automatically excluded as HRV could not be accurately measured (Schroeder et al., 2004; Sztajzel, 2004). None of the subjects in the sample could be heart transplant recipients with cardiac denervation (Sands et al., 1989) or have adrenal disorders with altered systemic response.

\section{Instruments}

In addition to measuring age in years derived from date of birth, all other variables are measured by acceptable psychometric instruments. Screening and diagnosis for MST, PTSD, and depression are routinely performed in primary care settings with standard VA instruments with referrals for further psychiatric evaluation made for diagnosis. Diagnosis for DM and CAD are based on standardized criteria and recorded by International Statistical Classification of Diseases and Related Health Problems (ICD-9) codes. 


\section{Universal Screening of Veterans for Military Sexual Trauma}

The VA initiated universal MST screening in 1999 (Kimerling et al., 2007) and evaluated $89.7 \%$ of veterans seeking healthcare within the VA system by 2006 . All veterans receiving VA healthcare must be screened for MST history (Kimerling et al., 2008). The first question, "While you were in the military, have you ever received uninvited and unwanted sexual attention (e.g., touching or cornering, pressure for sexual favors, verbal remarks)?" carries a sensitivity of .92 and specificity of .89 when evaluated against clinical interview (McIntyre et al., 1999). "While you were in the military, has anyone ever used force or the threat of force to have sex with you against your will?" has a sensitivity of .89 and specificity of .90 . Comparing blinded clinician assessment to questionnaire, the kappa estimate of reliability was .79 for each question $(95 \% \mathrm{CI}=.68$ .91 for harassment; $95 \% \mathrm{CI}=.69-.90$ for assault). Routinely appearing by electronic reminder on each client's EMR these two general questions provide valid non-threatening screening that enhances documentation of MST (Street \& Stafford, 2010). A positive answer to either question provided documentation of MST.

\section{Posttraumatic Stress Disorder}

The PTSD Checklist Civilian (PCL-C) is a self-report 17 point questionnaire for screening, diagnosing, and monitoring PTSD based on the Diagnostic and Statistical Manual of Mental Disorders-IV (DSM-IV) (Weathers, Litz, Herman, Huska, \& Keane, 1993) and is the tool most frequently used at the VA Medical Center. Cutpoint scores vary for PTSD diagnosis for mental health clinic (56), primary care (33), and active duty Operations Enduring Freedom/Operations Iraqi Freedom veterans (28) (Department of Veteran Affairs, 2010d). The PCL-C has both a sensitivity and specificity of .79 in female VA patients (Dobie et al., 2002). Indirectly, posttraumatic stress diagnosis provides a severity measure of a single traumatic event, such as MST, or multiple cumulative life events. PTSD diagnosis was retrieved from ICD-9 codes and mental health notes of the EMR.

\section{Depression}

If a veteran screens positive on half of the 2-question Patient Health Questionnaire-2 (PHQ-2) which measures impact on loss of interest or pleasure in doing things and feeling down, depressed, or hopeless, a full PHQ-9 depression screening must be done the same day to check for suicidality (Corson, Gerrity, \& Dobscha, 2008). Additional questions of the PHQ-9 focus on difficulty with sleep, fatigue, eating, selfesteem, concentration, sluggishness, restlessness, or self-injury. Cutpoints are listed for mild major (10), moderate major (15), and severe major (20) depression with antidepressant treatment suggested with a score of 15 (McIntyre et al., 1999). Complimentary instruments, the PHQ-2 has a specificity of $91 \%$ and sensitivity of $97 \%$, while the PHQ-9 has a specificity of $88 \%$ and sensitivity of $78 \%$ and is performed in 
primary care routinely prompted by electronic reminder. EMRs were scrutinized for depression diagnosis and antidepressant treatment.

\section{Coronary Artery Disease}

Although a variety of tests, including computed tomography, can be useful in detecting $\mathrm{CAD}$, the long time gold standard of diagnosis provided by cardiac catheterization was utilized by the VA cardiac catheterization unit for the data to be reviewed for this study. Cardiac catheterization provides five methods for measuring coronary blood flow, thermodilution, digital subtraction angiography, electromagnetic flowmeter, Doppler velocity probe, and pressure wire (Davidson \& Bonow, 2007). Interpretation of tests indicating greater than $70 \%$ blockage is dependent on expertise of the cardiologist. Presence of history of CAD was recorded in the EMR under cardiac consult notes.

\section{Diabetes Mellitus}

National guidelines for diagnosing DM include presence of any of three criteria (American Association of Clinical Endocrinologist, 2007; American Diabetes Association, 2004). The first criterion focuses on symptoms of diabetes (polyuria, polydipsia, unexplained weight loss) plus casual plasma glucose concentration $\geq 200$ $\mathrm{mg} / \mathrm{dL}$, the second criterion is based on fasting plasma glucose concentration $\geq 126$ $\mathrm{mg} / \mathrm{dL}$, and the third on 2-hour post-challenge glucose concentration $\geq 200 \mathrm{mg} / \mathrm{dL}$ during a 75-gram oral glucose tolerance test. Presence of DM was obtained from the veteran's EMR in the physical assessment, medications, and ICD-9 codes.

\section{Cigarette Smoking}

Traditionally, cigarette smoking is measured in number of cigarettes or packs per day (Cagirci et al., 2009). Consuming more than 20 cigarettes, or two packs, per day is considered heavy smoking. Information recorded in the physical assessment or ICD-9 codes most often provided binary smoker or nonsmoker status.

\section{Beta Blocker Treatment}

Treatment with beta blockers was obtained from medication lists. Reason for treatment or contraindication for use (Magee \& Duley, 2003) were not consistently recorded in the EMR and were not obtained. 


\section{Heart Rate Variability Measurement}

Internationally accepted, time and frequency measurements from 24-hour Holter readings are optimum (ESC \& NASPE, 1996). However, short 10-second electrocardiogram readings have been successfully used for measurement of HRV (de Bruyne et al., 1999). Use of the mean of three 10-second ECGs was recommended to enhance intraclass correlation coefficients (ICC) for time domain measures, SDNN (ICC $.78,95 \% \mathrm{CI}=0.68-0.88$ ), and $\mathrm{RMSSD}(\mathrm{ICC} 0.82,95 \% \mathrm{CI}=0.73-0.90)$ respectively (Schroeder et al., 2004). Mean SDNN and mean RMSSD scores were obtained for each subject using three manually counted 10-second ECGs or Holter recordings obtained through Vista Imaging in the EMR.

\section{Procedures}

Access to VA data required appointment and mandatory VA Research training as a Without Compensation (WOC) Research Assistant, and orientation to the Electronic Medical System (EMS) by the VA Information Technology department. The investigator, with 30 years of arrhythmia interpretation and four years of experience in Holter analysis for a private cardiology group, counted all 10-second ECG and Holter recordings utilized for the study (Wagner, Waugh, \& Lawson, 2000). Measurements were conducted under the oversight of the electrophysiologist sponsor and ten ECGs were submitted to him for inter-rater reliability.

The VA IRB advised upgrading the original exempt retrospective research submission to an expedited review and creating a code book with names to prevent duplication of data collected over several weeks. The research proposal to the UTHSC in Memphis was also resubmitted as an expedited review to maintain consistency between sites. All research data on veterans were considered sensitive, stored in secure VA government furnished equipment (VAGFE), and underwent Federal Information Processing Standard encryption by mandated protocol (Department of Veteran Affairs, 2010b). No personal information linked to the veteran could be recorded with the electronic data collected including: name, dates, address, phone, fax, email, fingerprints, URL, or record, social security, insurance, account, license, vehicle, or serial numbers. The Chief of Data Management emailed a secure VA electronic link containing a list of all female veterans who had Holter recordings from 2007 through 2010. A spiral bound notebook containing coding numbers and patient names was created and locked in a filing cabinet on site with cardiac catheterization log books to keep the code book separate from the electronic data. The VA IRB emailed a secure electronic link to a folder on the Research Services' server for storing de-identified coded data, with the subfolder "Data" only accessible by the investigator in charge of data collection. In compliance with Records Control Schedule-10-1 protocol of the VA, the electronic data and spiral bound code notebook will be stored indefinitely. However, no files will ever be stored on a hard drive. 
As soon as approval was received from the VA and UTHSC IRBs and VA's $\mathrm{R} \& \mathrm{D}$, data were collected on a spreadsheet under informative headings including Holter HRV-1, Holter HRV-2, ECG HRV-1, ECG HRV-2, age, MST, DM, CAD, smoker, depression diagnosis, depression score, PTSD diagnosis, PTSD score, and beta blocker with name, dose, and frequency. Individual HRV was recorded from the mean SDNN and the mean RMSSD obtained from three manually counted 10-second ECGs or Holter recordings from each subject. Official approval to transport de-identified data were acquired to access to VA electronic warehouse data to check accuracy of data on MST, PTSD, and depression variables acquired from the EMR. Data on HRV of exposed and unexposed cohort subjects was stored as de-identified information in an Excel $^{\circledR}$ spreadsheet (Excel 2010, version 14, Microsoft Corporation, Redmond, Washington) prior to statistical analysis on VAGFE equipped with SAS ${ }^{\circledR}$ statistical software (SAS Enterprise Guide 4.1, SAS Institute Incorporated, Cary, North Carolina). Use of a VA SAS computer required weekly scheduling. All research and analysis was mandatorily conducted on site.

Several additional steps were required for VA approval to use de-identified data in the dissertation. Creation of the Privacy, Confidentiality, and Information Security Checklist in March 2011 mandated a meeting with the Information Security Officer and the Privacy Officer to conform wording of research activities to new data security requirements. A second WOC position had to be obtained to maintain access to data for dissertation completion with approval from the IRB. Request to submit a manuscript of findings required additional amendment submission to the UTHSC IRB and the VA IRB and R\&D. See Figure 3-1 for timeline of events.

\section{Change in Methods}

Unexpected deviations occurred in data collection plans, and unusual events arose that complicated the research process. Full 24 hour Holter recordings were only stored on the MARS Holter Analysis System at the VA Medical Center for one month, and the Marquette Electrocardiogram Analysis Program was not equipped with the software required to generate permanent electronic HRV data. Holter recordings from 2007 through 2010 were limited to four short 10-second strips and two 10-second ECG strips for the three strips necessary for manual counting and calculation of a mean SDNN and RMSSD for each individual. Counting HRV on 464 strips containing over $2000 \mathrm{NN}$ intervals to obtain the 378 (three strips for the 126 female veterans) that met criteria for the study was very labor intensive. NN intervals were initially entered in seconds but had to be entered a second time as milliseconds for conventional reporting. $\mathrm{NN}$ intervals were manually counted and entered into an Excel ${ }^{\circledR}$ spreadsheet. The mean of three 10 -second ECG or Holter strips for each veteran was obtained for SDNN and RMSSD values for statistical analysis. SDNN was calculated as the standard deviation of the measure of normal to normal intervals. RMSSD was calculated by standard formula: 


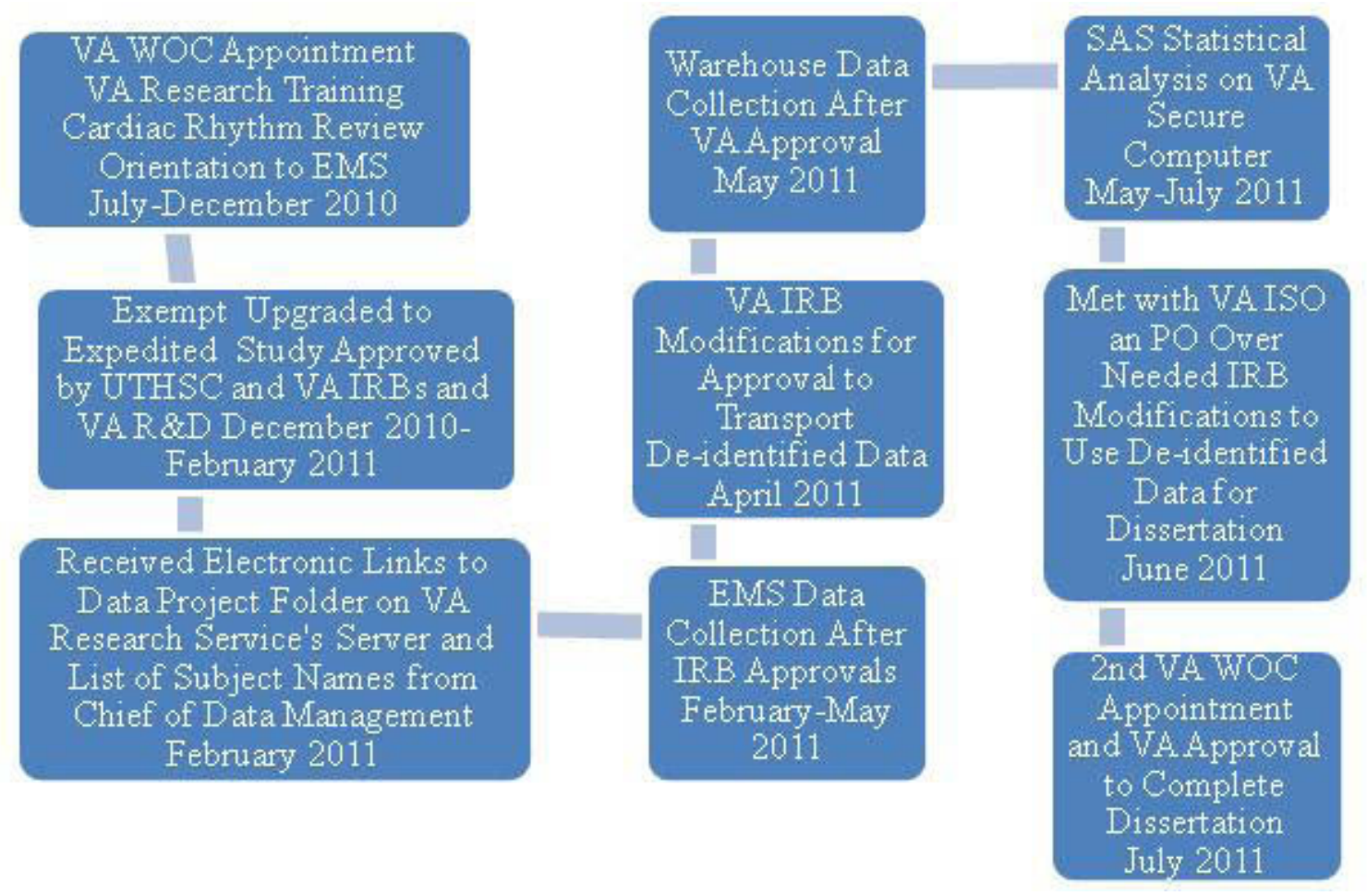

Figure 3-1. Timeline of steps required for data collection. 


$$
\operatorname{RMSSD}=\left(1 / 1-1 \sum_{j=1}^{1-1}\left(\mathrm{a}(\mathrm{j}+1)-\mathrm{a}(\mathrm{j})^{2}\right)^{1 / 2}\right.
$$

With data often fragmented throughout the EMR, gleaning comprehensive information on study variables required intense scrutiny of cardiology and mental consult notes, medications, ICD-9 codes, and electronic Mental Health Instrument scores. Additional security clearance forms and interviews were required to obtain collective mental health data stored for VA research in a computerized warehouse to compare to information from individual EMRs for data reliability enhancement. Instead of the expected Primary Care Posttraumatic Stress screening tool (Prins et al., 2003), the PTSD Checklist Civilian (PCL-C) was more routinely utilized and reported in the EMR. PTSD and depression scores were not available for each individual, thereby preventing assessment of severity. Evaluation of lower HRV was based on the sample with the upper three quartiles being compared against the lower quartile in accordance with previous study practices (de Bruyne et al., 1999; Rautaharju et al., 2006). Study design was changed from case-control to historical cohort as actual selection of subjects differed from that originally conceived; subjects were selected by exposure status rather than disease outcomes. Appropriate alterations to the research process were made as problems arose.

Security on VA data access was increased in March 2010, which mandated additional meetings with key information security and privacy personnel and additional IRB research amendments. The initial WOC sponsor for the study became severely ill, a situation which challenged supervised access to the data and any statistical analysis generated. Fortunately, the Deputy Associate Chief of Staff for Research graciously agreed to be the WOC sponsor for graduate student research dissertation requirements to be completed. Throughout the process, every effort was made to protect the reliability of findings while strictly maintaining the security of veteran information simultaneously.

\section{Analysis}

Preliminary analyses were performed for initial data assessment and in preparation for more advance statistical analyses. Data cleaning was performed by visually scanning columns for obviously incorrect entries. Any extreme or low SDNN or RMSSD indices were highlighted and R-R intervals in milliseconds were recounted directly from Holter and ECG tracings in the EMR. Age was measured in years, while MST, PTSD, depression, CAD, DM, smoking tobacco, and beta blocker treatment were measured as present (1) or absent (0). Data on depression and PTSD scores were incomplete and could not be used. Complete data sets for SDNN and RMSSD in milliseconds, age in years, and MST, PTSD, depression, CAD, DM, smoking tobacco, and beta blocker treatment in dichotomous (present $=1$ and absent $=0$ ) form were available on 126 subjects. 
Means, standard deviations (Hatcher, 2003d), and measures of central tendency were estimated for continuous variables (Hatcher, 2003f), while categorical variables were analyzed for frequency distribution (Hatcher, 2003d); results were checked for obvious errors. Initial examination of minimum and maximum HRV numeric variables did not reveal any out-of-bound values too large or small to be possible by international values in milliseconds (Nunan et al., 2010). Checking for skew and kurtosis, comparing mean, median, and mode, and visual scrutiny of stem-leaf and box plots were useful in understanding the shape of the distribution of numeric variables. HRV data are often right skewed (Dekker et al., 1997), which required logarithmic transformation (Rosner, 2006b; Tolley, 2010). Scattergrams were used to check for linear relationship between the sole multi-value predictor variable of age and the multi-value criterion (outcome) variables indicating HRV (Hatcher, 2003a).

To prevent a decrease in significance, inclusion of confounders was based on biological, as well as statistical, considerations (Rosner, 2006a). Including aging as a covariate in model building was supported by its association with decreased HRV (total $r^{2}=.53$ ) in previous studies (Cohen, Benjamin, et al., 2000; Cohen, Kotler, et al., 2000). Of all cardiac diseases implicated in the literature review, CAD was selected as the most inclusive covariate, and DM is a common comorbidity of CAD that decreases HRV as neuropathy progresses (Ewing et al., 1985). Over one third of veterans report cigarette smoking (Bray \& Hourani, 2007), a covariate associated with lower HRV (Sajadieh et al., 2004). Both clinical depression, a consistent predictor of CAD (Rugulies, 2002), and PTSD, frequently following MST, were considered as potential independent variables. Although the SDNN was not affected in a larger study (Dekker et al., 1997), beta blocker (Goldsmith et al., 1997) treatment was reported to increase HRV and was included as a potential independent variable. Controlling for confounding variables in statistical analysis is important to decrease bias and enhance reliability (Meirik, 2008).

Form of the continuous or dichotomous variables dictate which statistical method to use. In this study, the dependent or outcome variable, HRV, was measured on a continuous scale, and simple and multiple linear regression methods were used for exploring the regression of HRV on significant covariates. For additional verification of findings, the strength of association between HRV and significant covariates were estimated by odds ratios. Therefore, the research question was restated for analysis by methods for both continuous and categorical variables.

Worded for multiple linear regression analysis, the research question was, "What is the effect of HRV on MST among female veterans evaluated in a VA Medical Center with ECG and Holter monitoring after adjusting for the covariates of age, CAD, DM, smoking, depression, PTSD, and beta blockers?" A minimum of 5-10 observations for each of the seven potential independent variables is recommended, which required a minimum size of 35-70 per MST status group and 70-140 combined (Ginsberg et al., 2008). The sample size was within the range required for multiple linear regression analysis for moderate and large effect sizes (Soper, 2010). See Table 3-1 for size. Attempts to meet assumptions of normality for multiple linear regression were made by log transforming HRV; EMR and VA research warehouse data were compared to assure 
Table 3-1. A-priori sample size calculation for multiple regression for seven predictor variables.

\begin{tabular}{lcc}
\hline Sample size & $\begin{array}{c}\text { Moderate effect: } \\
\mathrm{f}^{2}=0.15\end{array}$ & $\begin{array}{c}\text { Large effect: } \\
\mathrm{f}^{2}=0.35\end{array}$ \\
\hline $\begin{array}{l}\text { Minimum sample size required for } \\
\text { desired statistical power level of 0.7 }\end{array}$ & 86 & 42 \\
$\begin{array}{l}\text { Minimum sample size required for } \\
\text { desired statistical power level of 0.8 }\end{array}$ & 103 & 49 \\
$\begin{array}{l}\text { Minimum sample size required for } \\
\text { desired statistical power level of 0.9 }\end{array}$ & 129 & 60 \\
\hline
\end{tabular}

Note: Alpha level at 0.05 .

the accuracy of measuring every explanatory variable $\mathrm{x}$ accurately (Rosner, 2006b; Tolley, 2010).

Correlations, simple linear regression, and t-tests were performed to eliminate insignificant variables. A priori significance was set at $\mathrm{p}<0.05$. Looking at simple correlations first and eliminating insignificant variables is a good strategy (Norman \& Streiner, 2008). Criteria used included \pm 1 for a perfect correlation, \pm .80 for strong, \pm .50 for moderate, \pm .20 for weak, 0 for no relationship, and a significance of $p<.05$ to reject the null that there is no relationship (Hatcher, 2003a). Only those variables with significant correlations were retained for model building. In complex exploratory studies with multiple predictor and criterion variables, initial simple regression analyses (Hatcher, 2003b) is useful for eliminating variables that account for less than $2-3 \%$ of the variance to increase power (Norman \& Streiner, 2008). Simple linear regression was performed on the only continuous independent variable, age. The independent-samples $t$ test is appropriate for continuous variables to compare the difference between the mean scores of two independent groups (Hatcher, 2003e).Independent-samples $t$ tests were used with remaining dichotomous covariates to estimate significance. Only variables with significant difference in means were included in the final models. Additionally, if there is strong multiplecollinearity, adding variables to a model decreases power from inflation of the standard error of the estimated regression coefficient (Norman \& Streiner, 2008). Model multicollinearity was avoided by creating separate models for variables with strong and significant collinearity.

Multiple regression analysis assumes that the dependent variable is normally distributed, but it does not assume that predictor variables are and allows for the use of dummy coding for nominal or ordinal variables (Norman \& Streiner, 2008). ANCOVA is used in cohort studies where two groups differ on one or more nominal or ratio variables that are related to the outcome variable and can improve power if the covariates account for a portion of the variance of the outcome variable (Norman \& Streiner, 2000a). For ANCOVA, lines must have the same slope but different intercepts, and test of homogeneity of slopes was performed. ANCOVA estimates and tests the significance of 
the intercept of two or more levels of a categorical variable, and the slope of the estimated regression line. The analysis of covariance (ANCOVA) model was used on appropriate variables to assess the difference between least squares means of the exposed and unexposed cohorts. Based on ANCOVA results, prediction of comparative age by HRV of those with MST to those without was made. Additionally, squared partial Pearson product moment correlation coefficients were estimated to quantify the individual contributions of included variables to the model after controlling for the other included variable.

After dichotomizing HRV according to the lower quartile and the upper three quartiles, the research question is stated, "What is the ratio of the odds of being in the lower quartile of HRV for individuals exposed to MST to the odds among unexposed individuals?" Age, DM, CAD, smoking, depression, PTSD, and beta blockers were also explored as potential risk factors.

The association between the presence of potential risk factors and a dichotomous outcome variable can be tested. Prevalence can be obtained by chi-square test of independence. Five assumptions for using chi-square include: The predictor and criterion variables can be measured on a scale (nominal, ordinal, interval, or ratio), random sampling from a population was used, subjects are only counted once in a two-by-two frequency table, no observed frequency cells contain zero, and no minimum expected frequency cells contain less than five (Hatcher, 2003c). To meet the assumption of the criterion variable being measured on a scale, SDNN and RMSSD were divided by lower quartile and upper three quartiles. The potential predictor variable age was converted to binary (under 65 years $=0$ and 65 years or older $=1$ ). Individuals were only counted once per two-by-two frequency table. Based on chi-square results, only significant variables were included in the logistic regression analysis. Again, separate models were created for variables with strong and significant multicollinearity

A categorical analogue of multiple linear regression analysis, logistic regression is frequently useful with varying cohort size when there are multiple dichotomous covariates (Norman \& Streiner, 2008). Logistic regression requires a minimum of 5-10 individuals per disease or exposure. To meet assumptions of logistic regression, the outcome variable must be binary and independent variables measured without error.

A loss of important data occurred by converting the continuous HRV variables to dichotomous form using quartiles, which affected significance of results and diminished insight into the form of the relationship. Although increased odds can provide support for association, multiple linear regression analysis with ANCOVA is a more appropriate method of analyzing the relationship between HRV and age adjusted for MST exposure or PTSD diagnosis.

SAS $^{\circledR}$ English version statistical software was available for analysis of deidentified data on a secure VAGFE computer at the VA Research Center. Outliers, multicollinearity, and goodness-of-fit were checked during SAS analysis of MST and HRV relationship for multiple linear regression analysis and logistic regression. 
Residuals with a score greater than three should be closely examined for data entry error (Norman \& Streiner, 2000b); however, no residuals exceeded a score of two. Random sampling was not done and the sample size was small but adequate $(\mathrm{n}=$ 126). All analyses were performed three times and with repeatable results.

Significance of $\mathrm{p}<0.05$ was set a priori for all tests. 


\section{CHAPTER 4. RESULTS}

The purpose of this quantitative retrospective study was to explore the association between military sexual trauma (MST) and heart rate variability (HRV) outcomes controlling for posttraumatic stress disorder (PTSD), depression, age, coronary artery disease (CAD), diabetes mellitus (DM), cigarette smoking, and beta blockers and to estimate the odds of a female veteran's having a HRV in the lower quartile when MST was present compared to when it was not. Results are derived from HRV measures obtained from 378 (three strips for the 126 female veterans) 10-second Holter or ECG tracings containing over a thousand normal sinus R-R intervals. A general description of study setting and sample characteristics and results from preliminary data analysis are presented. Implications for practice and research are discussed in Chapter 5.

\section{Research Question}

The research question was: "What is the relationship between MST and HRV in female veterans evaluated in a VA Medical Center by ECG and Holter monitoring from 2007 to 2010?" Presence of PTSD, depression, age, CAD, or DM, cigarette smoking status, and beta blocker treatment were considered in analysis as covariates or confounding variables.

\section{Sample Characteristics}

The total sample consisted of 126 female veterans with complete data sets. All subjects were seen by cardiology consult at a Veterans Affairs (VA) Medical Center and received Holter monitoring and electrocardiogram (ECG) for cardiac symptoms. See Table 4-1 for sample characteristics.

Age appeared normally distributed, but SDNN and RMSSD required log transformation. The stem-leaf and box plots were right skewed with the tail pulled toward larger values. Examination of outliers revealed the two highest SDNN and RMSSD values were from 21 and 35 year old female veterans, and the two lowest SDNN values were in older women. Three lower values for SDNN and RMSSD were found in female veterans in their 30s, 40s and 50s reporting MST. Log transformation of SDNN and RMSSD met the requirement for normal distribution of the outcome variable necessary for multiple linear regression analysis.

Each frequency table contained all 126 subjects. The variables SDNN25 and RMSSD25 divided the cohort appropriately with lower quartiles reflecting those with lowest SDNN (25\%) and RMSSD (25\%), respectively. See Table 4-2 for prevalence of various characteristics for the total sample. Examination of frequencies of character variables revealed no obvious problems with the data. 
Table 4-1. Sample characteristics of female veterans $(n=126)$ examined by electrocardiogram and Holter following cardiology consult 2007-2010 at a Veteran Affairs Medical Center.

\begin{tabular}{lcccccccc}
\hline Variables & Skew & M & SD & $\begin{array}{c}\text { Media } \\
\mathrm{n}\end{array}$ & Min & Max & $25 \%$ & $75 \%$ \\
\hline AGE & 0.07 & 48.59 & 14.12 & 50.00 & 21 & 86 & $21-36$ & $37-86$ \\
LOGS & 0.24 & 3.64 & 0.58 & 3.64 & 2.51 & 5.27 & $2.85-$ & $3.21-$ \\
& & & & & & & 3.20 & 5.27 \\
LOGR & 0.39 & 3.73 & 0.51 & 3.67 & 2.69 & 5.18 & $3.10-$ & $3.11-$ \\
& & & & & & & 3.34 & 5.18 \\
\hline
\end{tabular}

Note: $\mathrm{M}=$ mean, $\mathrm{SD}=$ standard deviation, $\mathrm{Min}=$ minimum outlier, $\mathrm{Max}=$ maximum outlier, $25 \%=$ lower quartile range, $75 \%=$ upper three quartile range LOGS $=\log$ transformation of standard deviation of all normal sinus R-R intervals, LOGR $=\log$ transformation of square root of the mean of the sum of the squares of differences between adjacent normal to normal intervals, $\mathrm{AGE}=$ age in years.

Table 4-2. Frequencies of covariates of female veterans $(n=126)$ examined by electrocardiogram and Holter following cardiology consult 2007-2010 at a Veteran Affairs Medical Center.

\begin{tabular}{lcc}
\hline \multicolumn{1}{c}{ Covariate } & $\mathrm{n}$ & $\%$ \\
\hline Military sexual trauma & 27 & 21 \\
Posttraumatic stress disorder & 37 & 29 \\
Depression & 74 & 59 \\
Coronary artery disease & 3 & 2 \\
Diabetes mellitus & 20 & 16 \\
Cigarette smoking & 28 & 22 \\
Beta blocker use & 36 & 29 \\
65 years or older & 10 & 8 \\
\hline
\end{tabular}

Note: $\mathrm{n}=$ number of subjects. 


\section{Association of Military Sexual Trauma with Other Study Variables}

HRV measures were lower in female veterans with MST but prevalence of PTSD, depression, and cigarette smoking were higher. DM and beta blocker treatment were more frequent in those with no MST, and CAD was diagnosed in three older patients ( $\mathrm{M}=71$ years), all of whom reported no MST. See Table 4-3.

\section{Research Question Regarding the Effects of Military Sexual Trauma and Other Characteristics of Female Veterans on Their Heart Rate Variability}

The appropriate question for multiple linear regression analysis is "What is the effect of MST on HRV of female veterans evaluated in a VA Medical Center by Holter and ECG monitoring after adjusting for the covariates of PTSD, depression, age, CAD, DM, cigarette smoking, and beta blocker treatment?"

\section{Correlation Analysis}

The purpose of estimating the Pearson product moment correlation coefficients statistical analysis was to quantify association between HRV and covariates and to test for significant associations..

For correlational analysis, the research hypotheses were:

1. There will be a negative relationship between the HRV measures log transformed SDNN and log transformed RMSSD and covariates:
(a) MST
(b) PTSD
(c) Depression
(d) Increased age
(e) $\mathrm{DM}$
(f) CAD
(g) Smoking tobacco
(h) Age
(i) Being 65 years or older

2. There will be a positive relationship between HRV measures (log transformed SDNN and RMSSD and lower quartile SDNN) and RMSSD and beta blocker treatment.

Refer to Table 4-4 for estimates of Pearson product moment correlation coefficients. All HRV measures were highly and significantly correlated. Strong or moderate relationships between any of the independent variables traditionally associated with decreased HRV were not supported in this study of predominately younger female 
Table 4-3. The association of military sexual trauma with heart rate variability outcomes and with confounders in female veterans $(n=126)$ examined by electrocardiogram and Holter following cardiology consult 2007-2010 at a Veteran Affairs Medical Center.

\begin{tabular}{|c|c|c|c|c|}
\hline \multirow[b]{2}{*}{ Variable } & \multicolumn{2}{|c|}{$\operatorname{MST}(n=27)$} & \multicolumn{2}{|c|}{ No MST $(n=99)$} \\
\hline & $\mathrm{M}$ & $\mathrm{SD}$ & $\mathrm{M}$ & $\mathrm{SD}$ \\
\hline $\mathrm{AGE}$ & 41.37 & 11.67 & 50.56 & 14.14 \\
\hline LOGS & 3.33 & 0.51 & 3.72 & 0.58 \\
\hline LOGR & 3.48 & 0.50 & 3.79 & 0.50 \\
\hline & $\mathrm{n}$ & $\%$ & $\mathrm{n}$ & $\%$ \\
\hline SDNN25 & 13 & 48 & 19 & 19 \\
\hline RMSSD25 & 9 & 33 & 22 & 22 \\
\hline PTSD & 22 & 81 & 15 & 15 \\
\hline DEP & 24 & 89 & 50 & 51 \\
\hline CAD & 0 & 0 & 3 & 3 \\
\hline DM & 2 & 7 & 18 & 18 \\
\hline Smoker & 11 & 41 & 17 & 17 \\
\hline BB use & 6 & 22 & 30 & 30 \\
\hline$\geq 65$ years & 1 & 4 & 9 & 9 \\
\hline
\end{tabular}

Note: $\mathrm{M}=$ mean, $\mathrm{SD}=$ standard deviation, $\mathrm{n}=$ number, $\mathrm{MST}=$ military sexual trauma, LOGS $=\log$ transformation of the standard deviation of all normal to normal intervals, LOGR $=\log$ transformation of the square root of the mean of the sum of the squares of differences between adjacent normal to normal intervals, SDNN25 = lower quartile of the standard deviation of all normal to normal intervals, RMSSD25 = lower quartile of the square root of the mean of the sum of the squares of differences between adjacent normal to normal intervals, $\mathrm{PTSD}=$ posttraumatic stress disorder, $\mathrm{DEP}=$ depression, $\mathrm{CAD}=$ coronary artery disease, $\mathrm{DM}=$ diabetes mellitus, Smoker $=$ tobacco smoker, $\mathrm{BB}$ use $=$ receiving beta blocker treatment. 
Table 4-4. Estimated Pearson product moment correlation coefficients among study variables $(\mathrm{df}=124)$ in female veterans $(n=126)$ examined by electrocardiogram and Holter following cardiology consult 2007-2010 at a Veteran Affairs Medical Center.

\begin{tabular}{|c|c|c|c|c|c|c|c|c|c|c|c|c|c|}
\hline Variable & 1 & 2 & 3 & 4 & 5 & 6 & 7 & 8 & 9 & 10 & 11 & 12 & $\overline{13}$ \\
\hline 1.LOGS & - & & & & & & & & & & & & \\
\hline 2.SDNN25 &. $.72 *$ & - & & & & & & & & & & & \\
\hline 3.LOGR & $.89^{*}$ & $.62 *$ & - & & & & & & & & & & \\
\hline 4.RMSSD25 & $.65^{*}$ & $.57 *$ & $.69 *$ & - & & & & & & & & & \\
\hline 5.MST & $.27^{*}$ & $.29 *$ & $.25^{*}$ & .11 & - & & & & & & & & \\
\hline 6.PTSD & $.29 *$ & $.24^{*}$ & $-.26^{*}$ & .12 & $.60 *$ & - & & & & & & & \\
\hline 7.DEP & .001 & .10 & -.003 & -.05 & $.32 *$ & $.47^{*}$ & - & & & & & & \\
\hline 8.DM & -.05 & .004 & -.06 & .10 & -.12 & .006 & .01 & - & & & & & \\
\hline 9.CAD & $.20 *$ & $.27 *$ & -.14 & .15 & -.08 & -.10 & .03 & -.07 & - & & & & \\
\hline 10.SMKR & -.002 & .005 & .03 & .005 & $.23 *$ & $.28^{*}$ & $.33^{*}$ & -.02 & -.08 & - & & & \\
\hline 11.BB & .03 & -.03 & .03 & -.03 & -.07 & -.10 & .14 & $.40 *$ & .13 & .13 & - & & \\
\hline 12.Age & -.17 & .12 & -.11 & .11 & $.27 *$ & $.20 *$ & -.12 & .09 & $.25 *$ & -.02 & .13 & - & \\
\hline $13 \geq 65$ years & -.17 & $.19 *$ & $-.18^{*}$ & $.20 *$ & -.07 & -.12 & -.08 & -.04 & $.36 *$ & -.07 & .10 & $54 *$ & - \\
\hline
\end{tabular}

Note: $L O G R=\log$ of square root of the mean of the sum of squared difference of successive normal sinus R-R intervals, RMSSD25 $=$ lower $25^{\text {th }}$ percentile of square root of the mean of the sum of squared difference of successive normal sinus $\mathrm{R}-\mathrm{R}$ intervals, LOGS $=\log$ of standard deviation of normal sinus R-R intervals, SDNN25 $=$ lower $25^{\text {th }}$ percentile of standard deviation of normal sinus R-R intervals, MST = military sexual trauma, DM = diabetes mellitus, CAD = coronary artery disease, $\mathrm{SMKR}=$ smoker, $\mathrm{PTSD}=$ posttraumatic stress disorder, $\mathrm{DEP}=$ depression, $\mathrm{BB}=$ beta blocker. ${ }^{*} \mathrm{p}<.05$. Pearson correlation coefficient between a continuous and categorical variable is called biserial and between two categorical variables is called phi coefficient. 
veterans. Negative associations between HRV indices and both MST and PTSD were weak but significant, with the association with PTSD being slightly weaker than that with MST. Weak negative but significant relationships were found between age and MST and between age and PTSD, while a weak positive relationship was found between age and CAD. Depression was weakly but significantly associated with MST and PTSD. Strong support for a positive relationship indicated that in this sample a risk of severe multicollinearity between MST and PTSD in this sample would occur if both variables were included in the same multiple linear regression model. Smoking was weakly associated with MST, PTSD, and depression. A weak but significant relationship between DM and BB treatment was noted. Other correlations between study variables were essentially zero. The significantly correlated continuous variable age was retained for simple linear regression.

\section{Simple Regression}

The purpose of using the linear regression statistical test was to determine whether the regression coefficients of the change in HRV for each year change in age were significantly different from zero.

For simple linear regression, the research hypothesis was: There will be a negative relationship between increasing age and log transformed SDNN and RMSSD values.

Both log transformed HRV indices were regressed individually on age to quantify the decline of HRV with aging. See Table 4-5 for simple regression of HRV on the predictor variable age. Age was not significantly associated with either HRV measure at traditional levels of significance.

\section{Independent Samples t Tests}

Eight sets comprised of two independent groups were created: MST exposure verses non-exposure, PTSD verses no PTSD, depression verses no depression, CAD verses no $\mathrm{CAD}$, DM verses no DM, smoker verses nonsmoker, beta blocker treatment verses no beta blocker treatment, and being geriatric, 65 years or older, verses younger than 65 years of age. In addition to the means in years, the means in milliseconds of log transformed SDNN and RMSSD were compared according to the eight sets of groups, except for age in years which was not compared for the older verses younger group.

For independent-samples $t$ tests, the research hypotheses were: The means of log transformed SDNN, log transformed RMSSD, and age in years of female veterans will differ from those with or without:

(a) MST

(b) PTSD 
Table 4-5. Simple regression of heart rate variability on age in female veterans $(n=126)$ examined by electrocardiogram and Holter following cardiology consult 2007-2010 at a Veteran Affairs Medical Center.

\begin{tabular}{cccccc}
\hline Regression & $\mathrm{b}$ & $\mathrm{SE}$ & $\mathrm{t}$-value & $\mathrm{p}$-value & $\mathrm{STB}$ \\
\hline LOGS on age & -0.007 & 0.004 & -1.95 & 0.054 & 0.172 \\
LOGR on age & -0.004 & 0.003 & -1.18 & 0.239 & -0.105 \\
\hline
\end{tabular}

Note: $\mathrm{df}=$ degree of freedom, $\mathrm{b}=$ estimated regression coefficient, $\mathrm{SE}=$ standard error, $\mathrm{STB}=$ estimated standardized regression coefficient, LOGS $=\log$ transformation of the standard deviation of all normal sinus rhythm R-R intervals, LOGR $=\log$ transformation of the square root of the mean of the sum of the squares of differences between adjacent normal sinus rhythm R-R intervals.

(c) Depression

(d) CAD

(e) DM

(f) Smoking tobacco

(g) Beta blocker treatment

(h) Being 65 years or older

Female veterans with MST had lower HRV indices and were nearly 10 years younger than their counterparts who reported no MST; see Table 4-6. Female veterans with PTSD had lower HRV indices and were almost 7 years younger than their counterparts who reported no PTSD; see Table 4-7. There was no significant difference found in age or mean HRV indices measured between those with or without a history of depression; see Table 4-8. Conflicting results were found for the three CAD cases. There was a significant difference in the mean values of log transformed SDNN, but not RMSSD, in female veterans with CAD compared to those without; see Table 4-9. Mean age differed significantly, by almost 23 years, in female veterans with CAD and those without. No significant difference in mean age or log transformed SDNN and RMSSD was found in female veterans with DM and those without DM; see Table 4-10. There was no significant difference in age or HRV in female veteran smokers and nonsmokers; see Table 4-11. There was no significant difference in mean age or any mean HRV indices measured with beta blocker treatment groups; see Table 4-12. There was a significant difference in the means of $\log$ transformed SDNN, but not RMSSD in female veterans who were 65 years and older verses those who were younger; see Table 4-13 for means.

\section{Analysis of Covariance}

Multiple linear regression assumptions regarding normality were met by log transformation of SDNN and RMSSD (Tolley, 2010). CAD has too few cases $(n=3)$ and the other variables of depression, DM, smoking history, and beta blocker treatment did not meet the inclusion criteria of $\mathrm{p}<.2$ for model building (Tolley, 
Table 4-6. Independent $t$ tests of the effect of military sexual trauma on continuous variables $(\mathrm{df}=124)$ in female veterans $(n=126)$ examined by electrocardiogram and Holter following cardiology consult 2007-2010 at a Veteran Affairs Medical Center.

\begin{tabular}{|c|c|c|c|c|c|c|}
\hline \multirow[b]{2}{*}{ Variable } & \multicolumn{2}{|c|}{$\operatorname{MST}(\mathrm{n}=26)$} & \multicolumn{2}{|c|}{ No MST $(n=99)$} & \multirow[b]{2}{*}{$\mathrm{t}$} & \multirow[b]{2}{*}{$\mathrm{p}$} \\
\hline & M & SD & $\mathrm{M}$ & SD & & \\
\hline LOGS (ms)* & 3.33 & 0.51 & 3.72 & 0.58 & 3.41 & .001 \\
\hline LOGR (ms) & 3.48 & 0.50 & 3.79 & 0.50 & 2.86 & .005 \\
\hline Age (years) & 41.37 & 11.67 & 50.56 & 14.14 & 3.10 & .002 \\
\hline
\end{tabular}

Note: $\mathrm{MST}=$ military sexual trauma, $\mathrm{M}=$ mean, $\mathrm{SD}=$ standard deviation, $\mathrm{df}=$ degrees of freedom, $\mathrm{t}=\mathrm{t}$-value, $\mathrm{p}=\mathrm{p}$-value, LOGS $=\log$ transformation of standard deviation of all normal to normal intervals, $L O G R=\log$ transformation of square root of the mean of the sum of the squares of differences between adjacent normal to normal intervals. ${ }^{*} \mathrm{df}=45$.

Table 4-7. Independent $t$ tests of the effect of posttraumatic stress disorder on continuous variables $(\mathrm{df}=124)$ in female veterans $(n=126)$ examined by electrocardiogram and Holter following cardiology consult 2007-2010 at a Veteran Affairs Medical Center.

\begin{tabular}{cccccccc}
\hline & \multicolumn{2}{c}{$\operatorname{PTSD}(\mathrm{n}=37)$} & & \multicolumn{2}{c}{ No PTSD $(\mathrm{n}=89)$} & & \\
\cline { 2 - 3 } \cline { 5 - 6 } Variable & $\mathrm{M}$ & $\mathrm{SD}$ & & $\mathrm{M}$ & $\mathrm{SD}$ & $\mathrm{t}$ & $\mathrm{p}$ \\
\hline LOGS $(\mathrm{ms})$ & 3.38 & 0.49 & & 3.74 & 0.59 & 3.33 & .001 \\
LOGR $(\mathrm{ms})$ & 3.52 & 0.43 & & 3.81 & 0.50 & 3.03 & .003 \\
Age (years) & 44.32 & 11.92 & & 50.36 & 14.63 & 2.22 & .028 \\
\hline
\end{tabular}

Note: $\mathrm{PTSD}=$ posttraumatic stress disorder, $\mathrm{M}=$ mean, $\mathrm{SD}=$ standard deviation, $\mathrm{df}=$ degrees of freedom, $\mathrm{t}=\mathrm{t}$-value, $\mathrm{p}=\mathrm{p}$-value, LOGS $=\log$ transformation of standard deviation of all normal to normal intervals, $L O G R=\log$ transformation of square root of the mean of the sum of the squares of differences between adjacent normal to normal intervals. 
Table 4-8. Independent $t$ tests of the effect of depression on continuous variables $(\mathrm{df}=124)$ in female veterans $(n=126)$ examined by electrocardiogram and Holter following cardiology consult 2007-2010 at a Veteran Affairs Medical Center.

\begin{tabular}{ccccccccc}
\hline & \multicolumn{2}{c}{ Depression $(\mathrm{n}=74)$} & \multicolumn{2}{c}{ No Depression $(\mathrm{n}=52)$} & & \\
\cline { 2 - 3 } Variable & $\mathrm{M}$ & $\mathrm{SD}$ & & $\mathrm{M}$ & $\mathrm{SD}$ & & $\mathrm{t}$ & $\mathrm{p}$ \\
\hline LOGS $(\mathrm{ms})$ & 3.63 & 0.59 & & 3.64 & 0.58 & & 0.02 & .984 \\
LOGR (ms) & 3.72 & 0.50 & & 3.73 & 0.53 & & 0.04 & .969 \\
Age (years) & 47.12 & 13.08 & & 50.67 & 15.37 & & 1.40 & .165 \\
\hline
\end{tabular}

Note: $\mathrm{M}=$ mean, $\mathrm{SD}=$ standard deviation, $\mathrm{df}=$ degrees of freedom, $\mathrm{t}=\mathrm{t}$-value, $\mathrm{p}=$ $\mathrm{p}$-value, $\mathrm{LOGS}=\log$ transformation of standard deviation of all normal to normal intervals, $L O G R=\log$ transformation of square root of the mean of the sum of the squares of differences between adjacent normal to normal intervals,.

Table 4-9. Independent $t$ tests of the effect of coronary artery disease on continuous variables $(\mathrm{df}=124)$ in female veterans $(n=126)$ examined by electrocardiogram and Holter following cardiology consult during 2007-2010 at a Veteran Affairs Medical Center.

\begin{tabular}{ccccccccc}
\hline & \multicolumn{2}{c}{$\mathrm{CAD}(\mathrm{n}=3)$} & & \multicolumn{2}{c}{ No CAD $(\mathrm{n}=123)$} & & \\
\cline { 2 - 3 } \cline { 5 - 6 } Variable & $\mathrm{M}$ & $\mathrm{SD}$ & & $\mathrm{M}$ & $\mathrm{SD}$ & $\mathrm{t}$ & $\mathrm{p}$ \\
\hline LOGS $(\mathrm{ms})$ & 2.90 & 0.20 & & 3.66 & 0.58 & 2.26 & .026 \\
LOGR $(\mathrm{ms})$ & 3.26 & 0.17 & & 3.74 & 0.52 & & 1.61 & .111 \\
Age (years) & 70.67 & 18.58 & & 48.05 & 13.65 & -2.82 & .006 \\
\hline
\end{tabular}

Note: $\mathrm{M}=$ mean, $\mathrm{SD}=$ standard deviation, $\mathrm{df}=$ degrees of freedom, $\mathrm{t}=\mathrm{t}$-value, $\mathrm{p}=$ $\mathrm{p}$-value, LOGS $=\log$ transformation of standard deviation of all normal to normal intervals, LOGR $=\log$ transformation of square root of the mean of the sum of the squares of differences between adjacent normal to normal intervals. 
Table 4-10. Independent $t$ tests of diabetes mellitus on continuous variables (df $=124)$ in female veterans $(n=126)$ examined by electrocardiogram and Holter following cardiology consult during 2007-2010 at a Veteran Affairs Medical Center.

\begin{tabular}{|c|c|c|c|c|c|c|}
\hline \multirow[b]{2}{*}{ Variable } & \multicolumn{2}{|c|}{ Diabetes $(n=20)$} & \multicolumn{2}{|c|}{ No diabetes $(n=106)$} & \multirow[b]{2}{*}{ 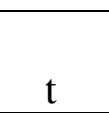 } & \multirow[b]{2}{*}{$\mathrm{p}$} \\
\hline & M & SD & $\mathrm{M}$ & SD & & \\
\hline LOGS (ms) & 3.57 & 0.53 & 3.65 & 0.60 & 0.54 & .593 \\
\hline LOGR (ms) & 3.66 & 0.43 & 3.74 & 0.53 & 0.65 & .517 \\
\hline Age (years) & 48.06 & 14.60 & 51.40 & 11.10 & -0.97 & .333 \\
\hline
\end{tabular}

Note: $\mathrm{M}=$ mean, $\mathrm{SD}=$ standard deviation, $\mathrm{df}=$ degrees of freedom, $\mathrm{t}=\mathrm{t}$-value, $\mathrm{p}=$ $\mathrm{p}$-value, LOGS $=\log$ transformation of standard deviation of all normal to normal intervals, $\mathrm{LOGR}=\log$ transformation of square root of the mean of the sum of the squares of differences between adjacent normal to normal intervals.

Table 4-11. Independent $t$ tests of cigarette smoking on continuous variables $(d f=124)$ in female veterans $(n=126)$ examined by electrocardiogram and Holter following cardiology consult during 2007-2010 at a Veteran Affairs Medical Center.

\begin{tabular}{|c|c|c|c|c|c|c|}
\hline \multirow[b]{2}{*}{ Variable } & \multicolumn{2}{|c|}{ Smokers $(n=28)$} & \multicolumn{2}{|c|}{ Nonsmokers $(\mathrm{n}=98)$} & \multirow[b]{2}{*}{$\mathrm{t}$} & \multirow[b]{2}{*}{$\mathrm{p}$} \\
\hline & M & SD & $\mathrm{M}$ & SD & & \\
\hline LOGS (ms) & 3.63 & 0.62 & 3.64 & 0.58 & 0.02 & .981 \\
\hline LOGR (ms) & 3.76 & 0.61 & 3.72 & 0.49 & -0.32 & .747 \\
\hline Age (years) & 48.00 & 11.31 & 48.76 & 14.87 & 0.25 & .804 \\
\hline
\end{tabular}

Note: $\mathrm{M}=$ mean, $\mathrm{SD}=$ standard deviation, $\mathrm{df}=$ degrees of freedom, $\mathrm{t}=\mathrm{t}$-value, $\mathrm{p}=$ $\mathrm{p}$-value, LOGS $=\log$ transformation of standard deviation of all normal to normal intervals, LOGR $=\log$ transformation of square root of the mean of the sum of the squares of differences between adjacent normal to normal intervals. 
Table 4-12. Independent $t$ tests of beta blocker treatment on continuous variables $(\mathrm{df}=124)$ in female veterans $(n=126)$ examined by electrocardiogram and Holter following cardiology consult during 2007-2010 at a Veteran Affairs Medical Center.

\begin{tabular}{cccccccc}
\hline & \multicolumn{2}{c}{$\mathrm{BB}(\mathrm{n}=36)$} & & \multicolumn{2}{c}{ No BB $(\mathrm{n}=90)$} & & \\
\cline { 2 - 3 } Variable & $\mathrm{M}$ & $\mathrm{SD}$ & & $\mathrm{M}$ & $\mathrm{SD}$ & $\mathrm{t}$ & $\mathrm{p}$ \\
\hline LOGS (ms) & 3.66 & 0.59 & & 3.63 & 0.58 & -0.29 & .770 \\
LOGR (ms) & 3.75 & 0.48 & & 3.71 & 0.53 & -0.37 & .712 \\
Age (years) & 51.50 & 11.99 & & 47.42 & 14.79 & -1.47 & .144 \\
\hline
\end{tabular}

Note: $\mathrm{M}=$ mean, $\mathrm{SD}=$ standard deviation, $\mathrm{df}=$ degrees of freedom, $\mathrm{t}=\mathrm{t}$-value, $\mathrm{p}=$ $\mathrm{p}$-value, LOGS $=\log$ transformation of standard deviation of all normal to normal intervals, LOGR $=\log$ transformation of square root of the mean of the sum of the squares of differences between adjacent normal to normal intervals.

Table 4-13. Independent $t$ tests of effect of age category on heart rate variability $(\mathrm{df}=124)$ in female veterans $(n=126)$ examined by electrocardiogram and Holter following cardiology consult during 2007-2010 at a Veteran Affairs Medical Center.

\begin{tabular}{cccccccc}
\hline & \multicolumn{2}{c}{$\geq 65$ years $(\mathrm{n}=10)$} & & \multicolumn{2}{c}{$<5$ years $(\mathrm{n}=116)$} & & \\
\cline { 2 - 3 } Variable & $\mathrm{M}$ & $\mathrm{SD}$ & & $\mathrm{M}$ & $\mathrm{SD}$ & $\mathrm{t}$ & $\mathrm{p}$ \\
\hline LOGS $(\mathrm{ms})$ & 3.19 & 0.47 & & 3.67 & 0.58 & 2.44 & .016 \\
LOGR $(\mathrm{ms})$ & 3.39 & 0.30 & & 3.75 & 0.52 & 2.01 & .047 \\
\hline
\end{tabular}

Note: $\mathrm{M}=$ mean, $\mathrm{SD}=$ standard deviation, $\mathrm{df}=$ degrees of freedom, $\mathrm{t}=\mathrm{t}$-value, $\mathrm{p}=$ p-value, LOGS $=\log$ transformation of standard deviation of all normal to normal intervals, $L O G R=\log$ transformation of square root of the mean of the sum of the squares of differences between adjacent normal to normal intervals. 
2010). Only MST, PTSD, and age met the criteria for inclusion. With $80 \%$ of female veterans with MST in this sample also having PTSD, separate models were constructed for MST and PTSD. All ANCOVA models contained the continuous variable age in years.

Estimated regression lines were parallel for MST exposure and non-exposure for the regression of both log transformed SDNN and RMSSD measures on age. Likewise, estimated regression lines for PTSD presence or absence were parallel for the regression of log transformed SDNN and RMSSD on age. See Table 4-14 for test of homegenity of slopes.

ANCOVA was conducted on the dependent variable log transformed SDNN with MST as the classification variable; see Table 4-15. For every year of increase in age, there was a significant decrease in $\log$ transformed SDNN by $-0.011 \mathrm{~ms}$ after adjusting for MST. The least squares means of log transformed SDNN and standard deviations differed significantly $(p=.0001)$ between female veterans with MST and those without adjusting for age in years; see Table 4-16. See Figure 4-1 for visual depiction of log transformed SDNN on age by MST. The SDNN of a 25 year old with MST exposure is comparable to that of a 69 year old without MST.

A one-way ANCOVA was conducted on the dependent variable log transformed RMSSD with MST as the classification variable; see Table 4-15. For every year of age, there was a significant decrease in log transformed RMSSD by $0.007 \mathrm{~ms}$ after adjusting for MST. The least squares means of log transformed RMSSD and standard deviations differed significantly $(\mathrm{p}=.001)$ between female veterans with and without MST; see Table 4-16. See Figure 4-2 for visual depiction of $\log$ transformed RMSSD on age by MST. The RMSSD of a 25 year old with MST compares to that of an 81 year old without MST.

ANCOVA was conducted on the dependent variable log transformed SDNN with PTSD as the classification variable. See Table 4-15 for details of ANCOVA. For every year of increase in age there was a significant decrease in log transformed SDNN by $-0.010 \mathrm{~ms}$. The least squares means for PTSD were again significantly different $(\mathrm{p}<$ .0002), after adjusting for age in years; see Table 4-16. See Figure 4-3 for visual depiction. The SDNN of a 25 year old with PTSD was comparable to that of a 67 year old without PTSD.

ANCOVA was conducted on the dependent variable log transformed RMSSD with PTSD as the classification variable. See Table 4-15 for ANCOVA details and Table 4-16 for least means squares. For every year of age, there was a decrease in log transformed RMSSD by $-0.007 \mathrm{~ms}$ after adjusting for PTSD; however, the slope was not significantly different from zero at traditional levels due to the small sample size of female veterans in this study. See Figure 4-4 for visual depiction of the 
Table 4-14. Test of homogeneity of slopes of change in heart rate variability for each unit of change in age $(\mathrm{df}=123)$ for female veterans $(\mathrm{n}=126)$ examined by electrocardiogram and Holter following cardiology consult during 2007-2010 at a Veteran Affairs Medical Center.

\begin{tabular}{clcccc}
\hline HRV & Source & SS & MS & F & p \\
\hline LOGS & MST & 0.0003 & 0.0003 & $<0.01$ & .975 \\
& AGE & 2.8233 & 2.8233 & 9.52 & .003 \\
& MST*AGE & 0.4170 & 0.4170 & 1.41 & .238 \\
LOGR & MST & 0.0006 & 0.0006 & $<0.01$ & .965 \\
& AGE & 1.4338 & 1.4338 & 4.53 & .035 \\
& MST*AGE & 0.2944 & 0.2944 & 0.93 & .337 \\
& & & & & \\
LOGS & PTSD & 0.5296 & 0.5296 & 1.75 & .188 \\
& AGE & 1.4015 & 1.4015 & 4.64 & .033 \\
& PTSD*AGE & 0.0283 & 0.0283 & 0.09 & .760 \\
& & & & & \\
LOGR & PTSD & 0.2557 & 0.2557 & 1.04 & .310 \\
& AGE & 0.5094 & 0.5094 & 2.07 & .153 \\
& PTSD*AGE & 0.0038 & 0.0038 & 0.02 & .901 \\
\hline
\end{tabular}

Note: $\mathrm{HRV}=$ heart rate variability, LOGS $=\log$ transformation of standard deviation of all normal sinus rhythm $\mathrm{R}$ to $\mathrm{R}$ intervals, $\mathrm{LOGR}=\log$ transformation of square root of the mean of the sum of the squares of differences between adjacent normal sinus rhythm R to R intervals, MST = military sexual trauma, $\mathrm{PTSD}=$ posttraumatic stress disorder, $\mathrm{df}=$ degrees of freedom, $\mathrm{SS}=$ sum of squares, $\mathrm{MS}=$ mean square, $\mathrm{F}=$ F-value, $p=p$-value, MST $=$ military sexual trauma, $A G E=$ age in years. 
Table 4-15. Parameter estimates from analysis of covariance $(\mathrm{df}=123)$ based on a sample of female veterans $(n=126)$ examined by electrocardiogram and Holter following cardiology consult during 2007-2010 at a Veteran Affairs Medical Center.

\begin{tabular}{cccccc}
\hline HRV & Parameter & Estimate & SE & $\mathrm{t}$ & $\mathrm{p}$ \\
\hline LOGS & Intercept & 3.7972 & 0.182 & 20.89 & $<.0001$ \\
& AGE & -0.0113 & 0.004 & -3.14 & .0021 \\
& MST & 0.4909 & 0.123 & 3.99 & .0001 \\
& (reference $=$ yes) & & & & \\
LOGR & Intercept & 3.7588 & 0.165 & 22.84 & $<.0001$ \\
& AGE & -0.0067 & 0.003 & -2.07 & .0407 \\
& MST & 0.3739 & 0.111 & 3.36 & .001 \\
& (reference $=$ yes) & & & & \\
& & & & & \\
LOGS & Intercept & 3.8281 & 0.181 & 21.18 & $<.0001$ \\
& AGE & -0.0101 & 0.004 & -2.85 & .0051 \\
& PTSD & 0.4220 & 0.1092 & 3.86 & .0002 \\
& (reference $=$ yes) & & & & \\
& Intercept & 3.7778 & 0.163 & 23.18 & $<.0001$ \\
LOGR & AGE & -0.0059 & 0.003 & -1.85 & .0666 \\
& PTSD & 0.3329 & 0.098 & 3.38 & .001 \\
& (reference $=$ yes) & & & & \\
\hline
\end{tabular}

Note: $\mathrm{HRV}=$ heart rate variability, $\mathrm{LOGS}=\log$ transformation of standard deviation of all normal sinus rhythm R-R intervals, LOGR $=\log$ transformation of square root of the mean of the sum of the squares of differences between adjacent normal sinus rhythm R-R intervals, MST = military sexual trauma, PTSD = posttraumatic stress disorder, $\mathrm{df}=$ degrees of freedom, $\mathrm{SS}=$ sum of squares, $\mathrm{MS}=$ mean square, $\mathrm{F}=\mathrm{F}$ value, $\mathrm{p}=\mathrm{p}$-value, MST = military sexual trauma, $\mathrm{AGE}=$ age in years. 
Table 4-16. Independent t-tests between least squares means $(\mathrm{df}=123)$ for presence or absence of military sexual trauma or posttraumatic stress disorder from analysis of covariance* of heart rate variability on age in female veterans $(n=126)$ examined by electrocardiogram and Holter following cardiology consult during 2007-2010 at a Veteran Affairs Medical Center.

\begin{tabular}{cccccc}
\hline HRV & Variable & LSM & SE & $\mathrm{t}$ & $\mathrm{p}$ \\
\hline LOGS & No MST & 3.7413 & 0.055 & 3.99 & .0001 \\
& MST & 3.2504 & 0.108 & & \\
LOGR & No MST & 3.8062 & 0.050 & 3.36 & .001 \\
& MST & 3.4323 & 0.098 & & \\
LOGS & No PTSD & 3.7600 & 0.058 & 3.86 & .0002 \\
& PTSD & 3.3380 & 0.091 & & \\
LOGR & No PTSD & 3.8239 & 0.053 & 3.38 & .001 \\
& PTSD & 3.4910 & 0.082 & & \\
\hline
\end{tabular}

Note: *ANCOVA. Least squared means were adjusted for the continuous variable age. $\mathrm{HRV}=$ heart rate variability, LOGS $=\log$ transformation of standard deviation of all normal to normal intervals, LOGR $=\log$ transformation of square root of the mean of the sum of the squares of differences between adjacent normal sinus rhythm $\mathrm{R}-\mathrm{R}$ intervals, $\mathrm{df}=$ degrees of freedom, $\mathrm{SE}=$ standard error, $\mathrm{LMS}=$ least mean square, $\mathrm{t}=\mathrm{t}$-value, $\mathrm{p}=\mathrm{p}$-value, $\mathrm{MST}=$ military sexual trauma, $\mathrm{PTSD}=$ posttraumatic stress disorder. 


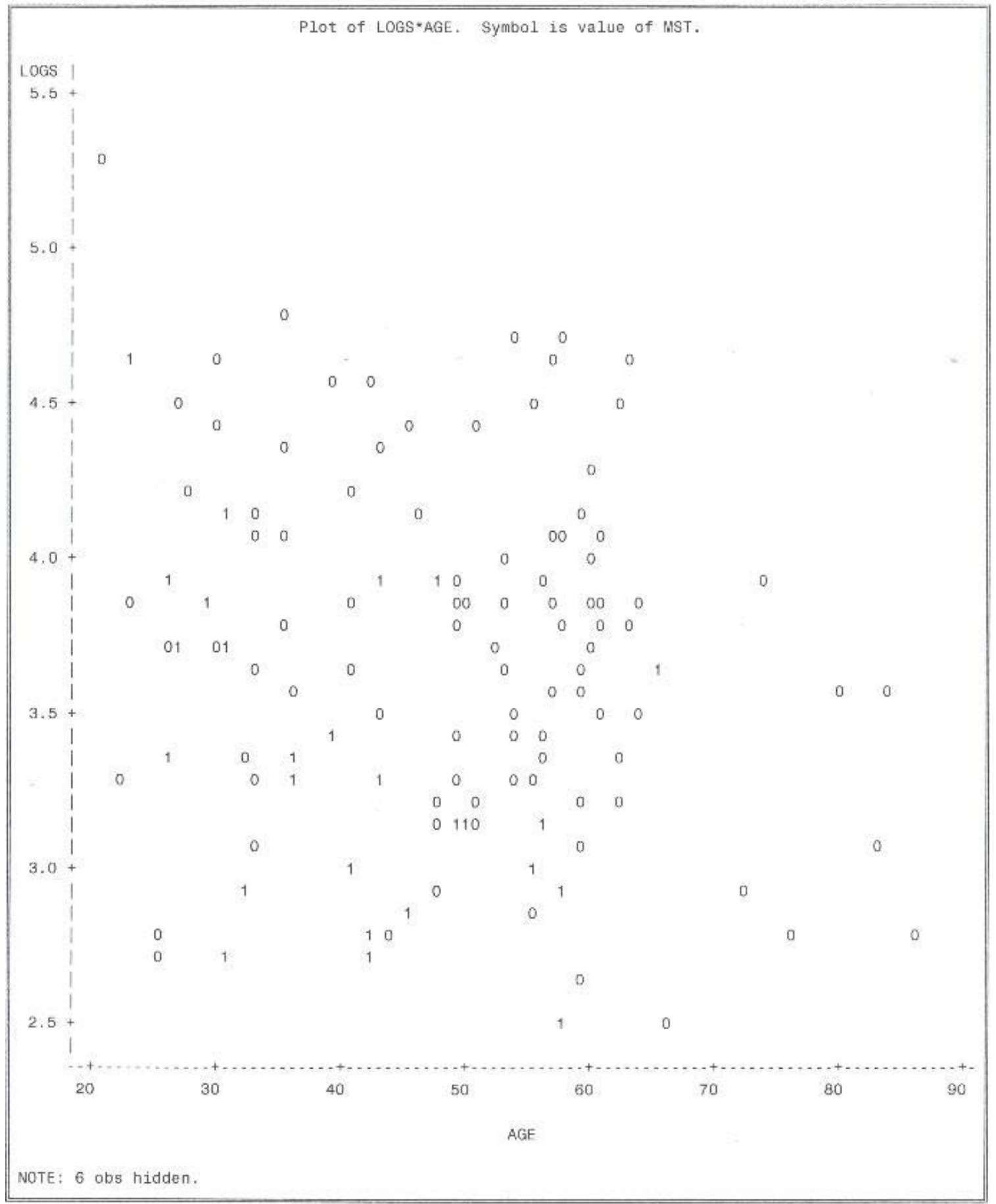

Figure 4-1. Log transformed standard deviation of all normal sinus rhythm R$R$ intervals on age by military sexual trauma group

Note: Military sexual trauma exposure $=1$ and nonexposure $=0$. 


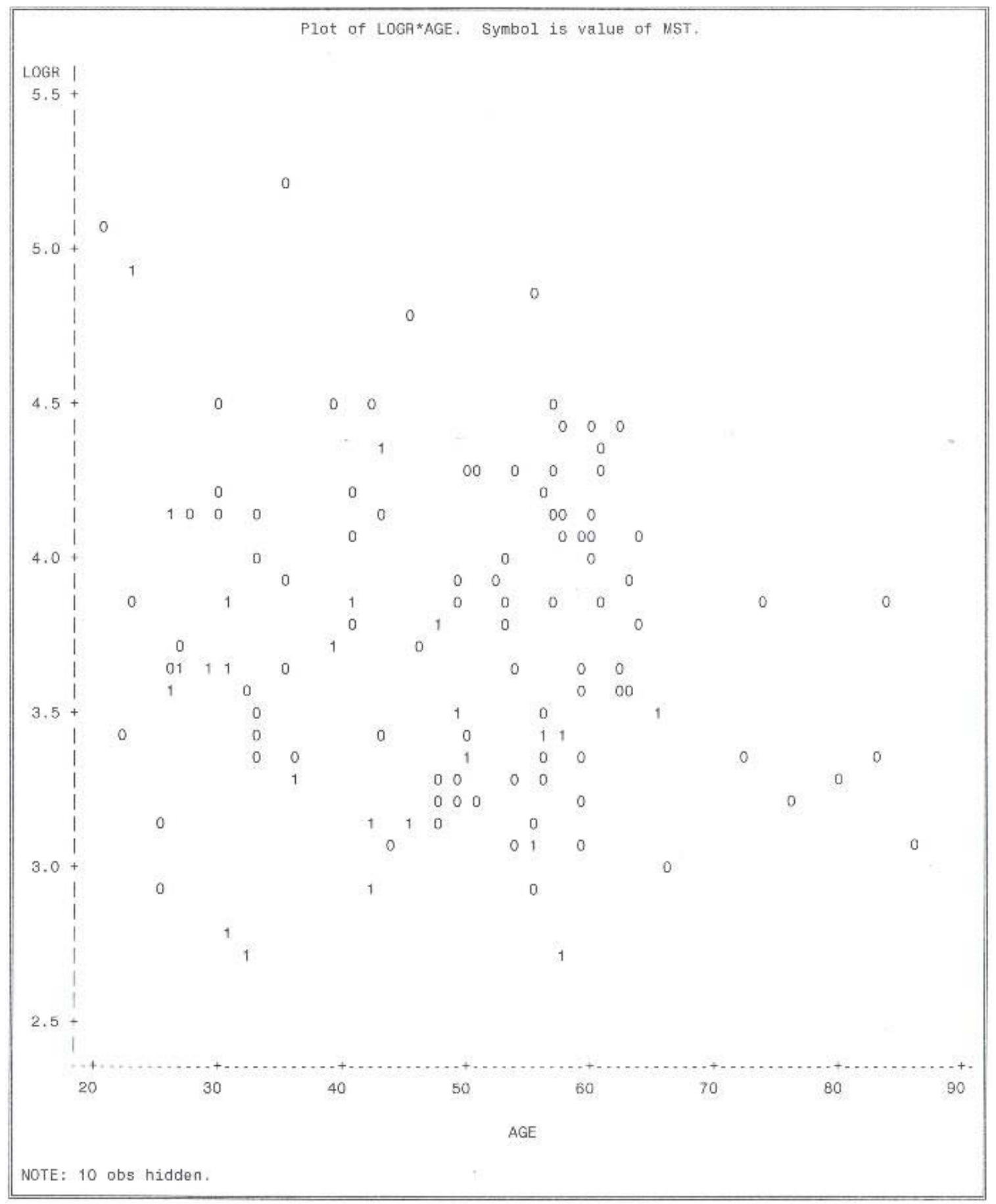

Figure 4-2. Log transformed square root of the mean of the sum of the squares of differences between adjacent normal sinus rhythm $R-R$ intervals on age by military sexual trauma

Note: Military sexual trauma exposure $=1$ and nonexposure $=0$. 


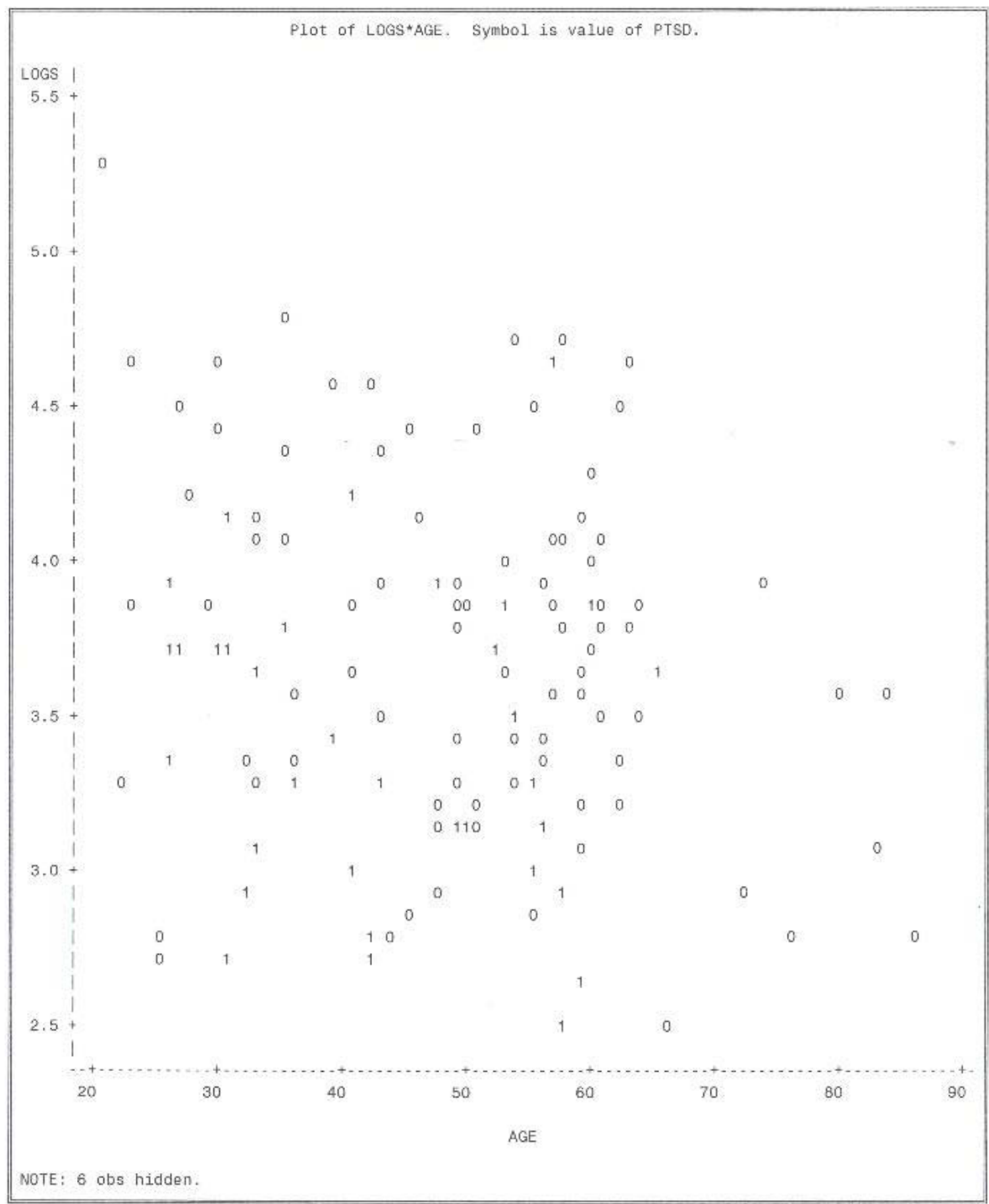

Figure 4-3. Log transformed standard deviation of all normal sinus rhythm $R-R$ intervals on age by posttraumatic stress disorder

Note: Posttraumatic stress disorder diagnosis $=1$ and no diagnosis $=0$. 


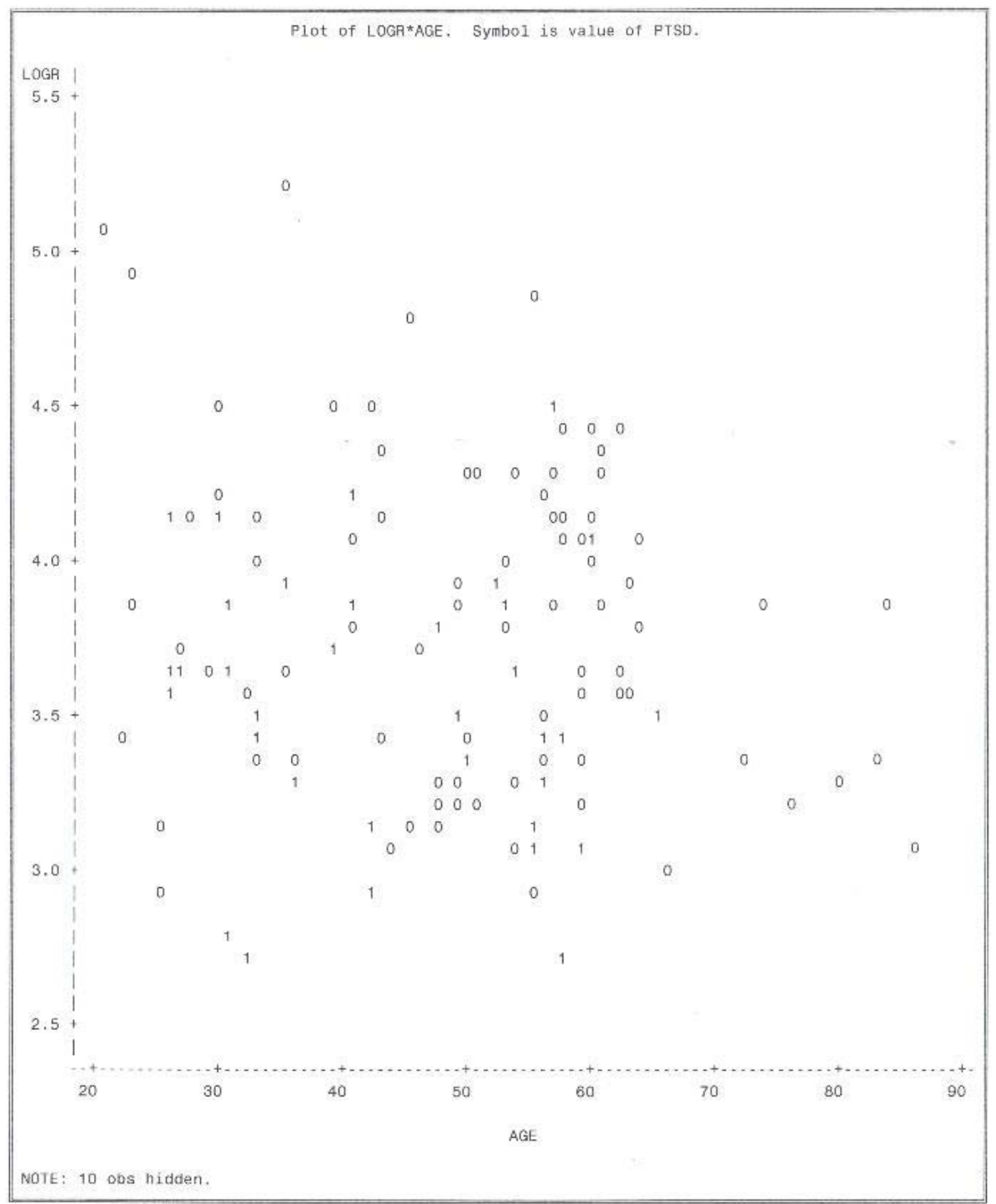

Figure 4-4. Log transformed square root of the mean of the sum of the squares of differences between adjacent normal sinus rhythm R-R intervals on age by posttraumatic stress disorder diagnosis

Note: Posttraumatic stress disorder diagnosis $=1$ and no diagnosis $=0$. 
relationship. The least squares means for PTSD were again significantly different ( $\mathrm{p}$ $<.001$ ), after adjusting for age in years; see Table 4-17.

\section{Partial Pearson Product Moment Correlation Coefficients}

The first purpose of estimating the partial Pearson product moment correlation was to quantify the correlation of HRV with age or MST, while controlling for the effects of each other. By squaring the estimated partial correlation coefficients, the proportion of the shared variance (i.e., variance explained) between age or MST could be estimated, while controlling for the effects of the other explanatory variable. Similar analyses were completed with models including PTSD as the classification variable.

Both MST and PTSD had a stronger association with HRV than did age, as indicated by both the total (i.e., Pearson) and partial correlation coefficients. See Table 4-17 for squared total and partial Pearson product moment correlation coefficients. The squared correlation between both HRV indices, log transformed SDNN and RMSSD, and MST adjusted for age was larger than the squared correlation between HRV and age adjusted for MST. MST adjusted for age explained more of the variability in $\log$ transformed SDNN and log transformed RMSSD than age adjusted for MST did. Additionally, the squared partial correlation between log transformed SDNN and PTSD adjusted for age was larger than the partial squared correlation between log transformed SDNN and age; PTSD explained more of the variability in log transformed SDNN than age adjusted for PTSD. In addition, the estimated partial squared correlation coefficients were numerically larger than the estimated squared total correlation coefficients, thereby indicating the appropriateness of including both the continuous and classification variables in the models.

\section{Research Question Regarding Estimation of Odds of Having Lower Quartile Heart Rate Variability in Female Veterans with and without Military Sexual Trauma}

Restated, the question appropriate for performing logistic regression, is, "What is the ratio of the odds of HRV being in the lower sample quartile in female veterans exposed to MST to the odds in a non-exposed group of female veterans seen for Holter and ECG monitoring at a Veterans Medical Center?" Additionally, "What is the ratio of odds of lower HRV in female veterans with PTSD, depression, DM, CAD, smoking tobacco, or with beta blocker treatment in these same women compared to those without the particular characteristic?" 
Table 4-17. Parameter estimates of squared partial and total Pearson product moment correlation coefficients in female veterans $(n=126)$ examined by electrocardiogram and Holter following cardiology consult during 2007-2010 at a Veteran Affairs Medical Center.

\begin{tabular}{cccc}
\hline HRV & Variable & Partial $^{2}$ & $\mathrm{r}^{2}$ \\
\hline LOGS & MST & 0.1148 & 0.0729 \\
& AGE & 0.0741 & 0.0297 \\
LOGR & MST & 0.0840 & 0.0615 \\
& AGE & 0.0336 & 0.0111 \\
LOGS & PTSD & & \\
& AGE & 0.10828 & 0.0819 \\
LOGR & PTSD & 0.06205 & 0.0297 \\
& AGE & 0.08500 & 0.0691 \\
\hline
\end{tabular}

Note: Partial $^{2}=$ partial (adjusted) Pearson product moment correlation coefficients squared $(\mathrm{df}=123), \mathrm{r}^{2}=$ total (unadjusted ) Pearson product moment correlation coefficients $(\mathrm{df}=124), \mathrm{HRV}=$ heart rate variability, LOGS $=\log$ transformation of standard deviation of all normal to normal intervals, LOGR $=\log$ transformation of square root of the mean of the sum of the squares of differences between adjacent normal sinus rhythm R-R intervals, MST = military sexual trauma, PTSD = posttraumatic stress disorder. 


\section{Chi-Square Tests of Independence}

The purpose of using the chi-square test of independence was to determine whether there was dependence, i.e. a relationship, between lower quartile HRV and each of the predictor variables, MST, PTSD, depression, DM, cigarette smoking, and beta blocker treatment. Data for CAD could not be analyzed by Chi-square test for failure to pass the assumption regarding no cells containing zeros or more than $20 \%$ of the cells having expected values less than 5; therefore, Fisher's exact test was used. Unadjusted, or crude odds ratios, were estimated to quantify the effect of female veterans having specific characteristics on their being in the lower quartile of SDNN or RMSSD.

For chi-square tests of independence, the research hypothesis was: There will be dependence, i.e., a relationship, between lower quartile SDNN and RMSSD measures and the variables:

(a) MST

(b) PTSD

(c) Depression

(d) Being 65 years or older

(e) DM

(f) Smoking tobacco

(g) Beta blocker treatment

See Table 4-18 for chi-square test of independence for prevalence of the seven independent variables, MST, PTSD, depression, age 65 year or older, DM, cigarette smoking, or beta blocker treatment with lower quartile HRV of sample. There were mixed results for MST and PTSD, with significant relationship of both attributes with lower quartile SDNN but not with RMSSD. There were also mixed results for the three cases of CAD, with a significant relationship with lower quartile SDNN but not with RMSSD using Fisher's exact two- tailed test. The category of being 65 years or older only approached significance due to small sample size. Other independent variables were not significant.

See Table 4-19 for unadjusted odds ratios for the estimated effect of significant characteristics (MST, PTS, and being 65 years or older) on female veterans being in the lower quartile of SDNN or RMSSD. A female veteran who had experienced MST was 4.18 times as likely to have her SDNN value in the lower quartile as a comparable female veteran without MST, and a female veteran diagnosed with PTSD was 3.11 times as likely to have her SDNN value in the lower quartile as a comparable female veteran without PTSD. Female veterans who were 65 years or older were 4.38 times more likely to have their SDNN values in the lower quartile and 3.78 times more likely to have their RMSSD values in the lower quartile as female veterans who were younger. 
Table 4-18. Prevalence of eight independent variables by lower quartile of heart rate variability in female veterans $(n=126)$ examined by electrocardiogram and Holter following cardiology consult during 2007-2010 at a Veteran Affairs Medical Center.

\begin{tabular}{|c|c|c|c|c|c|c|c|c|}
\hline \multirow[b]{2}{*}{ Variable } & \multicolumn{4}{|c|}{ Lower quartile SDNN } & \multicolumn{4}{|c|}{ Lower quartile RMSSD } \\
\hline & $\mathrm{n}$ & $\%$ & $\chi^{2}(1)$ & $\mathrm{p}$ & $\mathrm{n}$ & $\%$ & $\chi^{2}(1)$ & $\mathrm{p}$ \\
\hline \multicolumn{9}{|l|}{ MST } \\
\hline Exposure $(n=27)$ & 13 & 48 & 9.388 & .002 & 9 & 33 & 1.412 & .235 \\
\hline Non-exposure $(\mathrm{n}=99)$ & 19 & 19 & & & 22 & 22 & & \\
\hline \multicolumn{9}{|l|}{ PTSD } \\
\hline History $(\mathrm{n}=37)$ & 15 & 41 & 6.340 & .012 & 11 & 30 & 0.742 & .389 \\
\hline No history $(\mathrm{n}=89)$ & 17 & 19 & & & 20 & 22 & & \\
\hline \multicolumn{9}{|l|}{ Depression } \\
\hline History $(\mathrm{n}=74)$ & 21 & 28 & 0.841 & .359 & 17 & 23 & 0.257 & .612 \\
\hline No history $(\mathrm{n}=52)$ & 11 & 21 & & & 14 & 27 & & \\
\hline \multicolumn{9}{|l|}{ Age } \\
\hline$\geq 65$ years $(n=10)$ & 5 & 50 & 3.47 & .063 & 5 & 50 & 3.78 & .052 \\
\hline$<65$ years $(n=116)$ & 27 & 23 & & & 26 & 22.4 & & \\
\hline \multicolumn{9}{|l|}{ DM } \\
\hline History $(n=20)$ & 5 & 25 & 0.002 & .965 & 7 & 35 & 1.385 & .239 \\
\hline No history $(\mathrm{n}=106)$ & 27 & 25 & & & 24 & 23 & & \\
\hline \multicolumn{9}{|l|}{ CAD } \\
\hline History $(\mathrm{n}=3)^{*}$ & $3 *$ & $100^{*}$ & $*$ & $.015 * *$ & $2 *$ & $67 *$ & $*$ & $.150 * *$ \\
\hline No history $(\mathrm{n}=123)$ & 29 & 23 & & & 29 & & & \\
\hline \multicolumn{9}{|l|}{ Cigarette smoking } \\
\hline Smoker $(\mathrm{n}=28)$ & 7 & 25 & 0.003 & .956 & 7 & 25 & 0.003 & .956 \\
\hline Nonsmoker $(\mathrm{n}=98)$ & 25 & 25 & & & 24 & 24 & & \\
\hline \multicolumn{9}{|l|}{ Beta blocker } \\
\hline Treatment $(\mathrm{n}=36)$ & 8 & 22 & 0.268 & .605 & 8 & 22 & 0.154 & .695 \\
\hline No treatment $(\mathrm{n}=90)$ & 24 & 27 & & & 23 & 26 & & \\
\hline
\end{tabular}


Table 4-18. (Continued).

Note: $*$ Chi-square test not valid with $<5$ expected counts in more than $20 \%$ of the cells and once cell containing zero observations. **Fisher's exact test two-sided probability. SDNN = standard deviation of normal sinus rhythm R-R intervals, RMSSD = square root of the mean of the sum of squared differences of successive normal sinus rhythm R-R intervals, $\mathrm{MST}=$ military sexual trauma, $\mathrm{PTSD}=$ posttraumatic stress disorder, $\mathrm{DM}=$ diabetes mellitus, $\mathrm{CAD}=$ coronary artery disease. 
Table 4-19. Unadjusted odds of having a heart rate variability in the lower quartile associated with military sexual trauma or posttraumatic stress disorder and being 65 years or older in female veterans $(n=126)$ examined by electrocardiogram and Holter following cardiology consult during 2007-2010 at a Veteran Affairs Medical Center.

\begin{tabular}{ccccccc}
\hline HRV & Variable & OR & $\begin{array}{c}95 \% \\
\text { LCI }\end{array}$ & $\begin{array}{c}95 \% \\
\text { UCI }\end{array}$ & $\chi^{2}$ & $\mathrm{p}$ \\
& & & & & \\
\hline SDNN25 & MST & 4.18 & 1.68 & 10.40 & 10.270 & .001 \\
SDNN25 & $\geq 65$ & 4.38 & 1.10 & 17.48 & 5.006 & .025 \\
SDNN25 & PTSD & 3.11 & 1.33 & 7.28 & 7.173 & .007 \\
RMSSD & $\geq 65$ & 3.46 & 0.93 & 12.88 & 3.776 & .052 \\
\hline
\end{tabular}

Note: SDNN25 = lower quartile standard deviation of normal sinus rhythm R-R intervals, $\mathrm{OR}=$ unadjusted odds ratio, $\mathrm{LCI}=$ lower confidence interval, $\mathrm{UCI}=$ upper confidence interval, $\chi^{2}=$ chi square, $p=p$-value, MST $=$ military sexual trauma, $\geq 65=$ age in years, $\mathrm{PTSD}=$ posttraumatic stress disorder. 


\section{Logistic Regression}

The purpose of logistic regression analysis was to estimate the effects of characteristics of female veterans, (MST, PTSD, and being 65 years or older), on the binary outcome variable, being in the lower quartile of SDNN. Separate models were constructed for MST and PTSD because of multicollinearity.

A female veteran who had experienced MST was 4.45 times as likely to have her SDNN value in the lower quartile as a comparable female veteran without MST after adjusting for age. See Table 4-20 for estimated adjusted odds ratios. Similarly, a female veteran who had a diagnosis of PTSD was 3.45 times as likely to have her SDNN value in the lower quartile as a comparable female veteran without a diagnosis of PTSD, after adjusting for age. Regarding age, after adjusting for either MST or PTSD, female veterans older than 65 years were more than 4 times as likely to have their SDNN values in the lower quartile.

\section{Summary and Conclusion}

Multiple analyses support the hypothesis that decreased HRV is associated with MST exposure. An unexpected finding was that traditional characteristics previously reported as being associated with reduced HRV were not significant predictors of decreased HRV of female veterans in this sample. ANCOVA provided the best method for visually displaying lower HRV for those with MST and those with PTSD at younger ages compared to the reference cohort. Use of categorical variables for logistic regression caused loss of important information but provided estimates of the odds of developing reduced HRV associated with MST both unadjusted and adjusted for age. Results and implications for clinical practice and future research are discussed in Chapter 5. 
Table 4-20. Adjusted odds of having a heart rate variability in the lower quartile associated with military sexual trauma or posttraumatic stress disorder and being 65 years or older in female veterans $(n=126)$ examined by electrocardiogram and Holter following cardiology consult during 2007-2010 at a Veteran Affairs Medical Center.

\begin{tabular}{ccccccccc}
\hline HRV & $\begin{array}{c}\text { Variab } \\
\text { le }\end{array}$ & AOR & 95\% LCI & 95\% UCI & Estimate & SE & $\chi^{2}$ & $\mathrm{p}$ \\
& MST & 4.49 & 1.77 & 11.44 & 1.503 & 0.477 & 9.939 & .002 \\
SDNN25 & $\geq 65$ & 4.45 & 1.13 & 17.48 & 1.493 & 0.698 & 4.581 & .032 \\
& & & & & & & & \\
\multirow{2}{*}{ SDNN25 } & PTSD & 3.45 & 1.43 & 8.33 & 1.239 & 0.450 & 7.592 & .006 \\
& $\geq 65$ & 4.71 & 1.19 & 18.59 & 1.549 & 0.701 & 4.886 & .027 \\
\hline
\end{tabular}

Note: SDNN25 = lower quartile standard deviation of normal sinus rhythm R-R intervals, AOR $=$ adjusted odds ratio, LCI $=$ lower confidence interval, $\mathrm{UCI}=$ upper confidence interval, $\mathrm{SE}=$ standard error, $\chi^{2}=$ chi square, $\mathrm{p}=\mathrm{p}$-value, MST $=$ military sexual trauma, $\geq 65=$ age in years, $\mathrm{PTSD}=$ posttraumatic stress disorder. 


\section{CHAPTER 5. DISCUSSION}

This study is innovative by adding evidence to existing research literature of an association of heart rate variability (HRV) decline and military sexual trauma (MST) in female veterans who had 10 -second Holter and electrocardiogram (ECG) tracings at a Veteran Affairs (VA) Medical Center. HRV in this study was measured by customary, readily available time domain indices, the standard deviation of all normal to normal intervals (SDNN), and the square root of the mean of the sum of the squares of differences between adjacent normal to normal intervals (RMSSD) obtained from the mean of 3 tracings for each subject. Even though the mean age of female veterans with MST exposure in this sample was a decade younger $(\mathrm{M}=41$ years), their log transformed $\operatorname{SDNN}(\mathrm{M}=3.25, \mathrm{SD}=0.11)$ and $\operatorname{RMSSD}(\mathrm{M}=3.43, \mathrm{SD}=0.10)$ mean measures were significantly lower than corresponding $\log$ transformed $\operatorname{SDNN}(\mathrm{M}=3.74, \mathrm{SD}=0.06)$ and $\operatorname{RMSSD}(\mathrm{M}=3.81, \mathrm{SD}=0.05)$ indices in the older $(\mathrm{M}=51$ years $)$ unexposed female veterans $(\mathrm{p}=.0001 ; \mathrm{p}=.001$, respectively). This significant decrease of HRV associated with MST in early years was not detected by other studies that focused on measuring decline in HRV with aging cohorts.

These results extend knowledge and support of HRV decline (Lakusic et al., 2007) found in cardiac patients with posttraumatic stress disorder (PTSD) compared to similar patients without PTSD. A majority ( $80 \%)$ of subjects in the current research with MST had PTSD, which supports previous findings of increased adjusted odds ratio (AOR) of developing current ( $\mathrm{AOR}=7.15,95 \% \mathrm{CI}=4.03-12.69$ ) and lifetime ( $\mathrm{AOR}=$ 7.03, 95\% CI $=5.05-9.79$ ) PTSD following MST (Street et al., 2008). This study also found that a greater decline in HRV occurred with MST than with PTSD from all trauma types. Even though most $(60 \%)$ subjects with PTSD $(n=37)$ also reported MST $(n=22)$ odds of having SDNN measures within the lower quartile of the sample for those with PTSD compared to those without PTSD $(2.12,95 \% \mathrm{CI}=1.43-4.40)$ was numerically less than the odds ratio for MST $(2.51,95 \% \mathrm{CI}=1.43-4.40)$.Likewise, odds of having lower quartile RMSSD of those with PTSD compared to those without PTSD $(1.32,95 \% \mathrm{CI}=$ 0.71-2.48) was lower than the odds of lower quartile RMSSD of those with MST compared to those without MST $(1.50,95 \% \mathrm{CI}=0.78-2.87)$. Physiological findings that MST had a greater impact on HRV than PTSD resulting from all types of trauma supported prior reports by female veterans that MST was the worst trauma (68.3\%), even over combat (5.6\%) (Schnurr et al., 2007).

This study found a stronger association between decline in HRV and MST in this sample than previously reported for physical and psychological factors formerly associated with decreased HRV, including age (Dekker et al., 1997; Stein et al., 2009), coronary artery disease (CAD) (Bigger et al., 1992; Macfarlane \& Norrie, 2007), diabetes mellitus (DM) (Ewing et al., 1985; Pan et al., 2011), depression (Carney et al., 2001; Pan et al., 2011), and smoking (Munjal et al., 2009; Sajadieh et al., 2004). The premature HRV decline in middle aged female victims of MST in this study adds to previous reported evidence of decline of HRV in middle aged men (Dekker et al., 1997; Macfarlane \& Norrie, 2007) and elders of both genders (de Bruyne et al., 1999).Previous 
association between lower HRV with heart disease in women (de Bruyne et al., 1999) were notsupported in this study, possibly due to the younger mean age and the fact that there were only three cases of CAD. However, future collection of data on hypertension and other early cardiovascular risks may be warranted (Schroeder et al., 2003). The lack of any detectible association between DM and lower HRV in this study conflicts with traditional (Ewing et al., 1985) and current (Pan et al., 2011) findings of altered autonomic tone in patients with DM. However, this issue could also reflect elevation of HRV (Goldsmith et al., 1997) with more beta blocker use in patients with DM in this sample. Lack of significant association between lower HRV and depression in this study supports recent research in stable heart patients (Gehi et al., 2005). However, further investigation into the decline in HRV found with antidepressant treatment (Licht et al., 2008) may suggest the need for additional data on antidepressants given the high prevalence of depression associated with MST (89\%) in this sample. Lower HRV associated with cigarette smoking (Munjal et al., 2009; Sajadieh et al., 2004) was not supported by this study even though a third (33\%) of subjects with MST smoked. MST explained significantly $(\mathrm{p}=.0001)$ more of the variance in $\log$ transformed SDNN and significantly $(\mathrm{p}=.001)$ more of the variance in log transformed RMSSD than age. MST was more associated with HRV decline than any of the traditional variables.

Increased risk of physical and mental health problems following MST (Street et al., 2008) and increased risk of loss of almost 20 years of life after early life physical and sexual trauma found by Brown et al. (2009) are congruent with increased risk of all-cause mortality associated with low HRV (Dekker et al., 1997; Macfarlane \& Norrie, 2007). The projected HRV of a 25 year old with MST exposure was comparable to that of a 7080 year old without MST. This suggests that subjects with MST who also had low HRV may be at greater risk of premature mortality. HRV in female veterans with and without MST needs to be tracked to estimate decline over time and to document any increase in mortality. This finding has implications for developing and researching efficacy of clinical interventions to increase HRV in victims of MST to prevent disease development and early demise.

\section{Limitations}

A limitation of the study was that the long-term (5 minutes or more) Holter tracings for HRV measurement (ESC \& NASPE, 1996) were not available. Available MST data was not separated by harassment or assault. A third limitation in this exploratory historical cohort study was the small sample size $(n=126)$ of female veterans with cardiac symptoms evaluated by VA cardiology consult. Study limitations are balance by strong points including increasing data reliability by use of the mean of three short-term recordings to decrease observer bias and by comparison of data from individual electronic medical records with collective data stored in the central VA research warehouse. Knowledge of relationship between MST and HRV outcomes would be enhanced by conducting a large sample prospective cohort study using long-term Holter tracings to evaluate decline in HRV. 


\section{Implications for Theory Development}

Findings of this study are compatible with the general theoretical model of allostatic loading that links decline in cardiac function with severe or prolonged exposure to traumatic stress (McEwen \& Seeman, 1999; Sterling \& Eyer, 1988). The findings specifically support the theorized contribution of MST to development of PTSD, depression, and negative cardiovascular outcomes in female veterans (Groer \& Burns, 2009).

\section{Recommendations for Clinical Practice}

Improved recognition is needed by healthcare providers of the pattern of cardiac symptoms associated with a female patient's history of sexual trauma. Although beta blockers may sometimes be beneficial in controlling palpitations following sexual assault, long term use for enhancement of HRV could be prohibited in younger women of childbearing years. Maintaining healthcare provider sensitivity to sexual trauma and the willingness to extend psychological support and referral as a supplement to customary physical treatment is needed in all healthcare settings (Hamberger et al., 1998).

This study suggests that both psychological and physiological consequences of MST must be treated. Women exhibit greater reactivity at the sinus and AV nodes than men (Insulander \& Vallin, 2005) and may be more vulnerable to exaggerated autonomic response with repeated stress exposure (Schmaus et al., 2008). MST may evoke intense feelings of fear of recurrent attacks, anger over betrayal by a fellow teammate, and isolation from peers. Fear (Rainville et al., 2006), anger and lack of social support (Horsten et al., 1999) are associated with lower HRV even in healthy individuals. MST could be conceptualized as a form of surrogate incest perpetrated by a member of the military family and may augment the intensity of emotional and physical response. The high prevalence of PTSD and depression occurring concurrently with MST found in this study and previous work (Street et al., 2008) makes treatment and recovery even more complex for female veterans.

Currently there is no systematic provision of access to a safe haven that fosters recovery from the catecholamine bombardment of the heart following MST. Creation of gender specific safe shelters for active duty military personnel, similar to community battered women shelters, could provide rapid interdisciplinary support and multimodal therapy needed to prevent negative HRV outcomes such as those found in this sample. Self-regulation of personal emotions, attitudes, and lifestyle impact cardiovascular outcomes (Kubzansky et al., 2011) and highlight the importance of providing female veterans with treatment and skills needed to process personal MST experience and foster psychological and physical recovery. HRV improved following cognitive behavior therapy sessions in depressed patients in a previous study (Carney et al., 2000), and HRV could provide a physiological measure of psychotherapy effectiveness in future studies (Spira et al., 2006). Mandated removal of the soldier from the environment where the 
sexual assault occurred by temporary assignment to a safe shelter for timely processing of the traumatic event may prevent costly psychological and physical sequelae (Street et al., 2008; Suris \& Lind, 2008; Suris et al., 2004).

\section{Suggestions for Future Research}

Time domain HRV measures from readily available 10-second ECG strips were successful in documenting HRV decline in the ageing heart (de Bruyne et al., 1999; Dekker et al., 1997; Tibblin et al., 1975). This is the first study that utilized 10-second strips from ECG and Holter recordings to specifically document diminished HRV in younger female veterans with MST exposure and adds support to previous work suggesting lower HRVis associated with PTSD (Lakusic et al., 2007). As recommended, to enhance reliability of 10-second Holter and ECG tracings (Schroeder et al., 2004), the mean of three available 10-second strips for each subject was used for this study. However, future research projects are needed, using computer-generated 24-hour Holter data (ESC \& NASPE, 1996) from larger samples of veteran and civilians of both genders exposed to sexual trauma, to challenge and expand initial findings of this pilot work.

The need for research into the effects of sexual trauma is emphasized by National Institutes of Health (NIH, 2007) requests to explore biobehavioral influences and international requests to study psychosocial risks (ESC, 2007) related to cardiovascular health. Research of relationships between sexual trauma and the PTSD that often follows, with autonomic tone measures, such as HRV, is needed to develop pragmatic interventions that decrease lifetime risks for developing negative cardiac sequelae. Several questions for future research emerged from this study and could be explored in both genders of veterans:

- What is the relationship between MST and HRV controlling for the variables systolic and diastolic blood pressure, body mass index (BMI), lipid panel, blood glucose, complete blood count with differential, race, and ethnicity?

- Do HRV measures differ by severity of sexual trauma (verbal verses rape)?

- Do HRV measures in veterans with PTSD from alternate types of trauma (combat, intimate partner violence, or childhood sexual abuse) differ from those with PTSD from MST?

- Do PTSD scores for veterans with MST exposure differ from PTSD scores of female veteran exposed to other types of trauma?

- Does HRV differ in veteran with MST with PTSD and those with MST without PTSD?

- How quickly do HRV differences occur after MST exposure when compared to similar aged veterans with no MST?

- Does an initial period of increased HRV occur before a lasting decline?

- Could HRV screening effectively identify individuals with previous history of sexual trauma in emergency department or clinical settings?

- What interventions do veterans with MST exposure report as helping the best with cardiac related symptoms? 
- What is the difference in HRV between those with MST who receive antidepressants and those with MST who do not?

- What is the difference in HRV in veterans with MST who receive beta blocker treatment, psychotherapy, or a combination of the two within one month postassault?

- What is the HRV at three, six, nine, or 12 month follow-up appointments in veterans with MST exposure receiving beta blocker treatment?

- What is the HRV at three, six, nine, or 12 month follow-up appointments in veterans with MST exposure history participating in self-administered controlled breathing exercises twice a day?

- What is the association among precursor variables to CAD and DM, such as hypertension and increased BMI, to lower HRV?

- What is the association between immune function and MST and lower HRV?

- What is the difference in HRV measures in veterans of both genders with MST exposure compared to veterans of both genders without history of MST?

\section{Translating Findings into Practice}

Translation of findings into practice will require collaborative effort with major stakeholders in the VA system. An extension of this study involves collection of additional data including systolic and diastolic blood pressure, BMI, lipid panel, blood glucose, complete blood count with differential, type of trauma preceding posttraumatic stress disorder, race, and ethnicity. Both the UTHSC and VA IRBs granted approval for follow up research of these variables upon completion of dissertation and defense. Disseminating current research and pursing additional research are eagerly anticipated impending activities.

\section{Conclusion}

This study demonstrated in a sample of female veterans with cardiac symptoms requiring a cardiology consult that those female veterans with MST had significantly lower HRV. MST was more strongly related to HRV decline than other study variables. Unknowingly or willingly overlooked in the past, the message from the hearts of women who experienced MST can no longer be ignored (Lynch, 2000). This study provides supportive evidence for research to develop evidence-based interventions that increase HRV to prevent further cardiac decline in female veterans with MST exposure. 


\section{LIST OF REFERENCES}

Acharya, U. R., Joseph, K. P., Kannathal, N., Lim, C. M., \& Suri, J. S. (2006). Heart rate variability: A review. Medical and Biological Engineering and Computing, 44, 10311051. doi: 10.1007/s11517-006-0119-0

Acharya, U. R., Kannathal, N., Ong, W. S., Luk, Y. P., \& Chua, T. (2004). Heart rate analysis in normal subjects of various age groups. Biomedical Engineering Online, 3, 2432. doi: $10.1186 / 1475-925 X-3-24$

Age. (2002). In Dictionary.com. Retrieved September 28, 2011, from http://dictionary.reference.com/browse/age

Akashi, Y. J., Barbaro, G., Sakurai, T., Nakazawa, K., \& Miyake, F. (2007). Cardiac autonomic imbalance in patients with reversible ventricular dysfunction takotsubo cardiomyopathy. QJM: An International Journal of Medicine, 100, 335-343.

doi:10.1093/qjmed/hcm028

Akashi, Y. J., Nakazawa, K., Sakakibara, M., Miyake, F., Koike, H., \& Sasaka, K. (2003). The clinical features of takotsubo cardiomyopathy. QJM: An International Journal of Medicine, 96, 563-573. doi:10.1093/qjmed/hcg096

Akselrod, S., Gordon, D., Madwed, J. B., Sidman, N., Shannon, D. C., \& Cohen, R. J. (1985). Hemodynamic regulation: Investigation by spectral analysis. American Journal of Physiology-Heart and Circulatory Physiology, 247, H867-H875.

Algra, A., Tijssen, J. G. P., Roelandt, R. T. C., Pool, J., \& Lubsen, J. (1993). Heart rate variability from 24-hour electrocardiography and the 2-year risk for sudden death. Circulation, 88, 180-185.

Alvarenga, M. E., Richards, J. C., Lambert, G., \& Esler, M. D. (2006).

Psychophysiological mechanisms in panic disorders: A correlative analysis of noradrenaline spillover, neuronal noradrenaline reuptake, power spectral analysis of heart rate variability, and psychological variables. Psychosomatic Medicine, 68, 8-16. doi:10.1097/01.psy.0000195872.00987.db

American Association of Clinical Endocrinologist. (2007). AACE Diabetes Mellitus Clinical Practice Guidelines Task Force. AACE diabetes mellitus guidelines. Screening and diagnosis. Endocrine Practice, 13(Supplement 1), 10-12. Retrieved September 28, 2011, from http://resources.aace.com/PDF/Section_02-Final-

Clinical_Evidence/Clinical_Evidence_Abstracts_and_PDFs/Rodbard_EndocrPract_2007. pdf 
American Diabetes Association. (2004). Diagnosis and classification of diabetes mellitus. Diabetes Care, 27, S5-S10. doi: 10.2337/diacare.27.2007.S5

American Heart Association. (2010). Heart disease and stroke statistics 2010 update at-aglance. Retrieved September 28, 2011, from http://www.americanheart.org/downloadable/heart/1265665152970DS3241\%20HeartStrokeUpdate_2010.pdf

American Psychological Association. (2004). Anxiety disorder: Do you know the signs of an anxiety disorder? Retrieved September 28, 2011, from http://www.mhrmemphis.com/pdfs/SignsofAnxiety.pdf

Anderson, M. E. (2007). Multiple downstream proarrhythmic targets for calmodulin kinase II: Moving beyond an ion channel-centric focus. Cardiovascular Research, 27, 657-666. doi:10.1016/j.cardiores.2006.12.009

Barton, D. A., Dawood, T., Lambert, E. A., Esler, M. D., Haikerwal, D., Brenchhley, C., . . L Lambert, G. W. (2007). Sympathetic activity in major depressive disorder:

Identifying those at increased cardiac risk? Journal of Hypertension, 25, 2117-2124. doi: 10.1097/HJH.0b013e32829baae7

Berntson, G. G., \& Cacioppo, J. T. (2004). Heart rate variability: Stress and psychiatric conditions. In M. Malik \& A. J. Camm (Eds.), Dynamic electrocardiography (pp. 5764). New York: Futura.

Berntson, G. G., Cacioppo, J. T., Binkley, P. F., Uchino, B. N., Quigley, K. S., \& Fieldstone, A. (1994). Autonomic cardiac control. III. Psychological stress and cardiac response in autonomic space as revealed by pharmacological blockades.

Psychophysiology, 31, 599-608.

Beta blocker. (2011). WebMD. Retrieved September 28, 2011, from http://www.webmd.com/hypertension-high-blood-pressure/hypertension-treatment-betablockers

Bigger, J. T., Fleiss, J. L., Steinman, R. C., Rolnitzky, L. M., Kleiger, R. E., \& Rottman, J. N. (1992). Frequency domain measures of heart period variability and mortality after myocardial infarction. Circulation, 85, 164-171.

Binkley, P. F., Haas, G. J., Starling, R. C., Nunziata, E., Hatton, P. A., Leier, C. V., \& Cody, R. J. (1993). Sustained augmentation of parasympathetic tone with angiotensinconverting enzyme inhibition in patients with congestive heart failure. Journal of the American College of Cardiology, 21, 655-661.

Biobehavioral. (2007). American heritage medical dictionary (2nd ed.). Retrieved September 28, 2011, from http://medicaldictionary.thefreedictionary.com/biobehavioral 
Bissett, J. K., de Soyza, N., Kane, J. J., \& Murphy, M. L. (1976). Atrioventricular conduction patterns in patients with paroxysmal supraventricular tachycardia. American Heart Journal, 91, 287-291.

Bob, P., Susta, M., Grequsova, A., \& Jasova, D. (2009). Dissociation, cognitive conflict and nonlinear patterns of heart rate dynamics in patients with unipolar depression. Progress in Neuro-Psychopharmacology and Biological Psychiatry, 33, 141-145. doi:10.1016/j.pnpbp.2008.11.005

Bonomi, A. E., Anderson, M. L., Rivara, F. P., \& Thompson, R. S. (2007). Health outcomes in women with physical and sexual intimate partner violence exposure. Journal of Women's Health, 16, 987-997. doi: 10.1089/jwh.2006.0239

Bray, R. M., \& Hourani, L. L. (2007). Substance use trends among active duty military personnel: Findings from the United States Department of Defense Health Related Behavior, 1980-2005. Addiction, 102, 1092-1101. doi: 10.1111/j.13600443.2007.01841.x

Bremner, J. D., \& Brett, E. (1997). Trauma-related dissociative states and long-term psychopathology in posttraumatic stress disorder. Journal of Traumatic Stress, 10, 37-49.

Briere, J. (1992). Methodological issues in the study of sexual abuse effects. Journal of Consulting and Clinical Psychology, 60, 196-203.

Brown, D. W., Anda, R. F., Tiemeier, H., Felitti, V. J., Edwards, V. J., Croft, J. B., \& Giles, W. H. (2009). Adverse childhood experiences and the risk of premature mortality. American Journal of Preventive Medicine, 37, 389-396. doi:

10.1016/j.amepre.2009.06.021

Burger, A. J., Charlamb, M., Winerauch, L. A., \& D'Lia, J. (1997). Short- and long- term reproducibility in heart rate variability patients with long-standing type 1 diabetes mellitus. American Journal of Cardiology, 80, 1198-1202.

Cagirci, G., Cay, S., Karakrt, O., Eryasar, N., Kaya, V., Canga, A., . . Akdemir, R. (2009). Influence of heavy cigarette smoking on heart rate variability and heart rate turbulence parameters. Annals of Noninvasive Electrocardiology, 14, 327-332.

doi: $10.1111 / \mathrm{j} .1542-474 X .2009 .00321 . \mathrm{x}$

Campbell, J., Jones, A. S., Dienemann, J., Kub, J., Schollenberger, J., O’Campo, P., . . . Wynne, C. (2002). Intimate partner violence and physical health consequences. Archives of Internal Medicine, 162, 1157-1163.

Cannon, W. (1939). The wisdom of the body (2nd ed.). New York: W. W. Norton. 
Carney, R. M., Blumenthal, J. A., Stein, J. A., Watkins, L., Catellier, D., Berkman, L. F., ... Freedland, K. E. (2001). Depression, heart rate variability, and acute myocardial infarction. Circulation, 104, 2024-2028. doi: 10.1161/hc4201.097834

Carney, R. M., Freedland, K. E., Stein, P. K., Skala, J. A., Hoffman, P., \& Jaffe, A. S. (2000). Change in heart rate variability during treatment for depression in patients with coronary heart disease. Psychosomatic Medicine, 62, 639-647.

Casolo, G., Balli, E., Taddei, T., Amuhasi, J., \& Gori, C. (1989). Decreased spontaneous heart rate variability. American Journal of Cardiology, 64, 1162-1167.

Cerrone, M., Noujaim, S. F., Tolkacheva, E. G., Talkachou, A., O'Connell, R., Berenfeld, O., . . . Jalife, J. (2007). Arrhythmogenic mechanisms in a mouse model of catecholaminergic polymorphic ventricular tachycardia. Circulation Research, 101, 1039-1048. doi: 10.1161/CIRCRESAHA.107.148064

Chida, Y., \& Steptoe, A. (2010). Greater cardiovascular responses to laboratory mental stress are associated with poor subsequent cardiovascular risk status: A meta-analysis of prospective evidence. Hypertension, 55, 1026-1032. doi: 10.1161/ HYPERTENSIONAHA.109.146621

Cigarette smoking. (2009). In Mosby's medical dictionary (8th ed.). Retrieved September 28, 2011, from http://medical-dictionary.thefreedictionary.com/cigarette+smoking

Cohen, B., Marmar, C., Ren, L., Bertenthal, D., \& Seal, K. H. (2009). Association of cardiovascular risk factors with mental health diagnoses in Iraq and Afghanistan war veterans using VA health care. Journal of the American Medical Association, 302, 489492. doi: 10.1001/jama.2009.1084

Cohen, H., \& Benjamin, J. (2006). Power spectrum analysis and cardiovascular morbidity in anxiety disorders. Autonomic Neuroscience: Basic and Clinical, 128(1), 1-8. doi: 10.1016/j.autneu.2005.06.007

Cohen, H., Benjamin, J., Geva, A. B., Matar, M., Kaplan, Z., \& Kotler, M. (2000). Autonomic dysregulation in panic disorder and in post-traumatic stress disorder: Application of power spectrum analysis of heart rate variability at rest and in response to recollection of trauma or panic attacks. Psychiatry Research, 96, 1-13.

Cohen, H., Kotler, M., Matar, M., \& Kaplan, Z. (2000). Normalization of heart rate variability in post-traumatic stress disorder patients following fluoxetine treatment: Preliminary results. Israel Medical Association Journal, 2, 296-301.

Comorbidity. (2009). In Mosby's medical dictionary (8th ed.). Retrieved September 28, 2011, from http://medical-dictionary.thefreedictionary.com/comorbidity 
Corovic, N., Durakovic, Z., Zavallic, M., \& Zrinscak, J. (2000). Electrocardiographic changes in ex-prisoners of war released from detention camps. International Journal of Legal Medicine, 113, 197-200.

Corson, K., Gerrity, M. S., \& Dobscha, S. K. (2008). Screening for depression and suicidality in a VA primary care setting: 2 items are better than one. American Journal of Managed Care, 10, 839-845. Retrieved September 28, 2011, from http://www.ajmc.com/media/pdf/AJMC04novPrt2Corson839.pdf

Dantev, S. (2002). Physiological basis of heart rate variability. Retrieved September 28, 2011, from http://www.dantest.com

Davidson, C. J., \& Bonow, R. O. (2007). Cardiac catheterization. In P. Libby, R. O. Bonow, D. L. Mann, \& D. P. Zipes (Eds.), Braunwald's heart disease: A textbook of cardiovascular medicine (8th ed., pp. 439-463). Philadelphia: Saunders Elsevier.

de Bruyne, M. C., Kors, J. A., Hoes, A. W., Klootwijk, P., Dekker, J. M., Hofman, A., ... Grobbee, D. E. (1999). Both decreased and increase heart rate variability on the standard 10-second electrocardiogram predict cardiac mortality in the elderly: The Rotterdam Study. American Journal of Epidemiology, 150, 1282-1288.

Dekker, J. M., Crow, R. S., Folson, A. R., Hannan, P. J., Liao, D., Swenne, C. A., \& Schouten, E. G. (2000). Low heart rate variability in a 2-minute rhythm strip predicts risk of coronary heart disease and mortality form several causes: The ARIC study. Circulation, 102, 1239-1244.

Dekker, J. M., Schouten, E. G., Klootwijk, P., Pool, J., Sweene, C. A., \& Kromhout, D. (1997). Heart rate variability from short electrocardiographic recordings predicts mortality from all causes in middle-aged and elderly men: The Zutphen study. American Journal of Epidemiology, 145, 899-908.

Desai, R. A., Harpaz-Rotem, I., Najavitis, L. M., \& Rosenheck, R. A. (2008). Impact of the seeking safety program on clinical outcomes among homeless female veterans with psychiatric disorders. Psychiatric Services, 59, 996-1003. Retrieved September 28, 2011, from http://ps.psychiatryonline.org/cgi/reprint/59/9/996

Dobie, D. J., Kivlahan, D. R., Maynard, C., Bush, K. R., McFall, M., \& Bradley, K. A. (2002). Screening for post-traumatic stress disorder in female Veteran's Affairs patients: Validation of the PTSD Checklist. General Hospital Psychiatry, 24, 367-374.

Doppalapudi, H., Jin, Q., Dosdall, D. J., Quin, H., Walcott, G. P., Killingsworth, C. R., ... Huang, J. (2008). Intracoronary infusion of catecholamines causes focal arrhythmias in pigs. Journal of Cardiovascular Electrophysiology, 19, 963-970. doi: 10.1111/j.15408167.2008.011999.x 
Eby, K. K. (2004). Exploring the stressors of low-income women with abusive partners: Understanding their needs and developing effective community response. Journal of Family Violence, 19, 221-232.

Eby, K. K., Campbell, J. C., Sullivan, C. M., \& Davidson, W. S. (1995). Health effects of experiences of sexual violence for women with abusive partners. Health Care for Women International, 16, 563-576.

Eshtehardi, P., Koestner, S. C., Adorjan, P., Windecker, S., Meier, B., Hess, O. M., . . . Cook, S. (2009). Transient apical ballooning syndrome-Clinical characteristics, ballooning pattern, and long-term follow-up in a Swiss population. International Journal of Cardiology, 135, 370-375. doi:10.1016/j.ijcard.2008.03.088

Esler, M. D., Turbott, J., Schwarz, R. G., Leonard, P., Bobik, A., Skews, H., \& Jackman, G. (1982). The peripheral kinetics of norepinephrine in depressive illness. Archives of General Psychiatry, 45, 849-857.

European Society of Cardiology. (2007). European guidelines on cardiovascular disease prevention in clinical practice: Executive summary. European Heart Journal, 28, 23752414. doi: 10.1093/eurheartj/ehm316

Everson, S. A., Kauhanen, J., Kaplan, G. A., Goldberg, D. E., Julkunen, J., Tuomilehto, J., \& Salonen, J. T. (1997). Hostility and increased risk of mortality and acute myocardial infarction: The mediating role of behavioral risk factors. American Journal of Epidemiology, 146, 142-152.

Ewing, D. J., Martin, C. N., Young, R. J., \& Clarke, B. F. (1985). The value of cardiovascular autonomic function tests: 10 years' experience in diabetes. Diabetes Care, 8, 491-498.

Felitti, V. J., Anda, R. F., Nordenberg, D., Williamson, D. F., Spitz, A. M., Edwards, V., . . Marks, J. S. (1998). Relationship of childhood abuse and household dysfunction to many of the leading causes of death in adults: The Adverse Childhood Experiences (ACE) study. American Journal of Preventive Medicine, 14(4), 245-258.

Feng, J., Leniham, D. J., Johnson, M. M., Karri, V., \& Redd, C. V. R. (2006). Cardiac sequelae in Brooklyn after the September 11 terrorist attacks. Clinical Cardiology, 29(1), 13-17. doi: 10.1002/clc.4960290105

Fioranelli, M., Piccoll, M., Mileto, G. M., Sgreccia, F., Azzolini, P., Risa, M. P., . . . Puglisi, A. (1999). Analysis of heart rate variability five minutes before the onset of paroxysmal atrial fibrillation. Pacing and Clinical Electrophysiology, 22, 743-749.

Foa, E. B., Riggs, D. S., \& Gershuny, B. S. (1995). Arousal, numbing, and intrusion: Symptom structure of PTSD following assault. American Journal of Psychiatry, 152, 116-120. 
Fukuta, H., Hayano, J., Ishihara, S., Sakata, S., Mukai, S., Ohte, N., . . Kimura, G. (2003). Prognostic value of heart rate variability in patients with end-stage renal disease on chronic dialysis. Nephrology Dialysis Transplantation, 18, 318-325.

Gehi, A., Mangano, D., Pipkin, S., Browner, W. S., \& Whooley, M. A. (2005). Depression and heart rate variability in patients with stable coronary heart disease: Findings from the heart and soul study. Archives of General Psychiatry, 62(6), 661-666. doi: 10.1001/archpsyc.62.6.661.

Gill, J. M., Page, G. G., Sharps, P., \& Campbell, J. C. (2008). Experiences of traumatic events and associations with PTSD and depression development in urban health careseeking women. Journal of Urban Health: Bulletin of the New York Academy of Medicine, 85, 693-706. doi: 10.1080/016128406000781121

Gill, J. M., Saligan, L., Henderson, W., \& Szanton, S. (2009). PTSD: Know the warning signs. The Nurse Practitioner, 34, 30-37. doi:10.1007/s11524-008-9290-y

Ginsberg, J. P., Ayers, E., Burriss, L., \& Powell, D. A. (2008). Disruption of bradycardia associated with discriminative conditioning in combat veterans with PTSD. Neuropsychiatric Disease and Treatment, 4, 635-646. doi: http://dx.doi.org/10.2147/NDT.S2808

Goldsmith, R. L., Bigger, J. T., Bloomfield, D. M., Krun, H., Steinman, R. C., SacknerBernstein, J., \& Packer, M. (1997). Long-term carvedilol therapy increases parasympathetic nervous system activity in chronic congestive heart failure. American Journal of Cardiology, 80, 1101-1104.

Goldstein, D. S., Brush, J. E., Eisenhofer, G., Stull, R., \& Esler, M. D. (1988). In vivo measurement of neuronal uptake of norepinephrine in the human heart. Circulation, 78, $41-48$.

Goldstein, D. S., Robertson, D., Esler, M. D., \& Straus, S. E. (2002). Dysautonomias: Clinical disorders of the autonomic nervous system. Annals of Internal Medicine, 137, 753-763.

Goodwin, R. D., \& Stein, M. B. (2004). Association between childhood trauma and physical disorders among adults in the United States. Psychological Medicine, 34(4), 509-520.

Grippo, A. J., \& Johnson, A. K. (2009). Stress, depression, and cardiovascular dysregulation: A review of neurobiological mechanisms and the integration of research from preclinical disease models. Stress, 12(1), 1-21. doi: 10.1080/10253890802046281

Groer, M. W., \& Burns, C. (2009). Stress response in female veterans: An allostatic perspective. Rehabilitation Nursing, 34, 96-104. 
Guzzetti, S., Piccaluga, E., Casati, R., Cerutti, S., Lombardi, F., Pagani, M., \& Malliani, A. (1988). Sympathetic predominance in essential hypertension: A study employing spectral analysis of heart rate variability. Journal of Hypertension, 6, 711-717.

Hall, M., Vasko, R., Buysse, D., Ombao, H., Chen, Q., Cashmere, J. D., . . Thayer, J. F. (2004). Acute stress affects heart rate variability. Psychosomatic Medicine, 66, 56-62. doi: 10.1097/01.PSY.0000106884.58744.09

Hamberger, L. K., Ambuel, B., Marbella, A., \& Donze, J. (1998). Physician interaction with battered women. Archives of Family Medicine, 7, 575-582.

Hamilton, R. M., Mckechnie, P. S., \& Macfarlane, P. W. (2004). Can cardiac vagal tone be estimated from the 10-second ECG? International Journal of Cardiology, 95, 109115 .

Hatcher, L. (2003a). Bivariate correlation. In Step-by-step basic statistics using $S A S^{\bigcirc}$ (pp. 290-338). Cary, NC: SAS Institute.

Hatcher, L. (2003b). Bivariate regression. In Step-by-step basic statistics using SAS ${ }^{\mathcal{O}}$ (pp. 339-384). Cary, NC: SAS Institute.

Hatcher, L. (2003c). Chi-square test of independence. In Step-by-step basic statistics using $S A S^{\mathcal{O}}$ (pp. 629-672). Cary, NC: SAS Institute.

Hatcher, L. (2003d). Data input. In Step-by-step basic statistics using SAS ${ }^{\odot}$ (pp. 113144). Cary, NC: SAS Institute.

Hatcher, L. (2003e). Independent-samples $\mathrm{t}$ test. In Step-by-step basic statistics using $S A S^{\odot}$ (pp. 415-450). Cary, NC: SAS Institute.

Hatcher, L. (2003f). Measures of central tendency and variability. In Step-by-step basic statistics using $S A S^{\mathcal{O}}$ (pp. 181-214). Cary, NC: SAS Institute.

Heim, C., Newport, D. J., Heit, S., Graham, Y. P., Wilcox, M., Bonsall, R., . . Nemeroff, C. B. (2000). Pituitary-adrenal and autonomic responses to stress in women after sexual and physical abuse in childhood. Journal of the American Medical Association, 248, 592597. doi: $10.1001 /$ jama.284.5.592

Holbrook, T. L., Hoyt, D. B., Stein, M. B., \& Sieber, W. J. (2002). Gender differences in long-term posttraumatic stress disorder outcomes after major trauma: Women are at higher risk of adverse outcomes than men. Journal of Trauma, Injury, Infection, and Critical Care, 53, 882-888. 
Holman, E. A., Silver, R. C., Poulin, M., Anderson, J., Gil-Rivas, V., \& McIntosh, D. N. (2008). Terrorism, acute stress, and cardiovascular health: A 3-year national study following the September 11th attacks. Archives of General Psychiatry, 65, 73-80. Retrieved September 28, 2011, from http://archpsyc.ama-assn.org/cgi/reprint/65/1/73.pdf

Horsten, M., Erigson, M., Perski, A., Wamala, S. P., \& Schenck-Gustafsson, K. (1999). Psychosocial factors and heart rate variability in healthy women. Psychosomatic Medicine, 61, 49-57.

Hsia, J., Larson, J. C., Ockene, J. K., Sarto, G. E., Allison, M. A., Hendrix, S. L., . . Manson, J. E. (2009). Resting heart rate as a low tech predictor of coronary events in women: Prospective cohort study. British Medical Journal (Clinical Research Ed.), 338, b219-225. doi:10.1136/bmj.b219

Insulander, P., \& Vallin, H. (2005). Gender differences in electrophysiologic effects of mental stress and autonomic tone inhibition: A study in healthy individuals. Journal of Cardiovascular Electrophysiology, 16, 59-63. doi: 10.1046/j.1540-8167.2005.04117.x

Kang, H., Dalager, N., Mahan, C., \& Ishii, E. (2005). The role of sexual assault on the risk of PTSD among Gulf War Veterans. Annals of Epidemiology, 15, 191-195. doi: 10.1016/j.annepidem.2004.05.009.

Kapa, S., \& Somers, V. K. (2008). Cardiovascular manifestations of autonomic disorders. In P. Libby, R. O. Bonow, D. L. Mann, and D. P. Zipes (Eds.), Braunwald's heart disease: A textbook of cardiovascular medicine (8th ed., pp. 2171-2183). Philadelphia: Saunders.

Kawachi, I., Colditz, G. A., Rimm, E. B., Giovannucci, E., Stampfer, M. J., \& Willett, W. C. (1994). Prospective study of phobic anxiety and risk of coronary heart disease in man. Circulation, 89, 1992-1997.

Kawachi, I., Sparrow, D., Spiro, A., Vokonas, P., \& Weiss, S. T. (1996). A prospective study of anger and coronary heart disease. Circulation, 94, 2090-2095.

Keary, T. A., Hughes, J. W., \& Palmieri, P. A. (2009). Women with posttraumatic stress disorder have larger decreases in heart rate variability during stress tasks. International Journal of Psychophysiology, 73, 257-264. doi: 10.1016/j.ijpsycho.2009.04.003

Kibler, J. L. (2008). Cardiovascular risk in relation to posttraumatic stress disorder in young women. Retrieved September 28, 2011, from

http://projectreporter.nih.gov/project_info_description.cfm?aid=7515802\&icde $=2488646$ NHLBI 1R15HL085121-01A2

Kimerling, R., Gima, K., Smith, M. W., Street, A. E., \& Frayne, S. (2007). The Veterans Health Administration and military sexual trauma. American Journal of Public Health, 97(12), 21602166. doi: 10.2105/AJPH.2006.092999. 
Kimerling, R., Street, A. T., Gima, K., \& Smith, M. W. (2008). Evaluation of universal screening for military-related sexual trauma. Psychiatric Services, 59, 635-640. doi: 10.1176/appi.ps.59.6.635

Kleiger, R. E., Miller, P., Bigger, J. T., \& Moss, A. J. (1987). Decreased heart rate variability and its association with increased mortality after acute myocardial infarction. American Journal of Cardiology, 59, 256-262.

Kocovic, D. Z., Harada, T., Shea, J. B., Soroff, D., \& Friedman, P. L. (1993). Alterations of heart rate and of heart rate variability after radiofrequency catheter ablation of supraventricular tachycardia. Delineation of parasympathetic pathways in the human heart. Circulation, 88, 1671-1681.

Kreibig, S. D., Wilhelm, F. H., Roth, W. T., \& Gross, J. J. (2007). Cardiovascular, electrodermal, and respiratory response patterns to fear and sadness induced films. Psychophysiology, 44, 787-806. doi: 10.1111/j.1469-8986.2007.00550.x

Krittayaphong, R., Cascio, W. E., Light, K. C., Sheffield, D., Golden, R. N., Finkel, J. B., ... Sheps, D. S. (1997). Heart rate variability in patients with coronary artery disease: Differences in patients with higher and lower depression scores. Psychosomatic Medicine, 59, 231-235.

Kubany, E. S., Haynes, S. N., Leisen, M. B., Owens, J. A., Kaplan, A. S., Watson, S. B., $\&$ Burns, K. (2000). Development and preliminary validation of a brief broad-spectrum measure of trauma exposure: The Traumatic Life Events Questionnaire. Psychological Assessment, 12, 210-224.

Kubzansky, L. D., Park, N., Peterson, C., Vokonas, P., \& Sparrow, D. (2011). Healthy Psychological functioning and incident coronary heart disease: The importance of selfregulation. Archives of General Psychiatry, 68(4), 400-408. doi:

10.1001/archgenpsychiatry.2011.23

Ladwig, K. H., Baumert, J., Marten-Mittag, B., Kolb, C., Zrenner, B., \& Schmitt, C. (2008). Posttraumatic stress symptoms and predicted mortality in patients with implantable cardioverter-defibrillators: Results from the prospective living with an implanted cardioverter-defibrillator study. Archives of General Psychiatry, 65, 13241330. Retrieved September 28, 2011, from http://archpsyc.amaassn.org/cgi/content/full/65/11/1324

Lakusic, N., Fuckar, K., Mahovic, D., Cerovec, D., Majsec, M., \& Stancin, N. (2007). Characteristics of heart rate variability in war veterans with post-traumatic stress disorder after myocardial infarction. Military Medicine, 172, 1190-1193. 
Lang, A. J., Aarons, G. A., Gearity, J., Laffaye, C., Satz, L., Dresselhaus, T. R., \& Stein, M. B. (2008). Direct and indirect links between childhood maltreatment, posttraumatic stress disorder, and women's health. Behavioral Medicine, 33, 125-135. doi:

10.3200/BMED.33.4.125-136

Liao, D., Cai, J., Rosamond, W. D., Barnes, R. W., Hutchinson, R. G., Whitsel, E. A., . . Heiss, G. (1997). Cardiac autonomic function and incident coronary disease: A population-base case-cohort study. American Journal of Epidemiology, 145, 696-706.

Licht, C. M. M., De Geus, E. J. C., Van Dyck, R., \& Penninx, B. W. J. H. (2009). Association between anxiety disorders and heart rate variability in the Netherlands Study of Depression and Anxiety (NESDA). Psychosomatic Medicine, 71, 508-518. doi: 10.1097/PSY.0b013e3181a292a6

Licht, C. M. M., de Geus, E. J. C., Zitman, F. G., Hoogendijk, W. J. G., van Dyck, R., \& Penninx, B. W. J. H. (2008). Association between major depressive disorder and heart rate variability in the Netherlands Study of Depression and Anxiety (NESDA). Archives of General Psychiatry, 65, 1358-1367. Retrieved September 28, 2011, from http://archpsyc.amaassn.org/cgi/reprint/65/12/1358?maxtoshow=\&hits=10\&RESULTFO $\mathrm{RMAT}=\&$ fulltext $=+$ Association + between + major + depressive + disorder + and + heart + rate + variability + in + the + Netherlands + Study + of + Depression + and + Anxiety $+\% 28$ NESDA $\% 29$ \&searchid $=1 \&$ FIRSTINDEX $=0 \&$ resourcetype $=$ HWCIT

Linden, W., Phillips, M. J., \& Leclerc, J. (2007). Psychological treatment of cardiac patients: A meta-analysis. European Heart Journal, 28, 2972-2984. doi:

10.1093/eurheartj/ehm504.

Linden, W., Stossel, C., \& Maurice, J. (1996). Psychosocial interventions for patients with coronary artery disease: A meta-analysis. Archives of Internal Medicine, 156, 745752.

Lynch, J. J. (2000). The heart of human dialogue: Decoding the language of the heart. In A cry unheard: New insights into the medical consequences of loneliness (pp. 243-263). Baltimore, MD: Bancroft Press.

Macfarlane, P. W., \& Norrie, J. (2007). The value of the electrocardiogram in risk assessment in primary prevention: Experience form the West of Scotland Coronary Prevention Study. Journal of Electrocardiology, 40, 101-109. doi: 10.1016/j.jelectrocard.2006.05.003

Magee, L., \& Duley, L. (2003). Oral beta-blockers for mild to moderate hypertension during pregnancy. Cochrane Database of Systematic Reviews 2003, Issue 3. Art. No.: CD002863. doi: 10.1002/14651858.CD002863

Malpas, S. C., \& Maling, T. J. B. (1990). Heart rate variability and cardiac autonomic function in diabetes. Diabetes, 39, 1177-1181. 
Mann, D. L., Kent, R. L., Parsons, B., \& Cooper, G. (1992). Adrenergic effects on the biology of the adult mammalian cardiocyte. Circulation, 85, 790-804.

Mansour, V. M., Wilkinson, D. J., Jennings, G. L., Schwarz, R. G., Thompson, J. M., \& Esler, M. D. (1998). Panic disorder: Coronary spasm as a basis for cardiac risk? Medical Journal of Australia, 1998, 390-392.

McEwen, B. (2004). Protective and damaging effects of the mediators of stress and adaptation: Allostasis and allostatic load. In J. Schulkin (Ed.), Allostasis, homeostasis, and the costs of physiological adaptation (pp. 65-98). New York: Cambridge University Press.

McEwen, B. (2005). Stressed or stressed out: What is the difference? Journal of Psychiatry \& Neuroscience, 30, 315-318. Retrieved September 28, 2011, from http://www.ncbi.nlm.nih.gov/pmc/articles/PMC1197275/

McEwen, B., \& Seeman, T. (1999). Allostatic load and allostasis: Summary. Retrieved September 28, 2011, from http://www.macses.ucsf.edu/Research/Allostatic/notebook/allostatic.html

McIntyre, L. M., Butterfield, M. I., Nanda, K., Parsey, K., Stechuchak, K. M., McChesney, A. W., . . . Bastian, L. A. (1999). Validation of a trauma questionnaire in veteran women. Journal of General Internal Medicine, 14, 186-189.

Meirik, O. (2008). Cohort and case-control studies. Retrieved September 28, 2011, from http://www.gfmer.ch/Books/Reproductive_health/Cohort_and_case_control_studies.html

Melanson, E. L. (2000). Resting heart rate variability in men varying in habitual physical activity. Medicine and Science in Sports and Exercise, 32, 1894-1901.

Meyerfeldt, U., Wessel, N., Schutt, H., Selbig, D., Schumann, A., Voss, A., .. . Schirdewan, A. (2002). Heart rate variability before onset of ventricular tachycardia: Differences between slow and fast arrhythmias. International Journal of Cardiology, 84, 141-151.

Minami, J., Ishimitsu, T., \& Matsuoka, H. (1999). Effects of smoking cessation on blood pressure and heart rate variability in habitual smokers. Hypertension, 33, 586-590.

Morrow, D. A., \& Gersh, B. J. (2008). Chronic coronary artery disease. In P. Libby, R. O. Bonow, D. L. Mann, \& D. P. Zipes (Eds.), Braunwald's heart disease: A textbook of cardiovascular medicine (8th ed., pp. 1353-1417). Philadelphia: Saunders Elsevier.

Munjal, S., Koval, T., Muhammad, R., Jin, Y., Demmel, V., Roethig, H. J., . . Unverdorben, M. (2009). Heart rate variability increases with reductions in cigarette smoke exposure after 3 days. Journal of Cardiovascular Pharmacology and Therapeutics, 14, 192-198. doi: 10.1177/1074248409340340 
Murdoch, M., Polusny, M. A., Hodges, J., \& Cowper, D. (2006). The association betweein in-service sexual harassment and post-traumatic stress disorder among Department of Veterans Affairs disability applicants. Military Medicine, 171(2), 166-173.

Nabi, H., Kivimaki, M., Zins, M., Elovainio, M., Cosoli, S. M., Cordier, S., . . SinghManoux, A. (2008). Does personality predict mortality? Results from the GAZEL French prospective cohort study. International Journal of Epidemiology, 37, 386-396.

Narkiewicz, K., Montaro, N., Cogliati, C., van de Borne, P. J. H., Dyken, M. E., \& Somers, V. K. (1998). Altered cardiovascular variability in obstructive sleep apnea. Circulation, 98, 1071-1077.

National Institutes of Health \& National Institute of Mental Health. (2007). Mental health consequences of violence and trauma (R03). Retrieved April 30, 2009, from http://grants.nih.gov/grants/guide/pa-files/PA-07-313.html

National Institute of Mental Health. (2010). Anxiety disorders. Retrieved September 28, 2011, from http://www.nimh.nih.gov/health/topics/anxiety-disorders/index.shtml

Norman, G. R., \& Streiner, D. L. (2000a). Advance topics in regression and ANOVA. In Biostatistics the bare essentials (2nd ed., pp. 145-154). Hamilton, Ontario: B. C. Decker.

Norman, G. R., \& Streiner, D. L. (2000b). Multiple regression. In Biostatistics the bare essentials (2nd ed., pp. 145-154). Hamilton, Ontario: B. C. Decker.

Norman, G. R., \& Streiner, D. L. (2008). Logistic regression. In D. A. Farmer (Ed.), Biostatistics the bare essentials (3rd ed., pp. 159-166). Hamilton, Ontario: B. C. Decker.

Nunan, D., Sandercock, G. H., \& Brodie, D. A. (2010). A quantitative systematic review of normal values for short-term heart rate variability in healthy adults. Pacing and Clinical Electrophysiology, 33, 1407-1417. doi: 10.1111/j.1540-8159.2010.02841.x

Nussinovitch, U., Elishkevitz, K. P., Katz, K., Nussinovitch, M., Segev, S., Volovitz, B., \& Nussinovitch, N. (2011). Reliability of ultra-short ECG indices for heart rate variability. Annals of Noninvasive Electrocardiology, 16(2), 117-122. : doi: 10.1111/j.1542-474X.2011.00417.x

Orth-Gomer, K., Wamala, S. P., Horsten, M., Schenck-Gustafsson, K., Schneiderman, N., \& Mittleman, M. A. (2000). Marital stress worsens prognosis in women with coronary heart disease: The Stockholm Female Coronary Risk Study. Journal of the American Medical Association, 284, 3008-3013.

Pan, A., Lucas, M., Sun, Q., van Dam, R. M., Franco, O. H., Willett, W. C., . . Hu, F. B. (2011). Increased mortality risk in women with depression and diabetes mellitus. Archives of General Psychiatry, 68(1), 42-50. doi: 10.1001/archgenpsychiatry.2010.176 
Pitzalis, M. V., Iacoviello, M., Todarello, O., Fioretti, A., Guida, P., Massari, F., . . Rizzon, P. (2001). Depression but not anxiety influences the autonomic control of the heart after myocardial infarction. American Heart Journal, 141, 765-771. doi: 10.1067/mhj.2001.114806

Prins, A., Quimette, P., Kimerling, R., Cameron, R. P., Hugelshofer, D. S., ShawHegwer, J., . . . Sheikh, J. (2003). The primary care PTSD screen (PC-PTSD) development and operating characteristics. Primary Care Psychiatry, 9(1), 9-14.

Radaelli, A., Valle, F., Falcone, C., Calciati, A., Leuzzi, S., Martinelli, L., . . . Bernardi, L. (1996). Determinants of heart rate variability in heart transplanted subjects during physical exercise. European Heart Journal, 17, 462-471.

Rainville, P., Bechara, A., Naqvi, N., \& Damasio, A. R. (2006). Basic emotions are associated with distinct patterns of cardiorespiratory activity. International Journal of Psychophysiology, 61, 5-18. Retrieved September 28, 2011, from

http://www.usc.edu/projects/rehab/private/docs/advisors/damasio/2_damasio_basic_emot ions.pdf

Rautaharju, P., Kooperberg, C., Larson, J. C., \& LaCroix, A. (2006).

Electrocardiographic predictors of incident congestive heart failure and all-cause mortality in postmenopausal women the Women's Health Initiative. Circulation 113, 481-489. doi: 10.1161/CIRCULATIONAHA.104.496091

Rechlin, T., Weis, M., Spitzer, A., \& Kaschka, W. P. (1994). Are affective disorders associated with alterations of heart rate variability? Journal of Affective Disorders, 32(271-275).

Reinders, A. A. T. S., Nijenhuis, E. R. S., Quak, J., Korf, J., Haaksma, J., Paans, A. M. J., . . . Den Boer, J. A. (2006). Psychobiological characteristics of dissociative identity disorder: a symptom provocation study. Biological Psychiatry, 60, 730-740.

doi:10.1016/j.biopsych.2005.12.019

Rich-Edwards, J. (2008). Violence, genes, and cardiovascular events in women.

Retrieved September 28, 2011, from

http://projectreporter.nih.gov/reporter_searchresults.cfm?\&new $=1 \&$ icde $=2488751 \& 1$ loc $=$ $2 \& \mathrm{CFID}=23901517 \& \mathrm{CFTOKEN}=41 \overline{2} 7834$ NHBLI 5R01HL081557-02 and 5R01HL081557-03

Roca, V., Hart, J., Kimbrell, T., \& Freeman, T. (2006). Cognitive function and dissociative disorder status among veteran subjects with chronic posttraumatic stress disorder: A preliminary study. Journal of Neuropsychiatry and Clinical Neurosciences, 18, 226-230. doi: 10.1176/appi.neuropsych.18.2.226 
Rosenthal, J. Z., Grosswald, S., Ross, R., \& Rosental, N. (2011). Effects of transcendental meditation in veterans of Operation Enduring Freedom and Operation Iraqi Freedom with posttraumatic stress disorder: a pilot study. Military Medicine, 176, 626-630.

Rosner, B. (2006a). Design and analysis techniques for epidemiologic studies. In C. Crockett, \& A. Day, Fundamentals of biostatistics (6th ed., pp. 630-731). Belmont, CA: Thomson Brooks/Cole.

Rosner, B. (2006b). Regression and correlation methods. In C. Crockett \& A. Day, Fundamentals of biostatistics (6th ed., pp. 464-556). Belmont, CA: Thomson Brooks/Cole.

Rothman, K. J. (1986). Types of epidemiologic study. In Modern epidemiology (pp. 5176). Boston: Little, Brown, \& Co.

Rothman, K. J., \& Greenland, S. (1998). Types of epidemiologic study. In Modern epidemiology (2nd ed., pp. 67-78). Philadelphia: Lippincott-Raven.

Rozanski, A., Blumenthal, J. A., \& Kaplan, J. (1999). Impact of psychological factors on the pathogenesis of cardiovascular disease and implications for treatment. Circulation, 99, 2192-2217.

Rugulies, R. (2002). Depression as a predictor for coronary heart disease: A review and meta-analysis. American Journal of Preventive Medicine, 23, 51-61.

Rutledge, T., Reis, S. E., Olson, M., Owens, J. A., Kelsey, S. F., Pepine, C. J., . . . Matthews, K. A. (2001). Psychosocial variables are associated with atherosclerosis risk factors among women with chest pain: The WISE Study. Psychosomatic Medicine, 63, 282-288.

Sadler, A. G., Booth, B. M., Mengeling, M. A., \& Doebbeling, B. N. (2004). Life span and repeated violence against women during military service: Effects on health status and outpatient utilization. Journal of Women's Health, 13, 799-811.

Sajadieh, A., Nielsen, O. W., Ransnussen, V., Hein, H. O., Abedini, S., \& Hansen, J. F. (2004). Increased heart rate and reduced heart-rate variability are associated with subclinical inflammation in middle-aged and elderly subjects with no apparent heart disease. European Heart Journal, 25(5), 363-370.

Sandercock, G. R. H., Hardy-Shepherd, D., Nunan, D., \& Brodie, D. (2008). The relationships between self-assessed habitual physical activity and non-invasive measures of cardiac autonomic modulation in young healthy volunteers. Journal of Sports Sciences, 26, 1171-1177. doi: 10.1080/02640410802004930 
Sands, K. E., Appel, M. L., Lilly, L. S., Schoen, F. J., Mudge Jr., G. H., \& Cohen, R. J. (1989). Power spectrum analysis of heart rate variability in human cardiac transplant recipients. Circulation, 79, 76-82.

Scanga, C. B. (2008). Stress. In D. K. Moser \& B. Riegel (Eds.), Cardiac nursing: A companion to Braunwald's Heart Disease (pp. 495-515). St. Louis: Saunders Elsevier.

Schlotzhauer, S. D., \& Littel, R. C. (2007). Basic regression diagnostics. In SAS system for elementary statistical analysis (2nd ed., pp. 335-365). Cary, NC: SAS Institute.

Schmaus, B. J., Laubmeier, K. K., Boquiren, V. M., Herzer, M., \& Zakowski, S. G. (2008). Gender and stress: Differential psychophysiological reactivity to stress exposure in the laboratory. International Journal of Psychophysiology, 69, 101-106. doi:

10.1016/j.ijpsycho.2008.03.006

Schnurr, P. P., Friedman, M. J., \& Engel, C. C. (2007). Cognitive behavioral therapy for posttraumatic stress disorder in women: A randomized controlled trial. Journal of the American Medical Association, 297, 820-830. doi: 10.1001/jama.297.8.820

Schroeder, E. B., Liao, D., Chambless, L. E., Prineas, R. J., Evans, G. W., \& Heiss, G. (2003). Hypertension, blood pressure, and heart rate variability: The Atherosclerosis Risk in Communities (ARIC) Study. Hypertension, 42, 1106-1111.

Schroeder, E. B., Whitsel, E. A., Evans, G. W., Prineas, R. J., Chambless, L. E., \& Heiss, G. (2004). Repeatability of heart rate variability measures. Journal of Electrocardiology, 37(3), 163-172. doi: 10.1016/j.jelectrocard.2004.04.004

Schubert, C., Lambertz, M., Nelesen, R. A., Bardwell, W., Choi, J. B., \& Dimsdale, J. E. (2009). Effects of stress on heart rate complexity--A comparison between short-term and chronic stress. Biological Psychology, 80, 325-332. doi:

10.1016/j.biopsycho.2008.11.005

Sharkey, S. W., Lesser, J. R., Zenovich, A. G., Maron, M. S., Lindberg, J., Longe, T. F., \& Maron, B. J. (2005). Acute and reversible cardiomyopathy provoked by stress in women from the United States. Circulation, 111, 472-479. doi: 10.1161/

01.CIR.0000153801.51470.EB

Slaap, B. R., Nielen, M. M. A., Boshuisen, M. L., van Roon, A. M., \& den Boer, J. A. (2004). Five-minute recordings of heart rate variability in obsessive compulsive disorder, panic disorder, and healthy volunteers. Journal of Affective Disorders, 78, 141-148.

Soper, D. S. (2010). Statistics calculators: A-priori sample size calculator for multiple regression. Retrieved September 28, 2011, from http://www.danielsoper.com/statcalc/ 
Spira, J. L., Pyne, J. M., Wiederhold, B., Wiederhold, M., Graap, K., \& Rizzo, A. (2006). Virtual reality and other experiential therapies for combat-related posttraumatic stress disorder. Primary Psychiatry, 13(3), 58-64. Retrieved September 28, 2011, from http://www.usc.edu/projects/rehab/private/docs/advisors/rizzo/3_rizzo_virtual_reality_an d_other.pdf

Stary, H. C. (1990). The sequence of cell and matrix changes in atherosclerotic lesions of coronary arteries in the first forty years of life. European Heart Journal, 11(supplement E), 3-19.

Stein, J. A., Borer, J. S., Hochreiter, C., Okin, P. M., Herrold, E. M., Devereux, R. B., \& Klingfield, P. (1993). Prognostic value and physiological correlates of heart rate variability in chronic severe mitral regurgitation. Circulation, 88, 127-135.

Stein, P. K., Barzilay, J. I., Chaves, P. H. M., Domitrovch, P. P., \& Gottdiener, J. S. (2009). Heart rate variability and its change over 5 years in older adults. Age and Ageing, 38, 212-218. doi: 10.1093/ageing/afn292

Stein, P. K., \& Kleigher, R. E. (1999). Insights from the study of heart rate variability. Annual Review of Medicine, 50, 249-261.

Stemmler, G., Aue, T., \& Wacker, J. (2007). Anger and fear: Separable effects of emotion and motivational direction on somatovisceral response. International Journal of Psychophysiology, 66, 141-153. doi: 10.1016/j.ijpsycho.2007.03.019

Sterling, P., \& Eyer, J. (1988). Allostasis: A new paradigm to explain arousal pathology. In S. Fisher, \& J. Reason (Eds.), Handbook of life stress, cognition and health (pp. 629649). New York: John Wiley and Sons.

Street, A. E., Stafford, J., Mahan, C. M., \& Hendricks, A. (2008). Sexual harassment and assault experienced by reservists during military service: Prevalence and health correlates. Journal of Rehabilitation Research and Development, 45, 409-420. doi: 10.1682/JRRD.2007.06.0088

Street, A. E., \& Stafford, M. (2010). Military sexual trauma: Issues in caring for veterans Iraq War clinician guide. Retrieved September 28, 2011, from http://www.ptsd.va.gov/professional/pages/military-sexual-trauma.asp

Suris, A., \& Lind, L. (2008). Military sexual trauma: A review of prevalence and associated health consequences in veterans. Trauma, Violence, \& Abuse, 9(4), 250-269. doi: $10.1177 / 1524838008324419$

Suris, A., Lind, L., Kashner, T. M., Borman, P. D., \& Petty, F. (2004). Sexual assault in women veterans: An examination of PTSD risk, health care utilization, and cost of care. Psychosomatic Medicine, 66, 749-756. Retrieved from http://www.psychosomaticmedicine.org/cgi/content/full/66/5/749 
Syed, Z., Scirica, B. M., Morrow, D. A., Mohanavelu, S., Stultz, C. M., \& Guttag, J. V. (2008). ECG markers to predict cardiovascular death: Heart rate variability, deceleration capacity and morphologic variability in non-ST-elevation ACS from the MERLIN-TIMI 36 Trial. Circulation, 118, S670. Abstract retrieved September 28, 2011, from http://circ.ahajournals.org/cgi/content/meeting_abstract/118/18_MeetingAbstracts/S_670b

Sztajzel, J. (2004). Heart rate variability: A noninvasive electrocardiographic method to measure the autonomic nervous system. Swiss Medical Weekly, 134, 514-522.

Tanser, P. H. (2006). Heart. In R. S. Porter, and J. L. Kaplan (Eds.), Merck manuals. Retrieved September 28, 2011, from http://www.merck.com/mmhe/sec03/ch020/ch020b.html

Task Force of the European Society of Cardiology and the North American Society of Pacing Electrophysiology. (1996). Heart rate variability: Standards of measurement, physiological interpretation, and clinical use. Circulation, 93, 1043-1065.

Thong, T., Li, K., McNames, J., Aboy, M., \& Goldstein, B. (2003). Accuracy of ultrashort heart rate variability measures. Engineering in Medicine and Biology, Proceedings of the 25th Annual International Conference of the Institute of Electrical and Electronics Engineers, 2424-2427.

Tibblin, G., Eriksson, C. G., Bjuro, T., Georgescu, D., \& Svardsudd, C. (1975). Heart rate and heart rate variability a risk factor for the development of ischaemic heart disease (IHD) in the "Men born in 1913 study"--a ten years follow-up. International Research Communications System Journal of Medical Science, 3, 95.

Tolley, E. A. (2010). Regression methods. In Lecture notes BIOE 821: Biostatistics for the health sciences II. Memphis: University of Tennessee Health Science Center.

Tucker, P., Adamson, P., Miranda, R., Scarborough, A., Williams, D., Groff, J., \& McClean, H. (1997). Paroxetine increases heart rate variability in panic disorder. Journal of Clinical Psychopharmacology, 17, 370-376.

Turker, Y., Ozaydin, M., \& Yucel, H. (2010). Heart rate variability and heart rate recovery in patients with coronary artery ectasia. Coronary Artery Disease, 21, 8-12. doi: 10.1097/MCA.0b013e328332a69b

United States Department of Health and Human Services. (2009). Traumatic events and mental health. Retrieved September 28, 2011, from

http://www.hhs.gov/disasters/emergency/mentalhealth/index.html

United States Department of Veterans Affairs. (2010a). DSM-IV-TR criteria for PTSD. Retrieved September 28, 2011, from http://www.ptsd.va.gov/professional/pages/dsm-ivtr-ptsd.asp 
United States Department of Veterans Affairs. (2010b). Information security 201 for research and development personnel. Retrieved September 28, 2011, from http://mcw.edu/FileLibrary/Groups/InfoScopeVAMCResearchService/datasec201.pdf

United States Department of Veterans Affairs. (2010c). Military sexual trauma. Retrieved September 28, 2011, from http://www.ptsd.va.gov/public/pages/military-sexual-traumageneral.asp

United States Department of Veterans Affairs. (2010d). PTSD Checklist (PCL). Retrieved September 28, 2011, from http://www.ptsd.va.gov/professional/pages/assessments/ptsd-checklist.asp

Vanoli, E., Adamson, P., Ba-Lin, Pinna, G. D., Lazzara, R., \& Orr, W. C. (1995). Heart rate variability during specific sleep stages: A comparison of healthy subjects with patientw after myocardial infarction. Circulation, 91, 1918-1922.

Videlock, E. J., Peleg, T., Segman, R., Yehuda, R., Pitman, R. K., \& Shalev, A. Y. (2007). Stress hormones and post-traumatic stress disorder in civilian trauma victims: A logitudinal study. Part II: The adrenergic response. International Journal of Neuropsychiatry, 11, 373-380. doi: 10.1017/S1461145707008139

Virtanen, R., Jula, A., Salminen, J. K., Voipio-Pulkki, L., Helenius, H., Kuusela, T., \& Airaksinen, J. (2003). Anxiety and hostility are associated with reduced baroreflex sensitivity and increased beat-to-beat blood pressure variability. Psychosomatic Medicine, 65(751-756).

Wagner, G. S., Waugh, R. A., \& Lawson, W. T. (2000). Dynamic practical electrocardiography: A virtual clinic and classroom [Software and training CD-ROM]. Chicago: Lippincott Williams \& Wilkins.

Walters, K., Rait, G., Petersen, I., Williams, R., \& Nazareth, I. (2008). Panic disorder and risk of new onset coronary heart disease, acute myocardial infarction, and cardiac mortality: Cohort study using the general practice research database. European Heart Journal, 29, 2981-2988. doi: http://dx.doi.org/10.1093/eurheartj/ehn477

Weathers, F., Litz, B., Herman, D., Huska, J., \& Keane, T. (1993, October). The PTSD Checklist (PCL): Reliability, validity, and diagnostic utility. Paper presented at the Annual Convention of the International Society for Traumatic Stress Studies, San Antonio, TX.

Wen, Z., Chen, S., Tai, C., Huang, J., \& Cheang, M. (1998). Role of autonomic tone in facilitating spontaneous onset of typical atrial flutter. Journal of the American College of Cardiology, 31, 602-607. 
Wichterle, D., Simek, J., La Rovere, M. T., Schwartz, P. J., Camm, A. J., \& Malik, M. (2004). Prevalent low-frequency oscillation of heart rate: A novel predictor of mortality after myocardial infarction. Circulation, 110, 1183-1190.

Wilkinson, D. J., Thompson, J. M., Lambert, G. W., Jennings, G. L., Schwarz, R. G., Jefferys, D., . . . Esler, M. D. (1998). Sympathetic activity in patients with panic disorder at rest, under laboratory mental stress, and during panic attacks. Archives of General Psychiatry, 55, 511-520.

Williams, R. B., Barefoot, J. C., Califf, R. M., Haney, T. L., Suanders, W. B., Pryor, D. B., . . . Mark, D. B. (1992). Prognostic importance of social and economic resources among medically treated patients with angiographically documented coronary artery disease. Journal of the American Medical Association, 267, 520-524.

Wittstein, I. S., Thiemann, D. R., Lima, J. A., Baughman, K. L., Schulman, S. P., Gerstenblith, G., . . . Champion, H. C. (2005). Neurohumoral features of myocardial stunning due to sudden emotional stress. New England Journal of Medicine, 352, 539548.

Woo, M. A. (2008). Central nervous system and the heart. In D. K. Moser \& B. Riegel (Eds.), Cardiac nursing: A companion to Braunwald's Heart Disease (pp. 146-152). St. Louis: Saunders Elsevier.

Woods, S. J., Wineman, M., Page, G. G., Hall, R. J., Alexander, T. S., \& Campbell, J. C. (2005). Predicting immune status in women from PTSD and childhood and adult violence. Advances in Nursing Science, 28, 306-319.

Yaeger, D., Himmelfarb, N., Cammack, A., \& Mintz, J. (2006). DSM-IV diagnosed posttraumatic stress disorder in women veterans with and without military sexual trauma. Journal of General Internal Medicine, 21(S65-69). doi: 10.1111/j.15251497.2006.00377.x 


\section{VITA}

Elizabeth Ann Davis Lee was born in Holly Springs, Mississippi, in 1955. She graduated cum laude from Harding College in 1977 with a BSN and from Harding University in 2004 with an MSN. Transferring with her husband's work, Elizabeth practiced nursing in numerous hospital and clinic settings in four states, including the emergency department of Vanderbilt University Medical Center and Heart Partners cardiology clinic in Michigan. For ten years, she taught undergraduate BSN nurses at Harding University. In the fall of 2009, Elizabeth was accepted into the Graduate Health Sciences program at University of Tennessee Health Science Center to pursue a Doctor of Philosophy in Nursing. Her focus of research was on heart rate variability outcomes in female veterans with military sexual trauma exposure. After graduation, she intends to continue research that benefits women who have experienced abuse. 